UEBER

ENTWICKELLNG TND REGENERITION

IES

\title{
GLIEDM ASSENSKELETS
}

DER MOLCHE

roy

D. ALEXANDER GOE'TTE

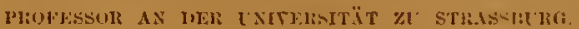

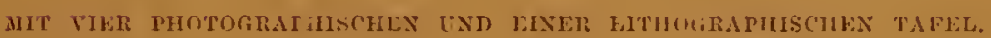

LEIPZIG

IERLAG ION LEOPULD VOSS.

1879. 
IPibrary of the attuscum

OF

\section{COMPARA'TIVE ZOÖLOGY,}

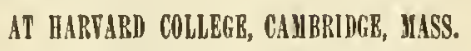

Jounde by pribate subscription, in 1861.

Deposited by ALEX. AGASSIZ.

No. 7398 


UEBER

\section{ENTWICKELLNG UXT) REGENERITION}

DES

\section{GLIEDMASSENSKELETS}

DER NOLCHE

$\operatorname{rox}$

$D^{\mathrm{R}}$ ALEXANDER GOET'TE

PROFESSOR AN DER CNIVEISITIT ZT STRASSILRG.

AIT TIER PHOTOGRAPHISCHEX LXD EINER LITHOGRAPHISCHEX TAFEL.

LEIPZIG,

IERLAG YON LEOPOLD YOSS.

$S_{m} 1579$. 



\section{Vorbemerkung.}

Ich habe die Entersuchungen iber die Entwickelnng und Regeneration der Gliedmafsen der Molche an Triton cristatus und Tr. taeniatus angestellt und mich dabei einer Methode bedient, welche ich nach mehrtachen Versuchen zur Erzielmg befriedigender Präparate als die giimstigste kennen Iernte. Ich lief's die frisch abgesehnittenen Extremititen eine ganz kurze Zeit in remem Wasser liegen nnd brachte sie dann mit demselben unter das Deekglas. Dort lïste sich die Epidermis in ilure einzelnen Zellen auf und ganz rein ron der subepidermoidelen Masse ab, welche röllig intakt und meist olne jede erkennbare Qnellung zuriekblieb. Sie erhielt sich dabei krrstallhell mit Ansnahme der Skeletanlagen, welehe selbst im jiingsten Zustande nach jener Behandlung in dunklerer Zeichnung herrortraten. Sobald diese Zeichunng den relatir hüchsten Grad ron Dentlichkeit erreicht hat, ist es Zeit, sie durch eine rorsichtige Färbung zu fixiren. Unterbleibt die letztere und wird das Präparat der Wirkung des Wassers zn lange ansgesetzt, so biifst es unter Quellung und Tribung seine Klarheit ein; anderseits wird bei der Anwesenleit ron zn wenig Wasser nnter dem Deekglase der Druck des letzteren für das zarte Objekt zu stark, sprengt dann die festere Kutisschicht, welche die weichere Innemmasse einschliefst, und lässt diese hervorquellen. Endlich macht ein zu triiher oder zu plötzlicher Zusatz des Färbe- nnd Konservirungsmittels das Gauze ebentalls mkenntlich. Kurz, diese Methode ist allerdings keine sichere zu nennen, da bestimmte Regeln zur Termeidung aller Uebelstände nicht anzugeben und daher einige Misserfolge mrermeillich sind: ihre Tortheile bestehen aber einmal in der Sehnelligkeit und Leiehtigkeit der Operation und dann in der Vollkommenheit der grelungenen Prïiparate, welche nieht nur die allgemeinen Formverhältnisse, sondern bei den juingeren nnd zarteren Extremitäten, wo es insbesondere daranf ankommt, aneh die Klarheit der feineren Textm betrifft. Um dies zu beweisen, habe ich einige meiner Präparate direkt unter dem Mikroskop) photographiren lassen; eine gleiehe Darstellung aller erforderlichen Figuren war aus manchen techmischen Griinden (ungleiche Dicke, wechselnde Gröfse und Färbnng der Objekte) unthunlich und hïtte auderseits nicht leieht den Vortheil der Uebersichtliehkeit gewährt, den ich dadurch zu erreichen suchte, dass ich alle 
beziiglichen Bilder in zu einander passenden Gröfsenverhältnissen und in kongrnenter Lage, d. h. die rechten Extremititen vou der Dorsal-, die linken von der Volarseite zeiehnete. - Um die Zahl der Figuren zu besehı̈änken, habe ieh die Bildungen der vorderen und hinteren Extremität, der primären Entwickelung und der Regeneration, so weit sie wirklieh mit eimander ibereinstimmen, nur je einmal dargestellt.

Noeh sehe ich mich veranlasst, der Verlagshandhung meinen besonderen Dank anszusprechen fiir die Bereitwilligkeit, mit der sie allen meinen Wiinsehen hinsichtlich der äufsereu Ausstattung dieser Abhandlung entgegenkam. 


\section{A. Die primäre Entwickelung des Arm- und Handskelets.}

Die erste Anlage der vorderen Extremität der Molche zeigt sich als ein Zellenhaufen innerhalb der ron mir sogenannten äufseren Segmentschicht*, hinter dem Kiemenapparat und etwas unter der Seitenlinie. Alsbald tritt dieser Zellenhaufen unter Verllängung der Oberhaut warzenförmig an der Körperoberfläche hervor und wächst alsdam horizontal nach hinten in einen kegelförmigen Fortsatz aus, während seine unter dem Nireau der Körperobertläche bleibende Basis sich auf- und abrärts zur Anlage des Schnltergürtels ausbreitet. Jene kegelförmige Anlage der freien Gliedmafse flacht sich darauf rou aufsen nach innen etwas ab, und erhält ihr Ende einen von zwei Zinken eingefissten Ausschnitt (vgl. Taf. I Fig. 1, 6). Während diese beiden Zinken zu den zwei ersten Fingern länger auswachsen, und die übrigen Finger dazn kommen, biegt sich der ebenfalls verlängerte Arm zuerst unmerklich, dann immer stärker in der Nitte seiner Länge so, dass scine zwei Hälften einen nach unten offenen stumpfen Winkel bilden, die proximate nach hinten etwas anfsteigt, die distale absteigt, und die Hand der Körperseite flach anliegt, also sich in einer sagittalen Ehene ausbreitet (Taf. IV Fig. 22-24). Die weiteren Drehungen des Armes und der Hand, welche in dem Nafse eintreten, als die Extremität zu functioniren beginnt, werden erst später betrachtet werden.

1. Stadium. Das Innere der zapfenfömuigen Anlage des Armes besteht aus gleichartigen rundlichen Zellen, welche in einer spärlichen, klaren und ziemlich konsistenten Zwischensubstanz. eingelagert sind. Eine Differenzirung dieser Zellenmasse zeigt sich zuerst in der proximalen IIälfte der Anlage in Gestalt einer festeren, d. h. aus dichter zusammengedrängten Zellen gebildeten Axe - der Anlage des IIumerus. - Sobald die Gabelung am freien Ende der Extremität eben sichtbar geworden, wird jene Humerusanlage deutlicher, indem das umgebende Gewebe in Folge einer Lockerung klarer und zarter wird, die Elemente der Skeletanlage aber sich unter stärkerer Aufhellung und Festigung der Zwischeusubstanz quer zu strecken beginnen, während die dadurch gebildete kurze Säule aufsen ron einer dichteren Schicht lïngsgelagerter Zellen begrenzt wird, der Anlage des Perichondriums und des späteren Röhrenknochens (Fig. 1). Beror aber die Humerusanlage den eben gesehilderten Charakter eines linorpelbildungsgewebes** erlangt hat, sind schon weitere Skeletanlagen in der distalen Hälfte der Extremität entstanden.

* Vgl. meine „Entwickelungsgeschichte der Unke“. Leipzig 1875, S. 468, Taf. XVI Fig. 299, Taf. XVII Fig. 3 I9.

* Bezüglich der Histiogenese des linorpels verweise ich anf meine früheren, diesen Gegenstand behandelnden Arbeiten, insbesondere die "Entwickelungsgeschichte der Unke“, S. 361, 367-371 377, u. s. w. 
Das distale Ende der Humerusanlage geht kontinuirlich in eine ebensolche dichte und dunkłe Zellenmasse iiher, woraus die erstere anfangs bestand. Diese Gewebsverdichtung setzt sich aber num nicht einfach axial fort, sondern tritt in zwei Aeste anseinander, welche dem oberen oder ulnaren und unteren oder radialen Pande der nach hinten gerichteten Extremität entsprechend bis in die eben herrortretenden zwei Zinken hinein verlaufen (Fig, 1, 6). Vom Humerus aus divergiren diese beiden Aeste, um sich auf der Mitte ihres bogenförmigen Verlanfes einander bis zur Beriihrmg zu nähern und dann wieder unter einem spitzen Winkel auseinanderzufahren. Man kömute daher diese Anlage der zwei Aeste, solange ihre divergirenden Enden noch kurz sind, eine leierförmige nennen.

Allerdings ist die Unabhängigkeit beider Aeste von einander an den jüngsten eben ausgeschlïpften Larven insofern nicht ganz rein zu erkennen, als ihre Berührung in der Nitte ihres Verlaufes gleich anfangs, wenn die ganze Anlage noch nicht scharf begrenzt ist, eine innige ist, und aus dieser Verbindung seln bald ein einfacher Skelettheil herrorgeht (Fig. 1, 2). Ein Bliek auf die regenerirten Extremitäten älterer Larven, deren Skeletanlagen in dem entsprechenden Stadium histiologisch weiter entwickelt und daher schïrfer begrenzt sind (Taf. III Fig. 14, 15), lehrt aber, dass beide Aeste wirklich getrennt angelegt werden. worauf ich noch ausführlicher zurückkomme. Ieh habe rieselben ferner immer mur gleichzeitig entstehen sehen, sodass ich sie zunïchst, vorbehaltlich einer späteren Erörterung dieser Flange, als koordinirte Bildungen ansehen muss. Eudlich traf ich ihre Anlagen nur in Kontinuität mit der Humerusanlage, als munterbrochene Fortsetzungen derselben. Diese Auffassung kann dadurch nicht beeinträchtigt erscheinen, dass die Gewebsbildung der genannten Theile, des Humerus und seiner beiden Aeste, nicht gleichzeitig dieselhe ist. Denn einmal bestand der Humerus vorher durchweg aus demselben Gewebe wie die eben angelegten Aeste, und ist ferner seine Knorpelbildung an distalen Ende anfangs nicht irgendwie scharf begrenzt, sondern verliert sich ganz allmählich in das noch weiche dunkle Gewebe, welches sowohl jenes Ende als die kontinuirliche Fortsetzung desselben, die beiden Aeste, bildet und sich vom iibrigen Bildungsgewebe der Extremität, wem auch nicht scharf, so doch sehr deutlich abhebt (Fig. $1-h, \imath$ ). Die Humerusanlage und die beiden von ilmm ausgehenden Aeste kamn ich daher nicht als völlig unablängig von einander anftretende Bildungen ansehen; und wenn in der Folge die Knnorpelbildung allerdings nicht kontinuirlich von des' ersteren in die beiden Aeste fortschreitet, sondern an der Grenze, dem späteren Ellenbogengelenk, eine Unterbrechung erfährt, so sehe ich darin nur eine ebensolche, durch die genannte listiologische Differenzirung hervorgerufene Gliederung ciner zusanmenhängenden Anlage, wie sie sich z. B. anch in der Entwickelung der äufseren Chordascheide darstellt. Wird die Einheit der letzteren zugegeben, obgleich die Verwandlung ihrer ersten Anlage in Knorpel anfangs nur in getremnten vertebralen Abschnitten erfolgt, so muss, wemn man nicht inkonsequent sein will, auch dasselbe Schlıssverfahren bei der Deutung der Anlagen des Extremititenskelets zur Geltung kommen.

Anch in jedem der beiden Aeste beginnt die Knorpelbildung weder einheitlich noch etwa regelmälsig centrifugal fortschreitend. Ihre schon am Humerus bezeichnete Vorbereitung zeigt sich zuerst in den proximalen und distalen oder Fingerabschnitten, sodass die zwischenliegenden mittleren Absehnitte darin noch zurückbleiben. Doch fängt diese Gewebsumbildung in den entsprechenden Abschnitten beider Aeste nicht immer gleichzeitig an. 
Im ersten Stadium entwickelt sich also zuerst die axiale Anlage des Humerus, und dann diejenige zweier kontinuirlicher Fortsetzungen desselben, eines radialen mi eines ulnaren Astes oler Strahls, welche in Leierform sich einander näheru und darauf in die $z \pi^{\circ}$ i ersten Finger amslaufen. Ihr ersterer Abschnitt, vom Humerus an bis zu ihrer Berïlnung, umfasst also den Yorderarm und die Handwurzel. Die Vorbereitung zm Knorpelbildung hegimnt zuerst im Humerus. dann in den proximalen und distalen Abschnitten der Aeste mit getremten Ausgangspmuten.

2. Stadiun. Als Hauptmomente dieses Stadiums sind zu nennen: crstens die Sonderung der proximalen Hälften beider Aoste in Handwurzel und Vorderarm, zweitens die Anlage eines ulnaren Seitenastes der Hand.

Die erste Sonderung wird durch folgende Vorgänge herbeigeführt. Erstens verschmelzen beide Aeste an der Beriihrungsstelle gewöhnlich rollständig mit einander und diese Verschmelzung stellt das Vorderende der allerdings noch unvollständigen, weil erst den zwei ersten Fingern angehörigen Handwurzel dar (Fig. 2, 8). Dieses Vorderende zeigt sehr friihe die schon beschriebene Umbildung in embryonales Ínorpelgewebe, welches bisweilen ohne merkliche Unterbrechung mit dem gleichen Gewebe der Finger zusammenfliefst, um sich erst später wieder ron demselben zu sonder'n (Fig. 8); gewöhnlich bleibt es aber vou Anfang an von demselben durch eine dunklere weiche Zwischenschicht, d. h. die noch nnveränderte indifferente Zellenmisse der ursprünglichen Anlage geschieden (Fig. 2-う̃). Diese bald dickere, bald schmälere Zwischenschicht bezeichnet das Gelenk der beiden ersten Mittelhandstiicke mit dem sogenaunten Carpale III aut. oder dem Carp. r’m III nach der von mir rorgeschlagenen Bezeichnnug (vgl. die Tabelle S. 10). Abgeseben ron dieser histiologischen Sonderung der Mittelhand und Handwurel ist die Grenze zwischen beiden anch durch eine Einschnürung der Bildungsmasse an jener Gelenkstelle angedentet. welche anch dort nicht zu verkemnen ist, wo die Knorpelbildnng ohne Unterbrechung von der Handwurzel in die Mittelhand iibergeht. Endlich ist die Anlage des Carp. rm III gewöhnlich etwas schmätor als der quere Durchmesser beider Skeletäste, was anf eine wirkliche Zusammenziehung der Bildungsmasse während der Verschmelzung schliefsen lässt. Aehnlich wie gegen die Mittelhand ist jenes Stiick auch in proximaler Ricbtung gegen die ïbrige Handwurzel durch eine leichte Einschnirmug und meist auch durch die dentlich abgesetzte Knorpelbildung geschieden, sodass das Carp. rm III frühzeitig als ein besonderes rundes Finorpelstiick hervortritt (Fig. 3-5, vgl. Taf. II Fig. 12). Bisweilen geht aber die Knorpelbildung dort entweder ebenfalls kontinuirlich in die indess knorpelig gewordenen karpalen Skeletäste oder ganz allmählich in deren noch weicheres und dunkleres Gewebe über (Fig. 2 und $s$ ), und zwar dies alles abwechselnd in Anlagen ron dem gleichen Alter, sodass kein Grund besteht, den ersteren Befund, nämlich eine anfängliche Diskontinuität der Ḱnorpelbildung der genaunten 'Theile, für die Regel zu erklären. Vielmelır wird man mit Rïicksicht daranf, dass die Sonderung aller' Theile in der Folge muzweifelhaft fortschreitet, den Zustand der geringsten Sonderung für den ursprünglichen halten und alsdann die erwähnten Unregelmäfsigkeiten darans erklären müssen, dass die Sonderung bald schneller, bald langsamer verläuft und daher frïher oder später zur Wahrnehmung kommt, oder dass nmgekehrt die Knorpelbildung zn rerschiedenen Zeiten beginnt und daher in den schon in der Sonderung begriffenen Theilen diskontinuirlich, in der jüngeren aber mehr kontinuirlich erscheint.

Die eben beschriebene Entwickelung des Carp. rm III, welche sich zunächst nur auf Triton cristatus bezieht, könnte es aber unter Umständen zweifelhaft erscheiren lassen, dass dieses im knor- 
peligen Znstande einfach gebildete Handwurzelstiick in der That aus zwei ursprünglich getrennten Theilen herrorgehe. Denn wemn es auch feststeht, dass das Carp. rm III ganz allein den Zusammenhang zwischen den proximalen und distalen Hälften der beiden Skeletäste rermittelt, in den Verlanf heider gleichsam eingeschaltet ist, so könnte doch deren unvollkommene Trennung an derselben Stelle noch vor der Bildung jenes Carpale die Ansicht herrorrufen. dass dort überhaupt keine Sonderung bestehe, also nicht zwei nebeneinander rerlaufende, nur an einer Stelle sich berïhrende und dort später verschmelzende Aeste, sondern ein dem Humerns angeschlossener länglicher Ring und zwei distale Fortsätze desselben die erste einheitlich zusammenlıängende Anlage des Vorderarm- und Handskelets bildeten. Wem ich aber schon hinsichtlich jener unrollkommen sichtbaren Sonderung auf andere ïberzengendere Bilder verweisen knnnte, so lässt sich auch die Auffassung, dass das Carp. Im III einer Doppelanlage entspreche, direkt bestätigen, wenn man die betreffende Entwickelung ron Triton cristatus mit homologen Erscheinnngen vergleicht. Schon die Regeneration an denselben jungen Larren zeigt einen etras abweichenden Bildungsmodus; nnd ganz denselben habe ich in der normalen Entwickelung des Carp. rm III und des homologen Tarsale tm III hei Triton taeniatus angetroffen. In allen diesen Fällen erfolgt die vollkommene T'erschmelzung der beiden Skeletäste zu einem morphologisch und histiologisch einheitlichen Carp. rm III nicht so früh wie in der ersten Beschreibung ron Triton cristatus angegeben war. Allerdings zeigt sich auch dort alsbald die Anlage eines runden halbknorpeligen distalen Handwurzelstiickes (Fig. 7, 12, 16, 18); disselbe gehört aljer nicht gleichmärsig beiden Aesten und Fingern an, sondern liegt ausschliefslich im Verlaufe des ulnaren Astes, während der radiale Ast noch gerade daran vorbeizieht und trotz der imnigen Anlagerung an jenes Carpale häufig noch in einem nicht knorpeligen weichen Zustande sich befindet. Aber sellsst nachdem dieses Stück des radialen Astes knorpelig geworden, erscheint es noch einige Zeit vom runden Umfange jenes Carpale bis zn einem gewissen Grade gesondert; ja, in einem Falle bahe ich diesen Zustand noch an einer etwas älteren Hand ron Triton taenitatus angetroffen, wo die Alggliederung jenes rordersten Karpalstiickes des radialen Astes sowohl distal gegen den ersten Metacarpus wie proximal gegen den übrigen Karjaltheil desselben Astes bereits eingetreten war, sodass jeder der beiden Aeste ein besonderes vorderstes Karpalstiick, je für den ersten und den zweiten Finger besafs (Fig. 9). Gewöhnlich rerschmilzt aber das betreffende Stück des radialen Astes (Carp. r.III) schon früher mit dem anderen Carp. (m III), nachdem es sich so gegen dasselbe zusammengezogen hat, dass die äufsere Grenzlinie des ganzen Astes dort eingebuchtet ererscheint.* Alle diese, an den homologen Stücken des Fufses (Fig. 12) sich wiederholenden Elscheinungen hestätigen es zur Genïge, dass das Carp. r'm III aus zwei genetisch zu tremnenden Stücken entstanden zu denken ist. Doch möchte ich nicht amehmen, dass die mir zunächst bekannt gewordene Vertheilung der beiderlei Bildungsweisen jenes Carpale und des homologen Tarsale auf die rerschiedenen Species eine durchgreifende Regel darstellt; bei weiteren Untersuchungen dürften sich Ausnahmen nach beiden Seiten hin finden.

Während dieser Vorgänge ändert sich auch der proximale Verlauf der beiden Skeletäste. Im ersten Stadium waren sie vom IInmerus an bis zu ihrer Verbindungsstelle konkar gegen einander

* Bei der Besprechung der Regenerationsrorgänge werde ich auf diese Erscheinung, welche auf eine gewisse Verkümmerıng des Carp. r III zu beziehen sein dürfte, zuruckkommen. 
gehogen (Fig. 1); in dem Vafse nun, als sie sich zur Anlage des Carl. rm III zusammenziehen, rïcken sie auch in den unmittelbar angrenzenden proximalen Abschnitten dicht zusammen, bleihen aber noch weiter anfwärts bis zum Humerus dưch eine weite, sflindelförmige Lüicke getrennt (Fig. 2, 4, 7). Da nun diese letzteren weit getrennten Absehnitte sich in die beiden Vorderarmknochen, den Radius und die Ulna, verwandeln, so ist durch jenen Vorgang auch eine proximale Grenze der Handwurzel gegelsen. Doch erfolgt jene Veränderung im Verlaufe der beiden Skeletäste nicht gleichmäfsig: der radiale Ast hehält vielmehr seine frïhere Lage unl scheint blofs der Handwurzelschnitt des ulnaren Astes sich gegen den ersteren zu rerschieben, sodass gerade an ihm dic Biegung beim Uebergange rom Vorderarm in die Handwurzel, wodurch beide geschieden werden. deutlich herrortritt. - Nicht gleich ebenso deutlich gilbt sich diese Scheidung auch geweblich zu erkennen, inden die Ḱnorpelbildung der beiden Vorderarmstiicke anfangs sich ganz allmählich gegen die Handwnzel verliert (Fig. 2). In der letzteren selbst, d. h. zwisehen dem Vorderarm und dem Carp. l'n 1 II beginnt die Knorpelbildung, wio schon erwähnt, später als in den iibrigen Theilen des Hand- und Armskelets; doch muss ich anch hier die individuelle Verschiedenheit hervorheben, diss zwischen der eben angelegten, ich möchte sagen embryonalen linorpclmasse jener proximalen Handwurzeltheile und derjenigen von Radins und Uha einerseits und des Carp. rm 1 II anderseits nicht immer gleich die dnnklen Gelenkanlagen deutlich zu erkennen sind, sondern bisweilen eine Kontinuität der linorpelanlagen sich zeigt. die erst nachträglich durch die Gelenkanlagen unterbrochen wird. Doch erstreckt sich dieses vorläufige Zusammentliefsen der línorpelanlagen nicht auf dic beiden nebeneinandergelagerten proximalen Handwurzelstiicke unter sich; denn wenn sie auch noch so dicht zusammenliegen, so vermisst man doch nicht eine Trennungslinie, in welcher die Zellen nicht quer ausgezogen sind wie in den beiden Aesten, sondern rund bleiben orler sich parallel zur Längsaxe der letzteren strecken (Fig. 3, 4). Ueberhaupt ist es wohl zu beachten, dass der Eindruck eines Zusammenfliefsens der knorpeligen Handwurzeltheile um so eher erzengt wird, als an ihrer Obertläche der faserige Ueberzug fehlt, den die langen, alsbald mit linochenröhren sich umgebenden Knorpel des Armes und der Finger besitzen. und der ihnen schon frühe eine schärfere Abgrenzung rerleint.

Während der Handwurzeltheil des ursprünglichen ulnaren Astes sich dem radialen Aste nähert mml anlagert, zeigt sich an seiner äufseren, ulnaren Seite eine Verdichtung des anliegenden Gewebes, welehe sich alsbald rom Carp. Im III bis zum distalen Ende der Ulna erstreckt (Fig. 2. 4). Diese Bildung kömnte in ihrem Anfange leicht ïbersehen werden, da sie alstam nach aufsen noch keine scharfe Grenze hat und, solange in dem angrenzenden Skeletaste die Knorpelbildung noch nicht begonnen hat, als cin allmählicher Uebergang seiner Anlage in das benachbarte Gewebe der Hand crscheinen mag. Ist sie aber eimmal als besondere Anlage zu erkemen, so beginnt die línorpelbildung in ihr gewöhnlich später als in den älteren Handwurzeltheilen, sodass sie sich wie eine selbstständige, von ihnen genetisch unabhängige und nur sofort sich innig ihnen anschliefsende Bildung ausnimmt (vgl. Fig. 7). Und doch halte ich diese Anffassung nicht für die richtige. Denn in den von mir allerdings seltencr beobachteten Fällen, wo die Knnorpelbildmug in den ursprünglichen Handwurzelstiicken sich schnell, schon vor dem ersten Erscheinen des neuen ulnaren Stiickes, entwickelte (Fig. 3), da sehe ich das letztere als eine kontinuirliche Fortsetzung der jungen linorpelsubstanz des ursprünglichen ulnaren Astes an der bezeichneten Stelle entstehen, so zwar, dass der nengebildete 
Knorpel sich zunïchst ohne dentliche Grenze in dem unliegenden Gewebe verliert. Vergleichen wir lamit endlich noch die entsprechenden Vorgänge bei der Regeneration der Hand älterer Larven, wo die hinurpelbildung stets an den noch einfachen beiden Skeletästen eingeleitet ist, so ergibt sich die Anlage des neuen ulnaren Handwurzeltheiles ebenso wie in letzten Falle der primären Entwickelung nur noch deutlicher und schärfer als eine linorpelige Wucherung an der Anfsenseite des ursplrünglichen uharen Astes, welche von ihrer distal beschränkten Ausgangsstelle an sich sehr bald ïber dessen ganze Länge erstreckt und allmählich ron ihm absondert (Fig. 15-18). Zum distalen Ende der Ulna, auf welches diese Wucherung in Folge der Abbiegung des ulnaren Astes gerade ausläuft, rerhält sich dieselbe ebenso wie zu dem linorpelstiick, an dem sie sich bildete; ist die Knorpelbildung in beiden kontimirlich und gleichzeitig, so steht die Neubildung anch mit der Uha in gleicher Terbindung (Fig. 7); andernfalls geht die nichtlinorpelige Zellemmasse der ersteren nu. in die perichondralen Schichten der Uhna über (Fig, 4), um wit ihr erst sekundär knorpelig zusammenzufliefsen (Fig. 5), oder durch cine nie ganz knorpelig werdende Gelenkinlage sich zu rerbinden. Eine gleiche und ebenso wechselnde Verbindung zeigt sich anfangs auch zwisehen dem distalen Ende der neuen Anlage und dem Carp. rm III, wogegen der Zusammenhang ihres proximalen Endes mit dem anliegenden Karpalast niemals ganz unterbrochen erscheint. In der Mitte zwischen beiden Enden erfolgt die Tremung beider Theile am friihesten und beständigsten.

Nach ihrer vollständigen Absonderung präsentirt sich die nene Bildung als ein vollkommenes Seitenstïck zu den beiden Karpalabschnitten der zwei ursprünglichen Skeletäste (Fig. 5). Um aber ein ïbersichtliches Bild ron der Zusammensetzung der in ihren Anlagen numehr fertigen Handmurzel zu gewimen, muss man stets im Auge behalten, dass das Carp. rm III aus einer Verschmelzung der leiden ursprïnglichen Skeletïste hervorging. also eine Fortsetzung ihrer proximalen Handwu'zelabschnitte darstellt. Unter Hinzurechung des an der Ulnarseite dieser primären Handwurzel entstandenen Stuickes hesteht also die defunitive Anlage des Carpus ans drei nebeneinanderliegenden stabförmigen Skeletanlagen, welche aber allerdings nicht gleichzeitig entrickelt werden und dalser wenigstens während der normalen oder primüren Bildung der Extremitït in jener einfichsten Gestalt nicht gleichzeitig nebeneinamder angetruffen werden. Von diesen Stücken ist das eine eine direkte Fortsetzung des Radius und kam daher als radialer Karpalast bezeichnet werden; der darauf folgende mediane Kinpalast ist ursprünglich eine ebensolche direkte Fortsetzung der Uhia, muss aber den Nimen eines uharen Karpalastes dem von ihm sich abspaltenden Seitenast abtreten, sodass alsdam beide als eine dichotomische Fortsetzung der Ulna zu denken wären, mit welcher sie anch in Yerbindung bleiben (Fig. 5, 11).

Der ulnare Karjalast hört nuı aber neben dem Carp. rm III nicht anf, sondern erhält schon gleich im Anf:nge seiner Bildung eine stab- oder sänlenartige Fortsetzung, welche schräg ror- und ulnarwärts gerichtet, dits umgelende Gewebe der Hand und die rorliegenden Oberhauttheile in derselben Richtung zu einem stumpfen Höcker hervortreibt (Fig. 4, 7); daraus entwickelt sich der dritte Finger, dessen Axe eben von jener Fortsetzung des uharen Karpalastes oder der Anlage des dritten Metacarpus und der zugehörigen Phalangen eingenommen wird (Fig. 5). Die Knorpelbildung dieses Metacarpus erfolgt so wie an den anderen, bald im Zusammenhange mit derjenigen des zugehörigen Carpale, bald getrennt davon; bei den regenerirten Extremitäten ist ersteres die Regel. Natiirlich sind aber die beiden ersten Finger sowoll im Wachsthum wie in der Knorpel- 
liblung dem dritten Finger anfangs weit voraus; ehe dieser hervortritt, lässt sich an jenen sellsst schon eine Gliederung in Metacarpus und Phalangen unterscheiden in Form ron zwei dunkleren queren Scheiben ron dicht gehäuften quer gezogenen Zellen, welche die anfangs liontinuirliche Knorpelsäule jedes Füngers durchsetzen (Fig. 2, 4, 5)** Diese Gelenkinlagen erscheinen in jedem Finger entweder gleichzeitig oder die proximale zuerst, und bald in dem einen, bald im anderen Finger. früher: Die Larven ron Triton taeniatus haben sowobl kiurzere Endglieder der Finger, als auch im ersten Finger ein Gelenk weniger (Fig. 9).

Die voranstehend beschriebenen Torgänge des zweiten Entwickelungsstadiuns sind also folgende:

1. die zwei urspringlichen Skeletäste des Unterarmes und der Hand rerschmelzen an ihrer Beriilir'ungsstelle zum Carp. r'm lI], wodurch Handwurzel und Finger" gesehieden werden.

2. Auf der Strecke zwischen lem Carp. rm III und dem Humerns bleiben die beiden Aeste proximalwärts dưch eine weite Lïcke geschieden (Radius, Ulna), rïcken aber ihre bezïglichen distalen Abschnitte im Anschlusse an jenes Carpale dicht zusammen (Carpus); die Biegung des ulnaren Astes zum Zrecke der Anlagerung an den radialen Ast bezeichnet die Gienze ron Unterarm und Handwruzel.

3. Tom Handwurzeltheile des uharen Astes sondert sich durch Wucherung und Abspaltung ein Seitenast, der jenem entlang verlaufend nelsen ihm mit der Ulua, distal mit dem Carp. Im III sich rerbindet mo in den dritten Finger answächst.

4. Die Handwurel besteht darnach aus drei parallel und dicht nebeneinander gelagerten Aesten, dem radialen, medianen und ulnaren, ron denen der erstere mit dem Radius in Verbiodung steht und in den ersten Finger ausläuft, dic zwei letzteren mit der Uha zusammenhängen und den zweiten und dritten Finger tragen.

3. Stadiun. Es folgt jetzt in der Entwickelung die Gliederung der hinorpeläste und die Bildung des vierten Fingers.

Nachdem das Carp. rm III als erstes von den definitiven Handwuzelsticken und zwar aus den miteinander rerbundenen distalen Enden des radialen und medianen Astes entstanden ist, gliedert sich der noch iibrige Theil der letzteren in je zwei, der ganze ninare Ast in drei annähernd gleich grofse Stuicke, sodass im Grunde genommen jeder ron imnen in eine gleich grofse Anzall von Stïcken zerfällt (Fig. 5, 9, 10, 11). Dabei zeigt sich an jedel Gliederung zuerst eine allseitige Einschnirumg des Knorpels und in der Ebene derselben eine Erweichung seiner Masse, sodass er ron einer dunkeln queren Schicht durchsetzt wird. Zugleich wölbt sich die Aufsentläche des auf diese Weise abgegrenzten Stïkes nach aufsen ror, sodass dessen ursprüuglich knrz eylindrische Form in eine rundliche ïbergeht.

Diese Gliederung begimnt bald im medianen, bald im ulnaren Aste zuerst; die Zweitheilung des noch ïbrigen radialen Astes scheint im allgemeinen zuletzt einzutreten. Lässt sich also eine bestimmte Reihenfolge in der Gliederung aller Aeste nicht feststellen, so verdient es doch Beobachtung, dass, sonie im radialen und medianen Aste die Bildung des distalen Cirp. rm III derjenigen ihrer anderen Glieder ausnahmslos vorausgeht, ebenso im ulnaren Aste stets das distale Eude sich zuerst abgliedert.

* Nur ausuahmsweise habe ich an 1. Finger ron Triton cristatus nur eiue Plalanx gefunden. GOETTE, Gliedmarsenskelet. 
Zn den genannten Unregelmälsigkeiten der Ghiederung kommt noch ferner hinzu, dass nicht selten yoch bei ansgewachsenen Larven die eine oder andere Gliederung anssteht, sodass man annehmen kann, dass sie wahrscheinlich auch nach der Metamorphose unterblieben wäre.

Da die proximalen Enden des medianen und ulnaren Astes dort, wo sie gemeinsam mit der Ulna znsammenhängen, sich niemals von einander völlig tremnen, so werden auch die proximalen Theilstiicke beider Aeste nur unvollständig getrennt sein und sich viclmehr wie ein einziges von vorn her tief eingeschnittenes Stück darstellen (Fig. 9, 10). Ein Getïls habe ich in diesem Einschnitte aus den jüngsten Stadien nur an frischen Objekten, an konservirten Präparaten nur bei etwas vorgeschrittener Entwickehnng erkennen können.

Mit den eben beschriebenen Vorgängen hat die Gliederung der Handwurzel ihr Ende erreicht und können nummehr alle ihre Stiicke ihre definitiven Namen erhalten. Die bisher ïblichen, von Gegenbaur eingeführten Bezeichnungen der Handwnzelstïcke bezichen sich nur auf die definitive Lage der letzteren, wogegen es mir wïnschenswerth scheint, deren genetische Beziehnngen zu einander schon im Namen anzudeuten. Ich schlage daher eine entsprechende Abänderung jener Bczeichnmen anf folgender Cirundlage vor. - Die drei Skeletïste, ans denen die Handwurzel hervorgeht, habe ich bereits als radialen, mediamen und nharen bezeichnet; die durch Qnertheilung derselben entstehenden kleimeren Stiicke sollen daher stets den Xamen desjenigen Astes führen, dessen Glieder sie sind, also: Carpalia radialia, mediana, ulnaria, oder abgekürzt: Carp. r, Carp. m, Carp. n. Die Reihenfolge der Glieder jedes Astes wird ferner durch römische Zahlen vom Unterarm anfangend bezeichnet, sodass also die bisher sogenannten Radiale, Intermedium, Ulnare Carp. rI, mI, n 1 zn nennen wären, das Centrale Carp. m II - u. s. w. Die Verschmelzung zweier' ursprünglichen Stiicke zu einem wird ebenso wie bisher durch Zusammenziehung der Zeichen angezeigt, wie in der von mir schon häufig gebranchten Formel Carp. rmullI für das zuallererst, ans den distalen Fnden des radialen und medianen Astes (1 I I , m Ill) gebildete Handwurzelstiick. In der folgenden Tabelle habe ich Gegenbaur's und meine Bezeichnumgen für dieselben Stiicke und zwar zur besseren Uebersicht schon hier vom Carpus und Tarsus zugleich untereinandergestellt; die Anordnung nach den queren Reihen geschah nur mit Riicksicht darauf, dass die Verschmelzungskomponenten nebeneinumderstehen mussten.

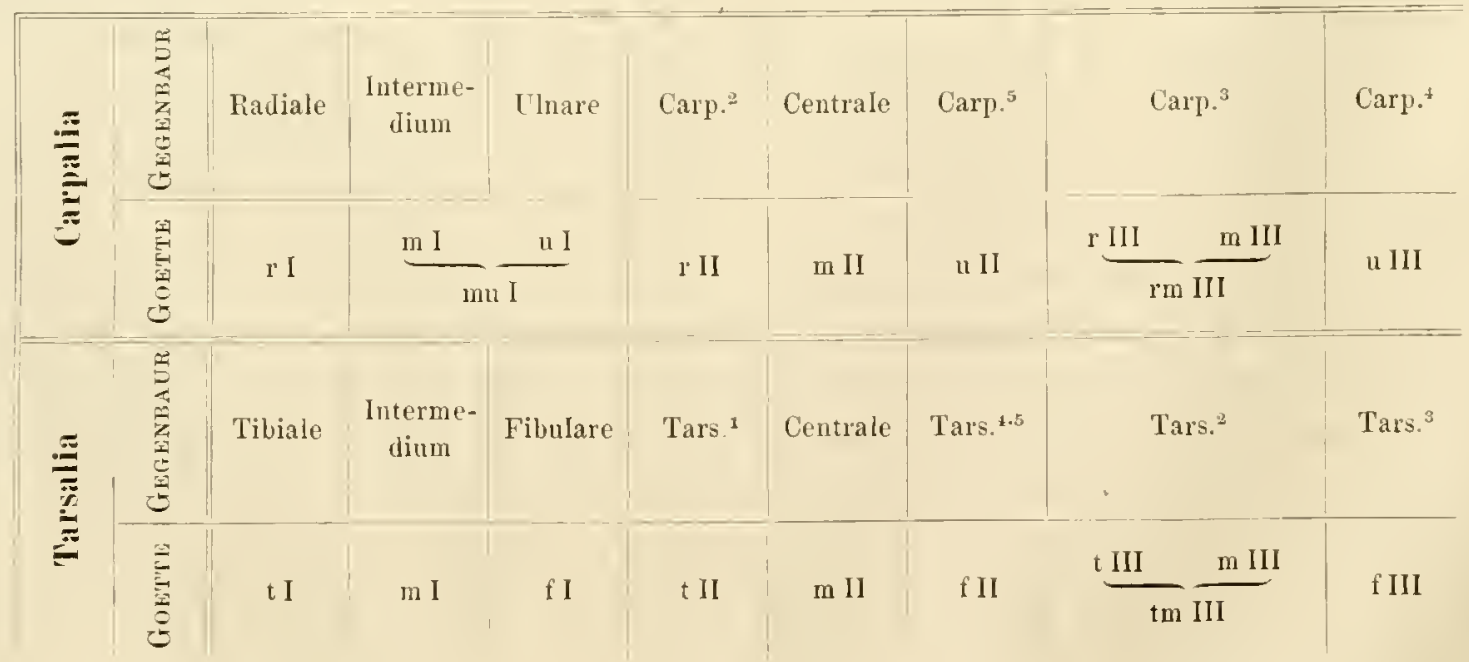


Doch muss hier gleich herrorgehoben werden, dass die eben bezeichnete Gliederung des Carpus und Tarsus der Molche nu' die Regel darstellt; eine nicht ungewöhnliche Erscheinung ist die Verminlerung der genaunten Stiicke durch das Unterbleiben der Gliederung in dem einen oder anderen Aste, worauf ich noch zurickkommen werde.

Wenn die Gliederung der llandwnrzel in den jungen Larren schon nahezu rollendet ist, besitzen ihre Stücke noch die alten Verhindungen, d. l. sie hängen in der Richtung der ihnen zu Grunde liegenden Skeletïste noch fest zusammen, wählend die Glieder der rerschiedenen Aeste, mit Ausuahme der Terbindung ron Carp. rm IlI mit u III und dem später rerschmelzenden mI-u I. nur locker aneinanderhaften, sodass sie beim leisesten Drucke auseinandertreten. oder selbst im intakten Zustande durch dentliche Lïcken getrennt sind (Fig. 11). Alhählich schliefsen sie sich aber auch dort dicht zusammen (Taf. T), morauf die dadurch entstehenden schmalen dunkeln Zwischenschichten von den ursprïnglichen Gelenkanlagen jedes einzehen Istes sich nicht unterscheiden. Wïhrend des Wachsthums der Carpalia rollzieht sich aber eine gerisse Verschiebung ihrer ursprünglichen Lage, und zwar in Verbindung mit der Entwickelung des vierten Finger's. Anfangs reicht nämlich der nlnare Karpalast distalwärts nicht so weit wie rer mediane, steht also das Carp. nIII ein wenig hinter dem Carp. I'm III zuriick (Fig. 5). In dem Mafse aber, als der vierte Finger rom Carip. u II aus lervorzurachsen beginnt, rïcht anch das Carp. u $11 \mathrm{I}$ weiter ror und schliefslich in die gleiche Linie mit Carp. rmIlI (Fig. 9-11). Die Ursache dieser Lagereränderung scheint mir die gleichzeitige Verlängerung der Anlagen ron Curp. uI und uII zu sein (Fig, 11). welche das Carp. u III rerschieben, worauf sogar das Carp. uIl etwas zur Seite ausljiegt und dadurch aus seiner Stellung hinter dem Carp. nIII herrortritt, um nun mit diesem und dem Carp. rm III eine quere Bogenlinie zu beschreiben.

Ich sagte eben rom rierten Finger, dass er aus dem Carp. u II herrorwachse. Anders kamn ich wenigstens die erste Entštehung desselben nicht auffassen: es bildet sich anfangs ein kleines Wärzchen an der Oberfläche jenes Carpale, indem die konzentrisch und dicht gelagerten Zellen seiner dunkeln und weichen Rindenschicht sich rermehren und schräg nach aufsen und rom rerschieben, sodass ihre quere Lage und Schichtung den Auswuchs viel deutlicher, als es beim dritten Finger" der Fall war, ron dem umgebenden Gewebe sondern (Fig. 9). Das Wachsthm und die weitere Entwickelung des vierten Finger's gleicht ganz derjenigen des dritten: mur sehe ich seine Gliederung relativ früher eingeleitet (Fig. 10). - Bei dieser Gelegenheit möchte ich die Anfmerksamkeit anf die sucessire Abänderung in der Entwickelung der einzelnen Finger lenken. Die zwei ersten entstehen gleichzeitig mit den zugehörigen Karpalstïcken und dew Unterarm; dic Anlage des dritten Fingers zeigt sich, wenn auch nm ein Gerimges später als diejenige des dritten Karpalastes, dam aber gleich als eine nicht unbeträclitliche Fortsetzung desselben; der rierte Finger endlich wächst angenscheinlich sekundär aus dem viel weiter entwickelten Carp. u II hervor, Während also die zwei ersten Finger ursprüngliche Theile der beiden ersten Skeletäste darstellen, der vierte als sekundärer Auswuchs eines Kirrpalstückes erscheint, bildet die Entwickelung des dritten Fingers einen Uebergang von der einen zur anderen Ursplungsweise.

Ueber die Verknöcherung des Armes und der Hand unserer 'Tritonen habe ich nur wenig zu bemerken. Sie beginnt mit der Bildung ron dïnnen periostalen hinochenröhren um die Mittelstïcke der langen Skelettheile, und zwar in derselben Reihenfolge wie die letzteren entstehen, also zuerst am Humerus, dann am Unterarm, zuletzt an der Mittelhand und den Phalangen (Fig. 5, 9, 10). 
Diese linochenröhren sind anfangs knrz und cylindrisch, nud ihre verdünnten Räuder gehen unmerklich in das Perichondrium der Epiphysen über (Fig. 21). Mit dem Lüngenwachsthum des Kunorpels schreitet anch die Verknöcherung in seinem Perichondrium vor; da aber der vom Knnochen noch nicht bedeckte linorpel zugleich auch in die Breite wïchst, wird der sich ïber ihn vorschiebende Knochenrand ebenfalls breiter und nimmt folglich die ganze linochenröhre alsbald die Form eines Doppelkegels oder Stundenglases an, ähnlich wie dies an den Wirbelkörpern geschieht. Diese Form wird in der Folge an der Imenseite der Knochenröhre noch anffälliger als am äufseren Umrisse, indem der Knorpel in der Mitte an Dicke gar nicht zunehmen kann, also gegenüber den Epiphysen sich andanernd relativ verschmälert, während der Knochen an derselben Stelle sich immer stärker verdickt als an den Rändern. Die Ersetzung des eingeschlossenen Knorpels durch Markhöhlen und Knochenmasse erfolgt erst nach der Metamorphose der Larven. Die Epiphysen bleiben knorpelig, mit Ausnahme der freien Enden der letzten Phalangen, deren Knorpel in eigenthümlicher Weise verschwindet. Es wurde schon hervorgehoben, dass diese Endphalangen namentlich an den Larven von Triton cristatus durch ihre Länge auffallen (Fig. 4, 5)); anfangs ïbertreffen sie darin nicht selten die anderen Glieder desselben Fingers, Netacarpus und Phalangen zusammengenommen. In der späteren Larvenzeit wachsen sie weniger schnell, sogar langsamer als die anderen Glieder, behalten aher ein lang und spitz ansgezogenes Ende, welches auch der ganzen Fingerspitze die gleiche Form verleiht. Sie erhalten auch wie die übrigen langen Knnorpel eine änfsere Knochenhülse, welche aber den dickeren proximalen Theil des Gliedes nicht ïberschreitet, sodass die gröfsere Hälfte des Knorpelfadens daraus frei hervorhängt (Fig. 21a). Zur Zeit nun, wenn die allgemeine Larvenmetamorphose sich vorbereitet, und wohl mit als eine Theilerseheinmng derselben, tritt eine rapide Veränderung der Fingerspitzen ein: sie vertauschen ihre dïmen spitzen Enden mit breiteren abgerundeten Kuppen und verkürzen sich beträchtlich, was aber äufserlich nicht gleich anffällt. Präparirt man aher das Skelet dieser Theile frei, so findet man den distalen freien Knorpelfaden geschwunden und die Kinochenlülse am distalen Ende mehr oder weniger rollstïndig geschlossen, sodass die Phalanx nummehr stumpf endet (Fig. 21a,b). Um zn veranschaulichen, dass diese Umbildung wirklich mur durch die Atrophie des freien linorpelfadens und nicht etwa durch ein Vorrücken der Verknöcherung zu Stande kommt, theile ich einige IJessungen mit, ans denen anch die beträchtliche Gröfse der Verkiurzung erhellt. Diese Ilessungen beziehen sich auf die sämmtlichen Endphalangen von zwei annähernd gleich grofsen Händen, von denen die eine in der beschriebenen Weise metamorphosirt war, die antere noch nicht." Von den Zahlen in jeder Abtheilung der Tabelle bezeichnen die rïber dem Strich befindlichen die Länge der Endphalangen, und zwar die erste Zahl die Länge des verknöchernden Theiles, die zweite eingeklammerte die Länge des freien Kinorpelfadens, welcher hei der zweiten Hand eben ganz fehlte; die Zahl nuter dem Strich gibt die Gesammtlänge der übrigen Glieder desselben Fingers an. Ueberall wurde einfach die Zahi der Theilstriehe des Mikrometers beibehalten, da eine Berechunng der wirklichen Gröfseu von keiner Bedentung ist, dagegen

* I)a es zur schnelleren Uebersicht wünschenswerth erscheint, nur annäherud gleich grofse Hände miteinander zu vergleichen, lie grofse Variabilität derselben im ganzen nnd im Verbältnisse der eiuzeluen Finger zn einander es aber erschwert, mehrere solcher gleichen Objekte zusammenzulringen, so habe ich mich hier auf den Vergleich von nur zwei Händen besehränkt. Es kehrt aher, wie ich mich an einer gröfseren Zahl von MIessungen äberzengte, stets dasselbe Terhältuiss wieder. 
weniger iibersichtliche Zahlen ergibt. Die Tabelle belehrt uns nun, dass (wenn wir ron den unrermeidlichen kleinen Schwankungen beim Vergleiehe von zwei Händen absehen) die Endphalangen nach der Metamorphose gerade so lang sind, als es vorher der moximale. mit einer Knochenhülse versehene Abschnitt allein war: der freie Konorpelfaden ist also trotz seiner Länge vollständig atrophirt.

\begin{tabular}{|c|c|c|c|c|}
\hline & 1. Finger & 2. Finger & 3. Finger & 4. Finger \\
\hline 1. Tor der Metamorphose & $\frac{12+14)}{45}$ & $\frac{17+23)}{74}$ & $\frac{20+22}{89}$ & $\frac{17+13)}{49}$ \\
\hline 2. Xach der Netamorphose & $\frac{14}{42}$ & $\begin{array}{l}17 \\
65\end{array}$ & $\begin{array}{l}18 \\
79\end{array}$ & $\begin{array}{l}15 \\
43\end{array}$ \\
\hline
\end{tabular}

Die Carpalia bleiben bis nach der ILtamorphose knorpelig und verknöehern dann bekauntlich nur im Innern, sodass eine knorpelige Pindenschicht übrig bleibt. Dies steht natïrlich im Zusammenhange mit der imnigen Verbindung der Carpalia unter sich, welehe theils flache Gelenkhöhlen, theils mit Bandmassen ausgefuilte Liieken zwischen sieh fassen. Der tiefe Einschnitt, welcher die Carp. u I und $\mathrm{mI}$ anfangs schied, verwächst noeh ror der Verknöcherung bis auf den sehrägen Kanal, durch welchen das sehon bezeichnete Blutgefäss hiudurehtritt; der erwachsene Triton besitzt ilso ein einfaches Carp. mu I.

\section{B. Die primäre Entwickelung des Bein- und Fursskelets.}

Dieselbe stimmt im allgemeinen so sehr überein mit derjenigen des Arm- und Handskelets, dass ich mich darauf beschränken kann, unter Hinweis auf den rorigen Abschnitt die Hauptzüge der dort beschriebenen Torgänge kurz zu wiederholen und dabei die wenigen in der Entwickelungsgeschiehte des Fufses etwas abweichenden Punkte besonders hervorzuheben.

Die Hinterbeine der Tritonen entwickeln sich bekanntlich etwas später als die Vorderbeine; sie erseheinen unterhall) der Schwanzwurzel ebenfalls als kleine Wärzchen, welche nach hinten zapfenförmig auswaehsen und sich dann ron aufsen nach innen etwas abplatten. Die Kiniebenge erfolgt aber nicht nach oben wie am Ellenbogen, sondern nach aufsen. Sobald die Gabelung des freien Endes eben sichtbar wird, erkennt man im Innern die Skeletanlage wie am Arme in Gestalt eines proximalen axialen Stammes - Femur, welcher sich in zwei bogenförmig konvergirende und nach der Berührung divergirend in die zwei ersten Zehen auslanfende Aeste fortsetzt, der obere, dem ulnaren entspreehende ist der fibulare. der untere, dem radialen Skeletast homologe, ist der tibiale Ast. An der Berülnungsstelle entsteht aus der Verschmelzung beider Aeste das Tarsale fmIII, das Homologon des Carp. rmIII; dahinter rïcken beide Aeste zur ersten Anlage des Tarsus zusammen, bleiben aber zwischen dieser und dem Femur durch eine weite Lücke getrennt - Tibia und Fibula. An der oberen oder fibularen Seite der primitiven Fufswurzel entsteht durch Wucherung und Abspaltung ron dem betreffenden Skeletaste ein dritter, in die dritte Zehe auslaufender Tarsalast, sodass also auch der Tarsus aus drei nebeneinander liegenden Skeletästen herrorgeht, der einfachen 
Fortsetzung der Tibia (tibialer 'Tarsalast) und der dichotomischen Fortsetzung der Fibula (medianer und tibularer Tarsalast). Die Gliederung dieser Aeste erfolgt ebenso wie im Carpus, nur unterbleibt die Verschmelzung der dem Carp. mu I homologen Tars. mI und fI (rgl. die Tabelle auf S. 10). Die vierte Zehe entsteht in derselhen Weise wie der rierte Finger aus dem distalen Ende des dem Carly. u HI entsprechenden Tars. fII, sodass letzteres dahinter noch die fünfte Zehe produciren liam (Fig. 13); dies erfolgt aber erst dann. wam die vierte Zehe in ihrer Entwickelung die drei ersten bereits eingeholt hat, also ziemlich spät.

Aus der Uebereinstimmung rer rier ersten Finger und rier ersten Zehen folgt ganz natürlich, dass an del Hund nicht ein lhomologon der ersten. sondern der fünften Zehe fehlt. GeGENBAUR schloss ersteres aus dem Verhalten der Anuren, deren vierfingerige Hand noch ein Pudiment eines ersten Fingers trage*, während Wievershen auf Grund der entsprechenden Lagebeziehungen der Carpalia und Tarsalia hei den Urodelen das ron mir eben nachgewiesene Verhalten für das wahrscheinlichere hielt.;

Die Terknöchenmg verläuft an den hinteren Extremitïten genau so wie an deu rorderen. Auch der Fufs ron Triton cristatus ist, ähnlich wie es die Hand zeigt. durch die Länge des ans der Kunochenhülse frei hervortretenden und später atrophirenden Kunorpelfadens der Endphalangen und durch die Dreitheilung der Skeletaxe der exsten Zehe (ein Metatissus, zwei Phalangen) von dem Fufs ron Triton taeniatus untersehieden, der bei kiirzeren Endplıalangen nur eine Zweitheilung der ersten Zehe (ein Metatarsus, eine l'halaux) besitzt (Fig. 12). Die folgende Tabelle, relche die vollständige Atrophie jenes freien hinorpelenites der Endphalangen am Fulse von Triton cristatus beweisen soll, ist in derselben Weise angeordnet, wie die auf die Finger der Hand beziigliche Tabelle (vgl. S. 13).

\begin{tabular}{l|c|c|c|c|c}
\hline \hline & 1. Zehe & 2. Zehe & 3. Zehe & 4. Zehe & 5. Zehe \\
\hline 1. Vor der Metamorphose & $\frac{12(+8)}{42}$ & $\frac{18(+15)}{72}$ & $\frac{18(+15)}{112}$ & $\frac{18(+15)}{92}$ & $\frac{15(+10)}{45}$ \\
\hline & 13 & 15 & 18 & 20 & $\frac{16}{41}$ \\
\hline
\end{tabular}

Ich habe eben als Bildungen, welche den Fuls rol der Hand anszeichnen, die Entwickelung der füuften Zehe und die bleibente Trennung der Tars. m I und f I, die Homologa des Carp. mu I angegeben; dazu käme noch die Entwickelung vou Tars. tm III, welche von derjenigen des Car'p. r'm III, wie bereits hervorgehoben wurde (S. 6), etwas verschieden ist. Doch will ich erst bei der Besprechung der Regenerationsrorgänge darauf zurückkommen. - Dagegen muss ich hier darauf aufmerksam machen, dass die Abbildung Taf. 11 Fig. 12, welche die erste Anlage des Tars. tm III sowie alle ïbrigen bereits in der Knorpelbildung begriffenen Theile der gesimmten Skeletanlage sicher erkemnen lässt, deren noch weiche l'artien neist ganz unbestimmt im Grundgewebe des ganzen

* Gegenbaur, Untersuchungen zur vergleicheuden Anatomie der Wirbelthiere. Leipzig 1864-72. Heft I. S. 4.

** Wiedershem. Die ältesten Formen des Carpus und Tarsus der heutigen Amphibien. in: Morphologisches Jahrbuch. Bd. II, S. 426, 427, 432. 
Fufses verschwommen zeigt. Aus solchen Bildern lässt sich natiurlich die von mir beschriebene Entwickelung des Extremitätenskelets mmöglich entnehmen: sie riihren aher auch nicht ron Triton cristatus, auf dessen Untersuchung sich meine Beschreibung in erster Linie stiitzt, sondern von Triton taeniatus her, dessen jüugere Larven nach meinen Erfalrungen stets (wohl in Folge ron reichlichem diffusen Pigment) jene dunkeln unklaren Ansichten der ersten Skeletanlagen in den Extremitäten liefern und daher zu Untersuchungen dieser ersten Stadien wenig tauglich sind. Lediglich um dies zu veranschaulichen, babe ich die Abbildung Fig. 12 gewählt; bej den Larven von Triton cristatus stellt sich die Entwickelung des Fufses zu jeder Zeit mit derselben Dentlichkeit dar wie diejenige der Hand.

\section{Die Regeneration des Extremitätenskelets.}

Die Regeneration der Extremititen bei den Molchen ist bekanntich ron SPALLAvzAxI, Bonnet, Todd, Phulppeaux* ud gelegentlich ron manchen Auderen (Budifarach, Treviraxus, v. Stebord u. s. w.) beobachtet und beschrieben worden, ohne dass dabei anf die Entwickelnng des Skelets oder anderer imerer Theile souderlich Riticksicht genommen wurle. Es handelte sich dabej stets mehr um physiologische und biologische Fragen über die Regenerationsfähigkeit iiberlaupt, iber ihre Grenzen, ihre Dauer, den Einfluss verschiedener äufserer Umstände, während die Wiederherstellung der einzehıen Theile nur soweit beachtet wurde. als sie sich äufserlich kund gab. Und diese äufseren Esscheinungen konnten nicht eimmal richtig verwerthet werden, indem z. B. die regenerirten Finger erwachsener Molche äulserlich viel später und bisweilen in eines anderen Reihenfolge sichtbar werden, als ihre eigentlichen Anlagen, nämlich die Skelettheile im Innern des Hossenförmigen Endabschnittes der Extremität gebildet werden (vgl. Fig. 17, 18, 20). Daher rihhen die ungenanen oder mrichtigen Angaben SpALIAxzAxts und Todo's iiber jene Reihenfolge. Spaldaxzart scheint übrigens die Regeneration des Skelets allerdings rerfolgt zu haben: leisler ist aber eine ansführliche Nittheilung iiber seine beziiglichen Beobachtungen unterblieben. - So kann ich von den genamnten. Arbeiten hier um so weniger Gebranch machen. als der 'Zweck meiner Untersuchungen über die Regeneration wesentlich der war, ihre Erscheinungen bezüghich der Skeletbildung mit denen der primären Entwickelung zu vergleichen.

Als allgemeines Resultat dieser Untersuchungen kann ich angeben, dass dic Skeletbildung bei der Regeneration im wesentlichen ebenso verläuft wie bei der primären Entwickelung und daher als eine Wiederholung der letzteren bezeichnet werden kam. Dies gilt insbesondere fïr die Fälle, wo die Regeneration an ganz jungen Larven herbeigeführt wurde (Fig. 7) und das oft in wenigen Tagen regenernte Glied sich alsbald in nichts mehr rou den anderen in Entwickelung begriffenen Extremititen unterscheidet. Je später jedoch die Regeneration, sei es noch in der Larvenzeit oder nach der Metamorphose eintritt, desto mehr zeigen sich gewisse Abweichungen in der bezïglichen Skeletentwickelung, welche freilich nicht den allgemeinen Bildnngstypus, der immer derselbe bleibt,

* Spallaxzaxi, Physikalische und mathematische Abhandlungen. Leipzig 1769. - Loxset, Oeurres d'histoire naturelle et de philosophie. Teufchatel 17-9-83. Vol. I, 1. - Tond, On the Process of Reproduction etc. in: Quaterly Journal of Science, Literature and Arts. Vol. XVI. - Philippeaux in: Comptes rendus de l'Acad. des sciences de l'Institut de France. Anuée 1866, 1867. 
sondern nebensächliche Nomente betreffen. Ich werde daher im Folgenden rorherrschend die Regeneration an älteren Larven und völlig ausgebildeten Indiriduen berücksichtigen. Nach dem aber, was ich über die normale Entwickelumg des Almes und des Bcines mitgetheilt labe, brauche ich sie bei der Beschreilung der Regenerationselscheinungen nicht getrennt zu behandeln.

Sobald an der Amputationsstelle - bei meinen Experimenten in der Regel am Oberarm oder Oberschenkel - ein konisclier mit zarter Epidermis überzogener Zapfen herrorgewachsen ist, erscheinen in seiner mehr oder weniger indifferenten Innenmasse die ersten Spuren des sich neubildenden Skelets. War die amputirte Extremität noch sehr jung, also auch die Knorpelbildung in dem durchschnittenen Humerus (Femur) noch sehr renig rorgeschritten, so wind die neue an dessen Stumpf sich anschliefsende Bildungsmasse keinen anffillenden Unterschied und Uebergang zu seinem Gerrebe anfweisen, und in ku'zer Zeit jede Spur der Stelle rerwischt sein, no die Regenerition begann, da anch dic Cröfse der Neubildung in richtigem Verhältnisse zu den erhalten gebliebenen Theilen stcht (Fig. 7). An etwas älteren Larren tritt der Unterschied der Neuhildung ron dem sie tragenden ursprïnglichen Abschnitte der Extremität in Grölse und Gerrebe bereits deutlicher hervor (Fig. 6). An der Amputationsstelle geht der fertige Konorpel des Humerus (Femur) ziemlich jüh in das zellenreichere, erst knorpelähnliche Gewebe des distalen Eudes über. welches zudem durch eine merkliche Verschmälerung und den Mangel der periostalen Kinochenrinde rom ursprünglichen proximalen Abschnitt gesondert ist. Dem entsprechend sind die äbrigen neuangelegten Skelettheile, obgleich in Kontinuitit unter sich und mit dem regencrirten Humernsende, histiologisch noch nicht so weit entwickelt als letzteres, und auch noch in der Grölse zurïckgeblieben. Es wird daher in solchen Fällen länger als bei den jüngsten Larven dauern, ehe das regenerirte Glied das ursprüingliche der andern Seite rollstï̈ndig eingeholt hat.

Anders wiederum erscheint die Regeneration des Extremitätenskelets dort, wo dieselbe an bereits röllig ausgebildete, verknöcherte Theile sich anschliefst, also nach der Amputation des Ober- oder Unterschenkels, des Oher- oder Interames von ausgewachsenen Larven odel vou Thicren nach der Metanurphose. Von einem allmählichen Uebergange der indirekt entstandenen Knochensubstanz in die nothwendig aus einer weichen Bililungssubstanz entstehende Neubildung hann natülich nicht die Rede sein. Die letztere entwickelt sich allerdings im Anschlusse und in Fortsetzung der alten linöchernen Theile, doch so, dass die weiche Masse der Neubildung die Amputationsenden der Knochen rollständig umwächst und fest cinschlielst, daher den Zusammenhang (lersclben wit den sich regenerirenden Skelettheilen in der Art eines Callus herstellt (Fig. 20). Die röllige histiologische Kontinuität zwischen den beiderlei Theilen wird erst durch die Verknöcherung der neugebildeten Stiicke herbeigefuhrt. Die ron jener Ansatzstelle ausgchende neue Anlage erscheint aber schon zu eincr Zeit, wann der ganze regenerirte Abschnitt der Extremität erst eine ruderförmige Gestalt und eine Länge ron renigen Millimetern hat. sodass also der Grössenunterschied zwischen den alten und nenen Theilen anfangs ein seh. bedeutender ist und erst durch das lange Zeit andauernde Wachsthum der letzteren aufgehoben wird. Fener ist für diese Regeneration des Extremitätenskelets an älteren Thieren bemerkenswerth, dass die nenen Anlagen viel friiher und riel mehr in ununterbrochenem Zusammenhange. als es bei den primär cntstehenden der Fall ist, knorpelig werden und daher auch manche Einzelvorgänge weit klarer zur Anschauung lıringen (Taf. III). Anderseits ist nicht zu rerkennen, dass. indem solche in der späteren Lebenszeit sich regenerirende Theile viel weniger schlank an- 
gelegt werden als bei der primären Entwickelung, die neleneinander liegenden Stücke nicht selten frülszeitig in imnige Beruihrung miteinander kommen und geradezu verschmolzen zu sein scheinen (Fig. 20); und selbst die Reihenfolge der Erscheinungen kam, wie ich zeigen reerde, abgeïndert sein. Doch lehrt eine genanere und rergleichende Untersuchung aller betreftenden Regenerationserscheinungen, dass es sich dabei nicht um wesentliche. sondern mehr äufserliche Unterschiede von der primären Entwickehung handelt, und die grundlegende Bildung iiberall dieselbe lleibt.

Die erwälnte frühe und kontinuirliche linorpelbildung bei der Regeneration der Glieimafsen altere' La'ven und ausgebildeter Tritonen bringt es mit sich, dass alsdann die beiden Skeletäste. relche in Fortsetzung des Humerus orler Femur die Grundlage des ïbrigen Extremitätenskelets bilden, siclı in ihrer ganzen Wesenheit hesonders deutlich darstellen (Fig. 14, 15). Die Kontinuitït der Bildungsmasse imerhalb jedes Astes nud mit derjenigen des Humerus (Femur), sowie andriseits das urspringliche Getrenntsein beider roneiunnder, sind in den hetreffenden Präparaten ganz unzweidentig* und bestätigen somit die Auffassung, welche sich ans der primären Fntwickelung der gleichen Theile, wemn auch nicht ebenso einfich ergiht. Dort nämlich heginut die Knorpelbildung nicht kontinuirlich in der ganzen zusammenhängenden Anlage, sondem getrennt in rerschiedenen Ahschnitten (Fig. 2, 4, 7, 12), und könnte daher von denjenigen Furschen, welche wie z. B. Hısse und Borx**, die genetischen Beziehungen der Skelettheile zu einander nur aus dem knorpeligen Zustande derselben glauben erscldiefsen zu dürfen, anf eine Melnheit von selbstständig nelseneinander entstehenrlen Anlagen des Extremitïtenslielets hezogen werden. Unrl diese Ansicht würde vielleicht anch angesichts jener kontinuirlichen Krnorpelbildung bei der Regeneration aufrecht erhalten werden, indem man erklärte, die Regenerationsrorgänge seien elsen nicht im wesentlichen Wierlerholungen der primären Entwickelung, sondern ron derselben gerarle durch die legleitenden Umstände - als l,lofse Ergänzmug schon vorgebildeter Theile am völlig auegebildeten Organismus so sehr rerschieden. dass eine Abünderung der primären Vorgänge gar nicht zu verwundern sei. diese Abänderung damn aber auch zur. Dentung der primär ontogenetischen Erscheinungen nicht benutzt werden dïrfe. Gegen eine sulche sehr wohl denkbare Argumentation wïrden sich aber selur gewichtige Finm:̈nde erheben lassen.

Wollte man auch zun̈̈chst zugeben. dass für die genetischen Beziehungen der Skelettheile zueinander der Zustand mafsgebend sei, in dem sich ihre primären Anlagen im Beginne dor linorpelbildung darstellen, so wäre damit in unseren Falle noch lange keine bestimmte Grundlage fül die gesuchte Dentung gefunden, da jener für mafsgehend gelaltene Znstand elen kein für alle lndiriduen gleicher ist. sondern, wie ieh schon im ersten Abschnitte dieser Alhandlung angab, bald in diesem, bald in jenem Punkte abweicht. Zunächst hebe ich noch einmal herror, dass nach meinen Erfahrungen nicht alle Arten von Triton, ja vielleicht niclit eimmal alle Individuen derselben Art fiir die betreffende Untersuchung gleich gecignet sind, diss im besonleren die Larven von Triton taeniatus viel weniger durchsichtige und klare Bilder von den Skeletanlagen der Extremitäten liefern,

* Die Trenmung des radialen Astes vom Humerus in dem Taf. Ill Fig. 14 dargestellten l'rüparate ist dureh einen unvorsichtigen Druck bei der Herstellung des letzteren künstlich entstanden; dagegen ist der ursprüngliche Zusammenhang von Ober- und Unterarm noch auf späteren Entwickelungsstnfen zu erkeunen. Ich will noch hinzufiugen, dass ich ganz solche Präparate, wie die hier ahgebilleten, auch ron ganz alten Thieren besitze.

* Vgl. Zoologischer Anzeiger: Jahrg. II, Nr. 21. S. \$t 
als die Larven von Triton eristatus. Die ersteren zeigen allerdings meist in einer dunkeln, scheinbar ungesonderten Grundmasse getrennte hellere Kinorpelpartien, deren Zusammenhang nicht zu erkennen ist (Fig. 12); die letzteren lehren dagegen, dass nicht um in allen Fällen einc vou der ïlnrigen Masse der Extremitäten deutlich gesonderte kontinnirliche Grundlage für alle einzelnen Kinvipelbildungsheerde besteht (Fig. 1), sonder'n diss fermer die letzteren zu verschiedener Zeit und an verschiedenen Stellen bald getrennt, bald ungesondert verbunden auftreten (Fig. 2-S). Ich habe dies bezïglich des Carpus und seiner Verbindungen mit den Fiugern und dem Vorderarm (und Gleiches gilt fiil den Tarsus) schon eingehendar erürtert (S. 5-8): weitere Beispiele lieferu die muter sich zu vergleichenten Skeletaxen der cinzehnen Finger. - In welcher Weise soll nun bei solehen wechsehden Befunden entschieden werden, ob die liontinuität oder die Diskontimuität der Knorpelbildung das Ursprïngliche, Primïre sei? Soll die gröfsere Häufigkeit der letzteren den Ausschlag geben, die erstere also als Abnormitiit zu betrachten sein, so ständen dem eine ganze Reihe von Schwierigkeiten im Wege. Eimmal wïre nicht zu verstehen, dass jene almorme Kontinnitüt in der Anlage zweier roneinandel eigentlich völlig unablängiger Skeletstiicke, wenigstens in vielen Fälleu. olme jeden Einfluss auf die spätere Ausbildung der Anlage bliebe, da ich gewisse entsprechende Abnormitiaten an den weiter entwickelten Extremitäten, z. B. Gelenkunangel am distalen und proximalen Ende des Carpus und Tirsus und in den Fingern stets rermisst habe. Ferner wirrle einc nothwendige Konseruenz jener Annahme die sein, dass, da die Skeletaxen der drei ersten Finger unl Zehen wie es scheint ohne Ausnahme eine liontinuirliche, diejenige der vierten und fünften Finger und Zehen aber eine diskontinuiliche linorpelinlage besitzen, jene bestïndig eine abnorme Entwickelung darböten, obwohl sie morphologisch und physiologiseh mit den anderen völlig übereiustimmen (Fig. 4,9, 10). Oder sollen wir etwa ammehmen, dass die besprochene Kontinuität auch ontogenetisch ıur scheinhar jrimär, in cler 'That aber der Folgezustand ciner voransgegangenen und nur wegen ihrer kurzen Daner uiber'sehenen diskontinuirlichen Knorpelanlage sei? - Die Möglichkeit einer solchen Täuschung für einzehne Fälle zugegeben, so würde dieselbe doch, um nur eins hervorzulueben, in dem zuletzt erwiilnten Beispicle geradezn an dis Wunder bare grenzen. Denn warum sollte wohl del Zustand, der bei den vierten und fünften Fingern und Zehen sich der Beobachtung niemals entzieht, bei den drei ersten konsequent unsichtbar bleiben? -

Lassen wir aber den Begrift der supponirten abnormen Entwickelung ganz fallen und erkliiren, mit dem Zugeständnisse von einzelnen Täuschungen del letzterwähnten Art, den gerado vorliegenden Befund für den Aushlruck des ursprünglichen Verhaltens, so bleibt eben der wiederholte Wechsel ron getrennter' und kontinuirlicher Knorpulbildmog der gleichen 'Theile (llandwurzel, Finger') als ungelöster IIiderspruch zưück, da die genetische Bedeutung gleicher Theile natiirlich nicht weehsehn kam. Aus dem Znstande der primären Anlizgen im Beginne inrer Knorpelbildung läisst sich also eine Form ilner genetischen Bezichungen nicht ibleiten, ohne den Thatsachen einen Zwaug anzuthun. Alerdings ist aber damit die Frage nicht entsehieden, ob wir desshalb die zuletzt beschniebenen Pegenerationsel'scheinungen zur Erlänterung del prinärcu Entwickelungsrorgänge benutzen dürfen; denn jene Erscheinungen unterscheiden sich von den letzteren gerarle durch die Beständigkeit, mit welcher sich die Kuntinnität der Knorpelbillung schon an den jünsten Skeletanlagen zeigt. Ielı muss hier aber daran crimern, dass die Regeneration des Extrenitätenskelets mu an älteren Larven und ausgebihleten 'Thieren in der traglichen Weise verlänft, an jungen Larven aber durch- 
aus so wie bei der primären Entwickelung derselben Theile (Fig. 7). Dit man nun die Regeneration an jungen und diejenige an älteren Larren nicht wohl fïr zwei ihrem Wesen nach inkongruente Vorgïnge erklären kann, so wird man auch die dabei sich ergehenden Unterschiede der lúnorpelbildung für untergeordnete ansehen missen. Und bei näherer I'riifung finden siclı demn anch Thatsachen, welche diese Verschiedenheit zn erklären rermögen. Tergleicht man die regenerirten Arme aus jenen zwei Lebensaltern. wenn sie noch gleichenteise erst je zwei cinfache Slieletäste rom Humerus abwärts cnthalten, so muss es auffallen, dass in denen der jungen Larven noch keine Spur ron Kunorpelbildung zu entdecken ist, dicjenigen der älteren Larven aber durchweg ans jungen Linorpel bestehen (Fig. 6, 14, 15). A ehmliches trifft man noch anf den nïchsten Entrickiclungstufen: stets begimnt die Trnorpelbildung in den älteren Larven relatir riel früher als in rlen jungen - eine Differenz, welche um so weniger eine wesentliche genannt werden kam, als sie. wie bemerkt. gelegentlich auch in der primäiren Entwickelung beobachtet wircl. - Num ist aber die Gliedermng der Skeletanlagen nicht etwa, wie es manchmal scheinen könnte, eine Folge der getremten Knorpellilflung, sondern sie erscheint ebenso gut in lontinuirlichen Linorpelanlagen (erster bis dritter Finger F'ig. 2. 4. 7. 9) und zeigt sich nicht selten in noch völlig weichen, nichtknorpeligen Theilen deutlich angelegt (vierter Finger Fig. 10): und im letzteren Falle wird sie rlurch die folgende kinorpelbildung nicht verwischt, sondern trennt dieselbe rielmehr in so riel Abschnitte als Gliecler angelegt waren. Anf diese Weise muss aber der an sich unwesentliche Zeitunterschied in dem Begimen dieser Gewebsveründerung nothwendig die fraglichen Verschiedenheiten der daraf folgenden Erscheinungen bedingen: die früher eintretende Knorpelbildung wird im allgemeinen keine Vorlbreitungen zur Glierlermug der beziiglichen Skeletanlagen antreffen, also kontinuirlich erfolgen können. wälnrend die spätere linorpelentwickelung durch die lereits rorhandenen Gelenkanlagen in getrennte Heerde gesondert wird.

Ist anf diese Weise dargethan, dass zwischen dem Zustande der Skeletanlagen der Gliermafsen bei der primären Entwickehnng und friihen Regeneration, und demjenigen hei der Regeneration an :ilteren Larren kein wesentlicher; principieller Unterschied hesteht. so dürfen auch die Erscheinungen der letzteren Kategorie mit Vortheil dazu benutzt nerden, nm die gleichen, aber weniger evidenten Formrerbältnisse in der primären Entwickelung zu bestätigen. Dem der knorpelige Zustand der jüngsten Anlagen im ersteren Falle lïsst dieselben natürlich viel deutlicher herrortreten. als wenn sie sich, wie im anderen Falle, von dem umgebenden Gewehe nur dureh den Grarl der Dichtigkeit unterscheiden.

Yon solchen uns hier interessirenden Befunden der Regeneration wurde zu Anfang der voranstehenden Erörterung bereits die Anwesenheit ron zwei durchans getrennten, aber in sich und mit dem Humerus oder Femu ununterbrochen zusammenhängenden Skeletiisten. als den ersten Skeletanlagen des Unterarmes und der Hand (Untersehenkels und Fufses) herrorgehoben (S. 1i). Obgleich sie bisweilen dicht nebeneinander liegen und daun mehr durch eine Spalte als durch eine offene Lücke roneinander getrennt sind, so habe ich letzteres doch mchrfich, selbst hei ganz alten Thieren beobachtet, und zwar mit einer Dentlichkeit, die bei den immerhin nicht ganz kleinen Ohjekten nach meiner Ansicht jerlen Zweifel ansschliefst (Fig. 14. 15). Die Verbindung beider Aeste in Bereiche des späteren Carp. rm III oder Tars. tm 111 wird freilich selu hald angelsahnt, vollzieht sich alser in einer Weise, dass jene Aeste auch an derselhen Stelle noch dentlich unterschieden 
werden kömen. Sie erseheinen nünlich dort nicht gleich anfangs eng zusammengesehoben und diffus verschmolzen, sonrenn wie durch eine kurze Brücke verbunden (Fig. 15), welche erst allmählich schwindet und einer stetig zunehmenden Zusimmenziehung der verbundenen IIassen Platz maeht (Fig. 16). Weun nun dieser ganze Verbintungstheil beider Aeste dureh die Alogliederung ihrer getrennten proximalen und distalen Abschnitte ebenso uumittelljar und einfach in das genannte Carpale oder Tarsale ïbergeht, wie ich es zuerst von der primären Entwickelung beschrieb, so wïre das letztere immerhin als Verschmelzungsprodukt zweier, beiden ursprïnglich getremiten testen angehöriger Theile anzuselıen (rgl. Fig. 15 und 19). Dies gesehieht aber nach meinen Erfahrungen in den selteneren Fällen. Häutiger sieht man an unseren Objekten den zweiten Mołus der Bildung jenes Hand- mıd Fnfswurzelstiiekes. Es lässt sich nümlich danı die deutliehe Sonderung eines r'unden Knorpelstïckes znerst nur im Verlaufe des ulnaren (fibularen) Astes erkemnen, während das damit rerbundene Stück des radialen (tibialen) Astes noch mmerbrochen mit dem ersten Metacarpus (Metatarsus) und dem iibrigen radialen Karpalast (tibialen Tarsalast) zusammenhängt (Fig. 16). Doch lileibt es dabei in ler fortsehreitenden Knorpelbildung etwas zurïck und erscheint daher um einen Schatten lunkler als das erstgenannte runde Stiick. Ein weiteres llerkmal einer Art von Rïckbildung in jenem Theile des radialen (tiljialen) Astes könnte man vielleicht darin erblicken, dass er ganz offenbar gegen den ulnaren (fibularen) Ast sich zusammenzieht und dadurch insbesondere die Einschniirung am radialen (tibialen) Rande der Handwuzel (Fufswurzel) erzengt (rgl. Fig. 15-18). Dieser Prozess führt aber nicht etwa zu einem wirklichen und vollkommenen Schwunde des betreffenden Theiles, sondern gleichzeitig vergrölsert sich das anliegende runde Knorpelstiick auf Kosten des ersteren. indem die rollkommenere Knnorpelbildung in dessen Masse vorrückt. welehe endlieh in das definitive Carjale oder Tarsale ganz aufgeht (Fig. 18, 17). Daraus allein lässt sich verstehen, dass, sobald letzteres allseitig fertig gesondert ist, der erste Metacarpus (Metatarsus) keine unmittelbare Verbindung mit dem Reste des zugehörigen Kirpar(Tursal)astes mehr besitzt, sondern vom Carp. r'II (Tar's. tII) durch die vorspringende Eeke des Car'p. I'm III (Tars. tm III) getrennt wird und unr auf dieser aufsitzt (Fig. 19, Taf. Y Fig. 27-30). - Also auch diese zweite Bildungsweise des letztgenamuten Stiickes bestiitigt die Auffassung, dass es ans zwei ursprïnglich getrennten Anlagen hervorgehe, lehrt aher zugleich die Möglichleit kennen, dass unter Linständen der in jenem Stücke enthaltene Abschnitt des radialen (tibialen) Astes rIII (t III) ganz verloren gehe und nur ein eintaches Carp. mIIl (Tars. mIII) zurüekblecibe, dem sich alsdan der erste Finger (die erste Zehe) anschliefst.

Anch die im ersten Abschnitte besehriebene Sonderung ron Handwurzel und Unterarm (Fufswurzel und Unterschenkel) lässt sich während der Regeneration dieser Theile gut verfolgen. Zur Bestätigung jener Beschreibung mache ich ganz besonders darauf anfmerksam, dass die beiden Skeletäste hinter ihrer Verbindungsstelle gerwühnlich merklich ronein:mder abstehen, ehe sie sich auf den späteren Entwiekelungsstufen dort innig aneinander schliefsen (Fig. 15-18). Ebenso klar ist die allmähliehe Vorwucherung und Abspaltung des dritten Karpal- oder Tarsalastes. Ieh glaube diesen Vorgang bei der Regeneration sehr vollstäudig gesehen zu haben und konnte dahei niemals irgend ein Merkmal fuir die genetische Sellsstständigkeit der Neubildung entdeeken, da sie stets in knorpeligem Zustande und bis zu ihrer relativ späten Abspaltung rom ursprüuglichen ulnaren oder fibularen Aste in Kontinuität mit demselben erscheint. Die Wucherung heginnt in cler Nähe des 
Carp. rmIII (Tars. tmIII) und schreitet dann bis zur Ulna (Fibula) fort (Fig. 15-17); es kamm daher unter Umständen u In mit dem dritten Finger oder fII mit der dritten Zehe fruiher sichtbar werden als die Anlage des ganzen Astes (Fig. 16). In einem sich regenerirenden Tarsus fund ich sogar eine Fortsetzung zu diesem isolirten Anftreten des fIll, indem an Stelle ciner glcichmälšigen Inlage des neuen Astes drei rundliche Tursprïnge hintereinindel dem ursprïnglichen fibularen, später medianen Tarsalaste aufsafsen. von denen die zwei distalen bereits kleine Fingerknospen trugen. Diese Anlagen dex Tars. fI-III erschienen dalıer nebst den ihnen aufsitzenden Zehen als getrennte koordinirte Auswüchse des fibularen Hanptastes. Doch stellt sich dieser Befund durchaus nicht in eigentlichen Widerspruch mit der gewöhnlichen Erscheinung dieser Billungen; dem anch die gewöhnliehe cinheitliche Grundlage ron f I- III wächst $\mathrm{ja}$ in ihrer ganzen Lünge aus dem fibularen Hanptaste hervor. sodass die ligenthïmlichkeit jenes dusnahmefilles lediglich darin beruht, dass die Sonderung jener Tarsalia voneininder früher als gewöhntich erschien.

Dass auch im iibrigen die Glieterung der Karpal- und Tilrsalïste nieht immer in der gleichen Reihenfolge verläuft, darf nach derselben Erfihrung bei der primären Entrickelungo nieht auffallen. Bemerkenswerth diirfte es rlagegen sein, dass eine andere, primär immer eingehaltene Reihenfolge in der Regeneration der Extremitäten häufig abgeändert wird. und zwar um so mehr, je älter die betreffenden Indivirluen sind. In ler primären Entwickehng erscheinen die zwei ersten Zchen (und Finger) znerst und gleichzeitig, die dritte, rierte, fïnfte aber später und in merlichen Zeitabständen nacheinander. Bei der Regeneration gilt dieselbe liegel mu für die zwei ersten Finger und Zehen; die übrigen zeigen sich aber oft so früihe und so bald hintereinander, dass eine Reihenfolge ron zwei-, drei-, vierfingerigen Händen oder zwei-, drei-, vier-, fünfzehigen Füfsen gar nicht mehr zum Ausdrucke kommt (Fig. 17, 18, 20). Dabei darf aber anf lie äufsere Erseheinnng der intakten Extremität kein Gewicht gelegt werden; denn im Zusammenhange mit der schon erwihnten Thatsache, dass die regenerirten Finger und Zehen älterer Geschöpfe besonders kurz angelegt werden, ist es leicht zu rerstehen, diss dieselben in den Hossenförmigen Hünden und Füfsen bereits alle vorhanden sind, wem anlsen vielleicht nur ein Einsehnitt zwischen len zwei oder drei ersten Fingern oder Zehen zu sehen ist. Selbst die fünfte Zehe, welche am regenerirten Fufse äufserlich so spät hervortritt (BохxEт), ist schon lange vorher im Inneren desselben angelegt. Diese Neigung der im späteren Lebensalter regenerirten Extremitäten. die eigentlich aufeinanderfolgenden Vorgänge mehr gleichzeitig nebeneinauder verlaufen zu lassen, rerdient unsere Aufmerksamkeit desshalb, weil dies der Iodus ist. nach welehem die Entwickehnng der Extremitäten bei allen über den Urodelen stehenden Vertebraten ausschliefslich erfolgt.

Bekanntlich sind monströse Extremitäten keine seltene Erscheinung bei den Molchen. Schon r. Siebold sprach die Ansieht aus*, dass sie in der Regel nielit angeboren, sondern Regenerationsprodukte seien: und nach meinen Erfahrmugen muss ich ihn beistimmen. Zn den gewöhnlichsten dieser Monstrositïten (unter denen ich iibrigens auch eine ausgebildete dreifingerige Hand beobachtete) gehüren die ïbcrzähligen Finger und Zehen, welche dureh dichotomische Theilungen eines solchen Gliedes entstehen; an einem Fulse fand ich die dritte Zehe ron der ersten Phakanx ab so getheilt, und am zugehörigen dritten Xetatursus noch eine seitlich herrorgewachsene Zehe, welche mit der 
zweiten verwachsen war. An merkwürligsten war dabei, dass diese zweite Zehe auf einem iiberzähligen Tarsale m IV aufsafs, welches rein knorpelig war und schon dadurch auf eine Regeneration hinwies. Whedershen lat offenhar einen ganz ähnlichen Fal] beobachtet (Salcmandrine propieillata und Geotriton fuscus. Genua 1875 S. 149).

Einen lan'zen Anszug der roranstehend aufgefïhnten Untersuchungen über die Entwickelung and Regeneration des Extremitätenskelets der Molche habe ich bereits in einem Vortrage anf der Naturforscherversammlung in München 1877 mitgetheilt und durch Ahbildungen mo Präparate ellïutert. Im daranffolgenden (rorigen) Jahre unternahm dann STrasser die gleiche Untersuchung an den sich primär entwickelnden Gliedıafsen allein. Es liegt mir darïber zunächst mur eine vorläufige Nittheilung im Zouloyisthen Anzeiger 1568 No.9 und 10 ror, welcher ich eine Beriehtigung in No. 14 desselben Blattes folgen liefs. STrasser glaubte nämlich, muter Rezugnalume auf das Referat über jenen meinen Vortrag in amtliehen Bericht der betreffenden Versammlnng schliefsen zu diurfen, dass iclu das ganze Glierlmafsenskelet in Gestalt eines kontiunirlichen Kunorpelbaumes rom Humerus orler Femur aus herrorwachsen lasse, was ich in jener Notiz eben als Missrerständniss bezeichnete. Welchen hedingten Werth ich übrigens rer Kontinuität orler Diskontinuität der ersten Knorpellildung im Extremitätenskelet beilege, wird ans den vorangegangenen Erörterungen geniigend erhellen. - Anf die Histiogenese des Knorpels nüher einzugehen, welche Strasser offenbar eingehend untersuchte, hahe ich nach der ausfiilurlichen Darstellung derselben in meiner Entwickchungsgeschichte der Thlie (rgl. o. S. 3) lieine Veranlassung gehabt und finde dariloer auch hei Strassen nichts principiell Neues. - Wiu weit Strassen mich im Uebrigen bestätigen kamn, ist mir aus seiner vorläufigen Mittheilung nicht ganz klar geworden; er spricht allerdings ron zwei säulenartigen fortsetzungen des Humerus und Femur (a. a. O. S. 194, 215). welche aber in eincr Platte. der gemeinsamen Anlage des ganzen Carpus (Tarsus) und der Finger (Zehen), endigen sollen. Soll damit gesagt sein. dass alle diese Theile gleichzeitig neheneinander und im allseitigen Zusammenhange angelegt werden, un erst sekundär sich ron einander zu tremen, und dass folglich ilire ron mir zuerst angegebenen hesonderen genetischen Beziehnugen nicht nachweishar scien. so rerweise ich einfach auf meine gegentrïrtige Darstellung. Was Strasser dagegen ron den aus jener Platte hervorgehenden drei Sïulen des Carpus (Tarsus) und ihrer Glierlerung anführt (a. a. O. S. 216. 217). ist allerdings eine Wiederholnng meiner friiheren Angaben. - Ueberhaupt wird sich die Frage. was in Strasser's Mittheilung eine wirkliche Widcrlegung und was eine Bestïtigung meiner Angaben sein soll, erst entscheiden lassen, wemn unsere beiden Arbeiten in extenso vorliegen, wesshalb ich auch anf eine ausfübrlichere Entgegnung hier verzichten zu müssen glaube.

\section{Ueber die Torsion des Humerus.}

Ich will hier auf diesen Gegenstand nur so weit eingehen. als meine einschlägigen Beobachtungen an 'Tritonen os rerlangen: zur Orientirung schicke ich alser eine kurze Uebersicht der' Torsionstheorie madh Martixs und Gegexbaur einerseits und nach Albrecht anderseits romus. 
Davon ansgehend. dass die vordere Extremität der höleren Wirhelthere im VerhäItnisse zur' hinteren eine direkt umgekehrte Stellung eimnehme, die Streckseite les Armes statt nach rorn, wie am Beine, nateh hinten sehe und das Homologon der Tibia, der Radius, statt an der Innenseite an der Aufsenseite des Unterarmes läge, nahm Martuss eine .virtuelle" Drehung blofs des distalen Theiles rom Humerus mm $180^{\circ}$ an. * Den Weg dieser Spirakdrehung sah Mlaktusis in der rauhen Linie vorgezeichnet. welche rom :̈nlseren Epicondylus ladialis des Ienschen sich auf die Hinterfläche des Humerus schlage und bis zur lmenseite seines Halses verlaufe. Die auf diesem Wege bewirkte Zurückdrehung des Humerns, welche den Arm in eine mit lem Beine iibereinstimmende Lage bringt, muss also, obne dass Ilırtxs es besonders beschreibt, hen Epieondylus radialis hinten herumführen (postaxial - A Lвkicnt). Der Grad der Torsion soll hei den unter den Säugern stehenden Vertebraten geringer sein, so hei den nugesehwänzten Amphibien wie bei den Reptilien c. 90 betragen (a. a. O. S. 63.64$)$.

Gegexbaur * verghich die naeh WeLcker konstruirten Axenehenen des proximalen und distalen Hunerusgelenkes beim Menschen und fand, dass sie in Erwachsenen einen kleineren Winkel (120) miteinander bildeten als in Kindern und Embryonen $\left(38^{\circ}, 43^{\circ}\right)$. Er schloss daraus anf eine wirkliche, individuell stattfindende mind nach seinen Abbildungen radio-postaxiale Torsion des menschliehen Humerus um $168^{\circ}$ und rermuthet eine äbuliche aber sehwächere Torsion bei den ïbrigen Vertebraten. Die Ursache dieses Vorganges rerlegt Gegexbıur in dis Waehsthum des distalen Gelenk- und Diaphysenendes (a. a. O. S. 60).

ALBRECht * * hat gegen diese Martins-Gegexbaur sehe Torsionstheorie hauptsächlieh folgende Einwendungen gemaeht. Erstens: Bei der angegebenen Rüekdrehung des Humerus in die ursprüngliche Lage wïrden dafür die Muskehn, Gefäfse und Nerven unnatiirlich gedreht; es köme also dadureh der ursprüngliche Zustand nieht hergestellt werden. Zweitens: Aus den Messungen Gegexbaur's an Ienschen und Thieren ergäben sich nur Schwankungen im Verlältnisse der beiden Gelenkaxen, wie sie anch an anderen nicht torquirten Pöhrenknoehen rorkämen; eine wirkliche Torsion werde dadurch nicht bewiefen. Drittens: Endlich stimmten mit der Theorie die Befunde in den übrigen Thierklassen nicht iibereju, welehe rielmeh" eine in anfsteigender Reihe zunehmende prataxiale Versehiebung des ursprünglieh medial gelegenen proximalen Radiusemles über die Uha bewiesen. So liege bei Ichtyosaurus der Ratius nach innen, bei den Amphibien bereits ror der Ulna, um sie erst bei den höheren Vertebraten ganz zu krenzen. Diese Versehiebung des Riudius geschühe bei feststehendem Humerus und rerde nicht durch Wachsthumsvorgänge an den Gelenkenden (Gegexbatr), sondern dadurch herbeigefïhrt, dass der Arm zum Greifen und HaIten benutzt und dureh die dahei zumeist in Aktion gesetzten Muskehn die Ulna zuriek und einwärts gezogen werde. Anch lasse sich eine solche Verschiebung an Rindsembryonen theilweise direkt nachweisen.

* Vartins, Nouvelle comparaison les membres pelviens et thoraciques etc. in: Annales des sciences naturelles IV. Serie. Zoologie. T. VIII, S. 56 .

frit Gegenbaur. Ueber die Drehung des Humerus in: Jenaische Zeitschrift für Medicin nnd Naturwissenschaft Bd. TV. 1868 .

min Albrecht. Beitrag zur' Torsionshlheoric des Humerus und zur morphologischen Stellung der Patella in der Reihe der Wirbelthiere. Dissertation, Kiel 1876. 
Dagegen hebt num aher. Howphr hervor, diss der Radius bei den Enaliosauren bereits ebenso wie bei den Amplibien am Vorderande des quer nach anfsen und mit rler Streckseite nach oben gerichteten Armes liege. gerade so, wie die homologen Theile der hinteren Extremität. Daher sieht Humphrx diese in beiden Extrenititen iibereinstimmende Lage für die ursprüngliche an, von der aus die definitive Lage bei den iibrigen Vertobraten durch eine Drehung der gesammten Extremität. an der Schulter- nnd Beckengürtel theihehnen, erreicht werde, .ohne jede Torsion mo Dislokation der einzehnen Theilew (a. a. O. S. 667). Jene Drehung erfolgt abel am Arme nach hinten. sodass die dorsile Streckseite zur hinteren werle, wobei die Hand durch Pronation sich mach rorm richtet; die hintere Gliednalse dagegen dreht sich entgegengesetzt nach rorn um.

Bevor jeh meine eigenen Beohahtungen ïber diu Entrickehung des Ellenhogengelenkes hei Tritonlarven anfïhre, nuss ich an die anfänglichen Lageheziehumgen ihrer Fxtremitäten erimern. Der Arm und die Hand liegen in gestreckten Zustande in einer Sagittalebene. dem Körper riokwärts dieht angesehmiegt. sodass der nhare liand der obere, der radiale der untere ist; Uha und Radius verlanfen ganz parallel. sodass die Gelenkinlage zwischen Rarlins und Humerus (Condylus radialis) genan ïber remjenigen zmischen Uha und llumens (Condylus ulnaris) liegt (Fig. 22). Die hintere Extremität ist ganz ähnlich gerichtet, mit einem filularen wberen und tibialen unteren Rande. Es wird aher diese ursuringliche Lage im Verlanfe der meiteren Entwickelung an lreiden Extremititen in rerschiedener. Weise ahgeändert.

Die Lageveränderungen tes Armskelets lönnen erst nit Hülfe einer distalen und einer proximalen Axenehene des Humerus. analog den ron Welcker und Gegexbaur benutzten Elienen. bestimmter beurtheilt werden. Die distale Axenebene nid dureh die Queraxe des distalen Humerusendes, welche dessen nluaren und radialen Rand verbindet, mul rlurch die Lüingsaxe des Humerns bestimnt, die antere Ebene durch die letztere und die Inlage des Processus lateralis lumeri (Fürbrnger). welche dicht hinter dem Humerusknpte an minteren Rande liegt und durch die betreffenden Muskelansätze (Mm. petoralis, dorso-humeralis, dorsalis scapulae etc. Fưrbrixgen) schon friihe kemutlich ist. Freilich habe ich an den jungen Slicletanlagen der laven die Lage jener beiden Axenebenen zu einander nicht wirklich messen können. sonłern sie an den in situ präprairten Theilen nu anühernd hestimnt, was aber für den rorliegenden Kweck vollionmen ausreicht. Anfangs fallen nun beide Axenehenen, wie sich ans der beschrebenen urspuinglichen Lage des Armes ergibt, in der Sagittalebene zusammen (Fig. 22): bald danuf beginnt aber eine Drehmg der distalen Axenebene, an weleher weder die moximale Axencbene noch die mit dem Unterame verbundene Hand theilnimnt. Denn sobald die luhende Extrenität einer solehen jungen Larve im ganzen in die urspringliche Lage zuriekkehrt, zeigt sich der Processus lateralis humeri noch immer wie anfangs nach unten gerichtet, die lland mit der Volarfläche mach immen sagittal gestellt, während gleichzeitig die Anlage des Condylus radialis nach anfsen und aufwärts halblugelig lervornachsend aus ihrer Stellung unter der Anlage des Condylus uhnaris allnählich ganz an die Anfsenseite der letzteren rïckt (Fig. 23. 24). Dadureh wirl natiolich die distale Axenehene des Humerus ans del senkrediten, sagittalen Lage in Sime einer Supination in eine horizontale, frontale gedreht und

* Humprr, The comparison of the fore and hind Limbs in Vertebrates. Jourual of Anatomy and Physiology. Vol. X. 
bildet alsdam mit der senkrecht bleihenden proximalen Axenebene einen Winkel; derselbe betrug nach einigen Messungen an erwachsenen Salamandrinen (Triton, Salamandra) c. $90^{\circ}$, ungefïhn ebensoviel bei ILenopoma, bei Sirea c. $50^{\circ}$. Dem Condylus radialis folgt aber maturgemäfs auch das Iröpfehen des Radius, dessen proximaler. Theil also ebenfalls zur Seite desjenigen der Ulna rückst und ilm ron anfsen theilweise rerdeckt, während im Zusammenhange mit der ruhenden Hand die distalen Enden beider Unterarmknochen die frühere Lage behalten (Fig. 23, 24). Wiihrend dieser Lageverändernng des Condylus radialis vollzielst sich autch die schon frïlıer erwähnte Biegung des Armes im Ellenbogengelenke, welche beiden Vorgänge aufs imnigste zusammenhängen. Dem bei der urspriinglichen Lage hätte eine Winkelstellung ron Humerus und Ulua in der Sagittalehene eine Verschiebung des Condylus radialis gegen den Radius und dieses gegen die Hand orler eine Verkiirzung desselben vorausgesetzt; war dies nicht möglich, hlieb also der Radius in seiner ursprüinglichen Lage ein Hinderniss für jene Biegung, so komite dasselbe nur dadurch leseitigt werden, dass der Condylus radialis mach aufsen auswich und so Ulna und Radius nebeneinander sich bewegen liefs. Dies ist aber anch die einzige Flexion des Armes, welche mit liezug auf die ursprüngliche oder Ruhelage in der Sagittalebene, also um eine zur Iledianebene des Körpers rechtwinkelige Drehnngsaxe ansgefühnt wird; die ïbrigen Flexionen der Hand und der Finger erfolgen in jener Beziehung um Drehungsaxen, welche mehr oder weniger senkrecht in der sagittalen oder ursprünglichen Richtungsebene des ganzen Armes liegen. Yit anderen Worten: die Flexion des Unterarmes unserer Thiere, so wie sie wirklich vollzogen wird, ist ron allen solelien Bewegungen der ganzen Extremitït die einzige, welche in der ersten Anlage des Armskelets nicht rorgebildet ınd, wenn wir den Arm mit einer flossenförmigen Extremität rergleichen. mit den Biegungen derselben nach der Fläche nicht vergleichbar ist.

Sobald der Arm ans der bisher allein heriicksichtigten Ruhelage gebracht wird, reränderı sich natïrlich die genannten Lagebeziehungen zum Körper. Bei der Lokomotion der Urodelen geräth der Oberarm in eine mehr oder weniger 'puere Ebene, sodass der Condylus radialis nunmehr allerdings ror dem Condylus nharis sich befindet, der Ellenbogen nach aufsen sieht; diese Lage ist aber nicht etwa als eine Uebergangsstufe von einem nach vorn zu einem nach hinten gerichteten Ellenbogen anzusehen (АцвRесnт), sondern steht zu der eigentlichen Umbildung des Ellenlogengelenkes in gar keiner ummittelbaren Beziehung. Wenn wir von einer ursprünglielıen Riehtnug des Ellenbogengelenkes reden wollen, so müssen wir es uns mit einer ohngeführ senkrechten Drehungsaxe und nach aufsen gekchrter Streckseite rorstellen. Und dass eine solche Bildmg olune dic beschriebene Verschiebung des Condylus radialis und des Radins thatsächlich stattfinden wiirde, erschen wir am Beine, dessen dem Ellenhogen homologes Kune aufangs wirklich jene supponirte Stellung einnimmt.* Das Bein der Tritonlarren, welches zuerst genau die gleichen Lageheziehungen zum Körper hat, wie der Arm vor der Umbildung des Ellenbogengelenkes, begimnt sich an linie und an Fufse zu biegen, beror es die urspriingliche Lage anfgibt, und ohne eine wesentliche Verändermng im Kiniegelenk zu erleiden. Allerdings hat es mir geschienen, als wenn auch die Tibia sich ähnlich wie der Radius etwas aufwärts rerschieht; aher da es mir nicht gelang, die Lage des sogenamnten

* Ich rerweise hierbei auf die Ablildungen der analogen Bildung der Anuren in meiner Entwickelungsgeschichte der Unuke. Taf. XVIII Fig. 325, 327.

foetre, Gliedmalsenskelet. 
Trochanter (Stannids) gut zu bestimmen, und so einen festen Anbaltspunkt für die Beurtheilung jener Verschiebung zu gewinnen, so muss ich die Möglichkeit offen lassen. dass eine solche Verschiebung nur scheinbar eintritt, indem der ganze Femur sich um seine Axe dreht. Dem eine solche Drehung im Sime einer Supination findet jedenfalls statt und richtet in Terbindung mit einer horizontalen Bewegung des Femur bis in eine qnere Lage die Queraxe des línies sagittal horizontal und den Unterschenkel abwärts. Eine solche Stellnng erreicht der Arm der Urodelen nicht röllig, indem der Ellenbogen stets etwas nach hinten sielit und dadurch an die Armstellung der höheren Vertebraten erimnert; das Knie dagegen rerschiebt sich aus jener queren Stellung noch weiter nach rorn, sodass darin eine Annäherung an die Stellung des Bcines bei den höheren Vertebraten nicht zu verkennen ist.

Die Richtung des Knies und des Ellenbogens nach anfsen, sowcit sic sich mit einer queren Stellung der ganzen Extremität und mit einer horizontal-sagittalen Drehungsaxe des betreffenden Gelenkes verbindet, ist also durchaus keine ursprïngliche (Нuмpнry); aber ebensowenig kam die Richtung derselben Gelonke nach vorn oder nach hinten eine primäre genannt werden. Die wirklich ursprüngliche Lage beider Extremitäten ist eine sagittale Flossenstellung mit nach hinten gerichtetem Ende nnd senkrechten Drehungsaxen der Beugegelenke; dann liegen die Unterschenkclund Unterarmknochen parallel übereinander, Fibula und Una oben, Tibia und Radius unten. Dies muss also den Ansgangspunkt bilden bei der Beurtheilung der Lagebeziehungen der ganzen Extremität zum übrigen Kö̈rper. In ihre definitiven Stelhngen kommen die Extremitäten erst sekundär, das Bein durch ansgedehnte allgemeine Bewegungen bei wenig oder gar nicht veründerten Lagebeziehnngen der Theile zueinander, der Arm durch eine Umbildung und partielle Umlagerung der Theile in sitn neben einer geringen Bewegung der ersteren Art.*

Beim Vergleiche meiner Untersuchungen mit denen ron Martins, Gegenbaur und Albrecht ergibt sich zunächst, dass die beiden A uffassungen derselben, wenigstens in Bczug auf die Amphibien, in gewissem Sinne zu verbinden sind: es findet eine wirkliche Torsion des distalen Humerusendes statt (Gegexbaur), aber nicht eine radio-postaxiale, wic Martixs und Gegexbaur amnehmen, sondern eine radio-praeaxiale, wie es ALbrecht für die Verschiebung des Radius angab. Wie aber diese Verschiebung bei feststehendem Humerus, ohne Torsion desselben vor sich gehen soll (ALbrecht), ist mir unverständlich geblielsen; sollen Ulna und Padins mit den Condyli tanschen, oder ein neuer Condylns radialis dort gebildet werden, wo das Capitulum des Radins seine Wandernng beschliefst? - Anch scheint es mir nach meinen Beobachtnngen unzweifelhatt, dass die Ursache der Torsion im Wachsthum der Epiphyse des Humerus zu suchen ist (GEgexpadr), und nicht die Verschiebung des Radius aus gewisson, durch lange Generationsreihen angchäuften und vererbteu Wirkungen des Gebranches hervorging (АLERECHT), namentlich wenn der letztere so wenig begrïndet ist; denn dass die Urodelen, bei denen die Torsion doch schon ziemlich stark ist, sich der Vorderextremitäten vorherrschend zum Greifen bedienen oder früher bedient bätten, wird wohl kaum behauptet werden kömnen.

* Die quere Stelluug des Almes ist hierbei ohne Bedeutung für die höheren Vertebraten, indem sie nur bei den Anureu einen höheren Grad erreicht, soust aber mehr und mehr zurückgeht. Die einzige Bewegung, welche die ruhende Vorderextremität der Urodelen nach der Umbildung des Ellenbogengelenkes auszufüren bat, nm die den Säugern eigenthümliche stellung einzunchmen, ist eine Prouationsbewegung der Hand. 
lst nun durch die von mir thatsächlich gesehene Tursion des Humerus der Urodelen der Widerspruch Hемpнry's gegen jede partielle Lageveränderung im Armskelet beseitigt, so ergilst sich ferner auch seine Vorstellung ron den ursprïnglichen Lagebeziehmengen der Gliedmafsen aller Vertebraten als irrige. Denn eine solche quere Lage, wie sie sich auch am funktionirenden Aru der Urorlelen zeigt, wird erst in Folge einer wirklichen Torsion erreicht, ist also indiriduell ein sekundïrer Zustand; und anderseits stimmt die ron mir beschriebene ontogenetisch primäre Lage der Gliedmafsen der Urodelen auch mit der liuhelage der Flossen ron Ceratodus und, wie mir scheint, auch der Enaliosamrier iiberein, und muss selbst die Flossenstellung der Selachier, wie ich noch zeigen werde, auf einen gleichen Ursprung zuriickgefïhrt werden, sodass alles auf eine solche Lage als die auch phyletisch ursprïngliche hinweist. Daher scheint mir anch alles das, was über die progressive Zumahme der IYumerustorsion oder Rarlinsversehiebung von den Amphibien aufwärts gesagt ist, indem dabei von der Stellung der ausgebildeten hinteren Extremität der höheren Vertebraten ausgegangen wurde, gleichfalls auf irrigen Voraussetzungen zu beruhen. Es ist eben, wie ich es für die Urodelen ansfülnte, welche in dieser Beziehung unzweifelhaft als Ausgangspunkt für die bölıeren Vertebraten gelten düıfen, ein Bein mit rorwärts gerichtetem Knnie aus seiner ursprünglichen Lage riel melnr verschoben als ein solches mit seitwärts gerichteten Kinie, oder ein Arm mit rïckwärts gekehrtem Ellenbogen; es darf daher ersteres für die Beurtheilung des letzteren gar nicht ohne weiteres zum Ausgangspunkt gewählt werden. Gehen wir aber von der fuir beide Extremitäten gleichmälsig nachgewiesenen U'sprungsstellung aus und finden alsdann, dass der ansgebildete Humerus der höheren Urodelen bei rückwärts gekehrtem Ellenbogen und ganz änfserem Condylus radialis (Fig. 24) - welche Lage der Arm anch der erwachsenen Thiere sehr häufig eimnimmt - eine Torsion voll c. $90^{\circ}$ erlitten hat. so liegt zunïchst gar kein Grund ror, bei durchaus gleicher Stellung des Armes eines Sängethieres für dessen Humerus eine bedentend stärkere Torsion $\left(168^{\circ}, 180^{\circ}\right)$ anzunehmen, wie eine solche sich ans den bezeichneten irrigen Voranssetzungen ergab. Allerdings lässt sich der Torsionsgrad bei den höheren Vertebraten gegenwärtig anch nicht anuähernd so genau bestimmen wie bei den Urodelen; dem wenn anch die distale Axenebene des llumerus in beiden Fällen übereinstimmend konstrnirt werden könnte, so lässt sich rloch nicht entscheiden, welcher Punkt am proximalen Humerusende z. B. der Säuger den Processus lateralis humeri der Uradelen durchaus homolog, wie also die entsurechende proximale Axenebene zu konstruiren ist. Erst weitere Untersuchungen werden dariber kilarheit bringen und dann auch die Frage beantworten können, welche Bedentung den durch Gegexbaur festgestellten Veränderungen der von ilum benutzten Axenebenen zukommt, welche, wie wir sahen, auf die besprochene; die Bildung des Ellenbogengelenkes begleitende Torsion des Humerus nicht zu beziehen ist.

\section{E. Vergleichender Theil.}

Es wird sich hier zunächst darum handehn, ob der aus der Entwickelungsgeschichte des Extremitätenskelets der Tritonen erkannte Aufbau desselben sich auch in den ausgebildeten Gliedmafsen der übrigen Urodelen nachweisen lasse. Die Bedeutung eines solchen Vergleiches beruht 
insbesondere darin, dass, wie mir seit Gegexback's grundlegenden Untersuchmgen* wissen, gerade das Extremitätenskelet der Urodelen den Ausgangspunkt für das Verständniss derselhen Theile bei allen über ihnen stehenden Wirbelthieren bildet, in seiner klar übersichtlichen Gliederung den relativ einfachen Typus darstellt, welcher dem durch Neu- und Rückbildung mannigfach abgeänderten Bau des Gliedmafsenskelets der anuren Amphibien, der Reptilien, Vögel und Süuger gemeinsam zu Grunde gelegt werden kann. Anderseits muss naturgemäfs an diesen bei den Urodeleu am reinsten erlialtenen Typus aller „oligalitinoten“ (Gegexbaur) Gliedmafsenformen angeknïpft werden, wenn man die letzteren mit deu "polyaktinoten" Formen der tiefer stehenden Vertebraten zu verknüpfen sucht. Und dabei erhellt die Nothwendigkeit einer vollständigen Erkemtniss aller morphologischen Beziehungen im Knochenbau der Extremitäten unserer Thiere um so mehr, als die ron dort aus ahsteigende Reihe von einander abzuleitender Formen eine aufserordentlich liickenhafte, meln oder weniger mur erst hypothetiseh konstruirte ist.

Der erwähnte Yergleich der Urodelen unter sich wird sich ïbrigens anf den Carpus und Tarsus beschränken können, da die Uebereinstimmung der zwei proximalen Abschnitte des Armes und des Beines bei allen Urodelen einer Erörterung nicht berlarf, und auch die insgesammt nach demselben Typus gebauten Finger und Zehen mur dureh die Art ihres Auschlusses an den Carpus und Tarsus erlsemnen lassen, welche unter ihnen miteinander speziell homolog sind.

Die Homologien der einzelnen Stiicke der Hand- und Fufswurzel der Urodelen sind aber ron Gegenbaur und Anderen in auatomischer Beziehung bereits so umfassend erörtert worden, dass mir nur mehr zu priffen iibrig bleibt, ob die Stiicke einer Hand und eines Fufses bei allen Urodelen sich in denselben genetischen Zusammenhang bringen lassen, wie er sich mir aus der Ontogenie bei den Molchen ergab. Es wird sich daher empfehlen, hier diejenigen Resultate der voransgegangenen Untersuchungen an deŕ Molchen zusanmen- und voranzustellen, welche gecignet sind, jener Prüfung zur Richtsehnur zu dienen. Wenn ich dabei zuerst nur von der Hand spreche, so brauche ich nach den schon ansgefülrten Vergleichen von Hand und Fufs lkaum zu bemerken, dass dasselhe auch fuir den Fufs gilt.

1. Vom Humerus laufen zwei einfache, in ihrer Aulage kontinuinliche Skeletäste bis in die zwei ersten Finger ans. Dureh korrespondirende quere Sonderung zerfallen sie in Unterarm, Handwurzel und Finger (mit Einschluss der Mittelhand). - Die Handwurzel besteht also zuerst aus zwei nebeneinander und zur Axe des ganzen Armes parallel liegenden Aesten, zu welchen die zwei ersten Finger gehören.

2. Dazu kommt auf der ulnaren Seite noch ein dritter Kiarpalast, welcher distal den dritten Finger, lateral den vierten Finger trägt. - Auf der zweiten Entwickelungsstufe besteht also die Handwurzel ans drei parallelen (theilweise schon gegliederten) Aesten mit vier Fingern.

3. Das distale Ende der beiden primären liarpaläste (radialer, medianer Karpalast) rerschmilzt friihe zn einem einfachen Carp. rm III; der Rest beider gliedert sich in je drei, der dritte (uluare) Ast in drei Stiicke. - Fïr die definitir gegliederte Handwurzel ergibt sich somit eine Zusammensetzung ans drei parallelen Reihen mit ursprünglich drei Sticken, von denen abjer zwei von Anfang an (rm III), zwei andere nachträglich verschmelzen (mu I).

* Gegenbaur, Untersuchungen zur rergleichenden Anatomie der Wirbelthiere I. Carpus und Tarsus. 
4. In Bezug auf den genetischen Zusammenlıang dieser Carpalia unter sich und mit den ïbrigen Skelettheilen des Armes miissen wir erstens zwei der Anlage nach koordinirte Hauptgliederreihen aufstellen, welche rom Humerus ausgehend die drei Abschnitte des Unterarmes, der Handwurzel und der Finger durchzichen; darauf folgt ein Seitenast des ulnaren Hauptastes, welcher nur in der Handwurzel und dem digitalen Abschnitte enthalten ist; endlich darf die nur durch den vierten Finger dargestellte Reihe als Zweig jenes dritten Ḱarpalastes angesehen werden. Nach den Bezeichnungen geordnet stellen sich diese Reilıen folgendermafsen dar (rgl. Fig. 10):

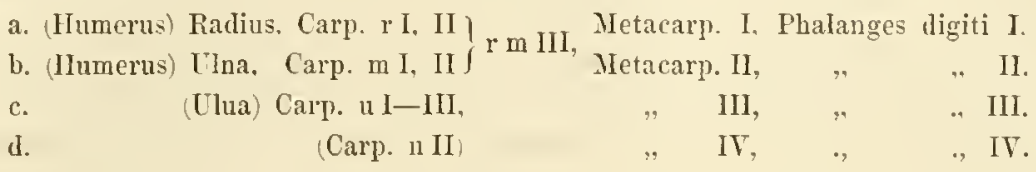

5. Die urspringlich ziemlich symmetriseh angelegte Gliederung der drei Kirpaläste wircl durch das Vorriicken ron uII in die vorderste Linie des Carpus sowie dureh die beiden Versehmelzungen in r'm III und muI verriickt.

Die Genese des Tarsus lässt sich wie gesagt in derselben Weise zusammenfassen, wobei als einzige wesentliche Abweichung die Anwesenheit ciner fünften Zehe zu verzeichnen wäre, deren Homologon der Hand nieht an der radialen, sondern an der ulnaren Seite fehlt (S. 14), und welche am Fufse neben der vierten Zehe aus dem Tars. fII herrorsprosst (Fig. 13).

In welcher Woise lassen sich num die anatomischen Befunde des Carpus und Tarsus der iibrigen Urodelen in den Rahmen dieses genetisehen Verhaltens derselben Theile bei Triton cristatus und taeniatus einfuigen? - Bei zahlreichen Indiriduen der genannten Arten sowie des Triton alpestris und Cynops perhogaster habe ich in der Regel die bekannten sieben Carpalia und acht Tarsalia in den nämlichen Lagebeziehungen angetroffen. Stets, sowohl bei erwachsenen wie bei Larven, salı ich den Metacarpus (Metatarsus) I dem Carp. I'm III (Tars. tm lII) aufsitzen und anfser Beriihrung mit dem Carp. rII (Tars. tII), sodass beide Stiicke theils durch einen Vorsprung des rm III (tm III), theils durch eine Liicke getrennt wurden (Taf. $\mathrm{T}$ Fig. 27-30). Gegexbaur hat darin ganz Recht, dass der Metacarpus I ursprünglich mit deın r. II ,in Beziehung stände“, sich aber darauf vou ihm löse (a. a. O. S. 7); nur muss ich hinzufügen, dass der ursprïngliche Zusammenhang kein unmittelbarer ist und dadurch gelöst wird, dass das Verbindungsstiiek zum Theil in Im III aufgeht, zum Theil atrophirt, wobei die Möglichkeit nicht ansgeschlossen ist, dass, wie schon frïher erwähnt, die Atrophie allein eintritt, sodass an Stelle von rm III ein einfaches m III liegt, was natiirlich im einzelnen Fall nicht zu entscheiden ist. An sich wäre anch eine solche Entscheidung ron keinem besonderen Interesse. Denn die Bedeutung des Umstandes, dass Carp. rm III in mainchen Fällen ganz nuzweifelhaft das Produkt einer Doppelanlige ist, kann nur darin liegen, dass dies die Folge ist der an derselben Stelle erfolgenden Verbindung der zwei ursprünglichen Skeletäste, wodurch ehen die Sonderung des Carpus eingeleitet und veranlasst wird; und die vollstïndige Atrophie des den ersten Metacarpus und rII anfangs verhindenden Stückes r III stände offenbar in derselben innigen Beziehnug zu jenem Vorgange, da sie nur eine weitere Ansdehnung der dabei regelmäfsig erfolgenden partiellen Atrophie wäre. Dasselbe gilt natïrlich auch für die homologen Tarsalia, unter denen ich ïbrigens gelegentlich eine hochgradige Verkümmerung auch des tII gesehen habe. 
Eine Terminderung der regelmäfsigen Zahl der Carpalia und Tarsalia ist bei den Tritonen nicht selten anzutreffen. Dieselbe dürfte aber nicht sowohl eine Folge von Verschmelzungen bereits gesonderter Stiicke als rielmelı eines Ausfalles der gewöhnlichen Gliederung sein. Dem die Terbindungen bestanden immer im Tcrlaufe je eines urspriinglichen Karpal- oder Tarsalastes (Fig. 29), wie es auch der ron WiEdensinem angefühte Fall ron Triton helveticus zeigt, und waren, soweit ich sie beobachtete, loereits im knorpeligen Zustande, bei erwachsenen Larven, nachweisbar, wo doch die Spuren einer rorangegangenen Sonderung nicht rollständig lıätten fehlen können. Dieser Ausfall der Gliederung kann alle drei Karpal- und Tarsaläste betreffen, scheint aber am bäufigsten im radialen und tibialen vorzukommen.

Bei den Embryonen ron Salamandra maculosa ist der tiljiale Tarsalast in zwei Stücke gutheilt, ron denen das vordere und merklich längere noch bei den Larven bis an den ersten Metatarsus reicht (Taf. IV. Fig. 25, 26). Später ist letzterer von dem t II getrennt; da er aber seinen friiheren Platz behalten hat, tII abser relatir viel kleiner erscheint als in den Larren, so ist oftenbar das. Terbindungsstiick zwischen beiden atrophirt (rgl. Fig. 32, 33). Damit stimmt auch der theilweise Rückgang in rer Entwickelung des ganzen Astes überein, welcher sich sowohl in der relatiren Grölsenabnahme ron t I und tII als anch ihrer unvollkommenen oder ganz fehlenden Verknöcherung ausspricht. Immerhin ist es mit Bezug auf den ron BrüHL mitgetheilten und von mir

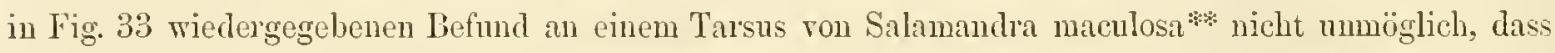
das aufserordentlich vergröfserte Tarsale, welches die beiden ersten Finger trägt, anch Elemente eines tIII enthält. Aelnnlich verhïlt es sich mit dem Carpus. - Von allen iibrigen hier noch zu erwähnenden Salamandrinen (Salamandrella, Salamandrina, Geotriton, Ranodon, Siredon und Amblystoma) schliefst sich in jener Beziehung ein Theil scheinbar mehr an Triton, ein anderer an Salamandra an.

Die auffallendste Besonderheit der letzteren gegeniiber Triton fundet sich aber in der Anwesenheit eines neunten, den Metatarsus $V$ tragenden Tarsale, welches zwischen $f I$ und $f$ II ron aufsen eingekeilt erscheint (Fig. 26, 33). Dasselbe kommt auch der vierzehigen Salamandrella, Geotriton, Ranodon ${ }^{*}$, Siredon (Amblystoma), Cryptobranchus und Nenopoma zu, wäluend es aufsel den Tritonen auch noch den iübrigen rierzehigen Salamandrinen, nämlich Salamandrina (WredERsHErm) und Batrachoseps, ferner Amphinma und den Perennibranchiaden fehlt (Taf. $\mathrm{T}$ ). Dieser Mangel soll nach Gegexbaur bei Triton durch eine sekundäre Verschmelzung des fraglichen Tarsale mit dem fII zu erklären sein, welche allerdings in der individuellen Entwickelung nicht mehr nachweisbar sei, aber angenommen werden müsse, weil jeder der anderen Finger ein eigenes iln tragende Tarsale besitze (a. a. O. S. 58, 59). Ich finde num lei Salamandla, dass jenes ron mir als fa (Tars. fibulare accessorium) bezeichnete Stuick sehr spät entsteht und zwar nicht in der Reihe der übrigen fibularen Stiicke, sondern als seitliche Abspaltming ron dem schon deutlich gesonderten fII (Fig. 25, 26). Daraus geht aber hervor, dass der ungetheilte Zustand des fII renigstens ontogenetisch der ursprüngliche ist und dass, selbst wem ein einfaches fII wie dasjenige der Tritonen phyletisch aus

* Wiedersheis, Salamandrina perspicillata und Geotritou fuscus. Gemua 1875. S. 149 Fig. 113.

* BrẗHL, Zootomie aller Thierklassen. Atlas. Wien 187t-1879. Taf. XXYl Fig. 3.

Hat. Wredershein a. a. O.. ferner Desselben: Die altesten Formen des Carpus und Tarsus der heutigen Amphibien, in: Mlorphologisches Jahrbuch Bd. Il. 
einem wie bei Salamandra sich theilenden Stïcke herrorging, dics nicht auf eine Verschmelzung zweier schon in der ersten Anlage getrennter Stiicke, sondern lediglich auf ein Unterbleiben des sekundären Zerfalles einer cinfachen Anlage zurickzufiih'en ist; zweitens, dass fa nach seiner Entsteliung eine den übrigen Tarsalia nicht koordinirte, sondern mehr untergeordnete Bildung ist, deren Insfall den genetischen Aufbau des Tarsus, wie wir ihn bei Triton kennen lernten. in keiner Weise stört.

Aelnlich dürfte es sich mit einer anderen Vermehrung der Tarsalia und Carpalia rerhalten, welche zuerst nur im Tarsus ron Cryptobranchus und Menopoma (Hrrtu, Cryptobranchus japonicus), neuerdings aber anch im Tarsus und Carpus ron Salamandrinen (Salamandrella, Ranodon, WIEdersHens a. a. O.) bekannt wurde: die Verdoppelung des sogenannten Centrale oder m II (Fig. 35, 37). Diese Bildung ist ron Gegexbaur bekanntlich ebenfalls für eine altvererbte erklärt und mit grofsem Scharfsinn dazu benutzt worden, um die Reste des Archipterygium in der Extremität der Urorlelen zu konstruiren.* Ich werde anf diese Bedeutung der zwei Centralia noch zuriickisommen und will hier nur konstatiren, dass, obgleich sie lei unbeständigem Vorkommen wechselnde Lagebeziehungen zeigen, bald quer neben-, bald hintereinander liegen*\%, es gar nicht zu bezweifeh ist, dass sie immer ans einer Spaltung des Carp. oder Tars. m II hervorgehen, also ontogenetisch als Theile eines anfangs liontinuirlichen Skeletastes sich darstellen.

Einen ganz anderen Werth können dagegen einige gleichfalls ïberzählige Kinorpelstiickchen beanspruchen, welche Wiedensherm im Tarsus von Ranodon und Cryptbranchus neben fa und weiter proximalwärts fand und als Reste eines änfsersten filbularen Strahles deutete (a. a. O.). Nach meiner Ansicht lässt sich gegen eine solche Auffassung im allgemeinen nichts einwenden und dürfte uur die weniger wesentliche Detailfrage diskutirbar bleiben, ob jeno zwei weit getrennten Ḱnorpelstiickchen von Ranodon nicht noch leichter auf zwci Strahlen zu beziehen mären, welche sich zu fI ebenso rerhielten, wie die vierte und fünfte Zehe zu fII (vgl. Fig. 48)?

Bevor ich die Salamandrinen verlasse, möchte ich noch liurz auf den von mir untersuchten Batrachoseps attenuatus aufmerksam machen. Von allen erwähnten Salamandrinen lässt allein Batrachoseps a priori ga nicht daran zwcifeln, dass der Träger seines zweiten Fingers ein einfaches m III ist; es spricht dafiir einmal, dass dieses Stück die anderen des medianen Karpalastes, m I und mII, an Breite nicht ïbertrifft, und ferner, dass der erste Finger unmittelbar und rollständig auf r.II aufsitzt (Fig. 31). Es könnte nur fraglich bleiben, ob die Anlage eines r III iiberhaupt unterbleibt, oder auch hier durch Atrophic verloren geht; für letzteres liefse sich anfilhren, dass rII ziemlich genau neben m II liegt, der radiale harpalast also gerade um das Stïck des dritten distalen Gliedes der anderen Aeste verkürzt erscheint. Bemerkenswerth ist auch der rein knorpelige Zustand des ganzen Carpus sowie die vollkommene Tremnung ron ul und w I; nimmt man dazu, dass der Tarsus von Batrachoseps sich genau so verhält wie der Carpus, also eine fünfte Zehe cntbehrt (was iibrigens anch Salamandrina und Salanmandrella zeigen), so ertrcisen sich die Gliedmafsen dieses Thieres als auf einer noch ticferen Entrickelungsstufe stehend als diejenigen ron Cryptobranchus und Menopoma.

* Gegeviatr, Cntersuchungen zur vergleichenden Anatomie der Wirbelthiere Heft II. 2. Brustllosse der Fische. Lei |zig 1865 S. 165. - Ueher das Gliedmafsenskelet der Enaliosaurier, in: Jenaische Zeitschrift für Medicin und Naturwissenschaft Bd. V.

*\% Vgl. Wiedersheır a. a. O. und nachträgliche Bemerkungen dazu in: Morphologisches Jahrbuch Bd. II. 
Ton den Ichthyodea wurden Cryptobranchus und Menopoma (Fig. 34, 35, 37) linsichtlich der doppelten Centralia des Tarsus und der Anwesenheit eines fa bereits erwähnt. Beide iiberzähligen Tarsalia sind aber unbeständig, sowie Menopoma auch darin rariirt, dass sein radialer Karpalast ungegliedert bleiben kann (Hyrтt a. a. 0.); m I und u I bleiben bei denselben Urodelen unrerschmolzen. Dieses sowie der knorpelige Zustand des Carpus und Tarsus der beiden letztgenannten Arten bezeichnen gegeniber den Salamandrinen eine niedere Entwickelungsstufe der Gliedmafsen. Noch tiefer stellt sich tarin Menobranchus (Fig. 35, 39), indem bei ihm die Sonderung vou uII-nIII und fII-fIII unterbleils, wogegen Carp. mI-uI und, ausnahmsweise unter den Urodelen, auch Tars. mI-f I miteinander verschmelzen. Die Beziehungen des ersten Metacarpus zur Handwurzel sind insofern bemerkenswerth, als seine kuorpelige Epiphyse ununterbrochen mit dem Carpale zusammenhängt, welches anch den zweiten Metacarpus trägt, dagegen mit rII keine Verbindung hat. Sollte dies nicht darauf hinweisen, dass jenes erstere Carpale ein wirkliches rm III ist?

Die einfachsten Gliedmafsen unter den Urodelen besitzen Amphiuma, Siren und Proteus, deren Hand- und Fufswurzeln elonfalls unverknöchert bleiben. Den Carpus ron Siren (Fï. 36) rersteht man am besten, wenn man ihn mit dem von Wiedershen beschriebenen Tarsus von Triton helveticus rergleicht (S. 30). In demselben waren t I und II, m I und II durch je ein Stiick repräsentirt, welche sich nebst tm III in den homologen Handwurzelstiicken von Siren leicht wiedererkennen lassen (rI II, mI II rm III); ferner waren in jenen Fall auch fII und III rereinigt, sodass wenu wir fl dazu nehmen, wir durchaus das Homologon des einfachen Stïckes erhalten, welches den ganzen Uharrand in der Handwurzel ron Siren eimnimmt. Die letztere zeigt also im liöchsten Mafse das, was wir nur mehr vereinzelt anch bei Salamandrinen antreffen (vgl. auch Fig. 29), nämlich den Ausfall der Gliederung in Verlaufe der einzelnen Karpal- oder Tarsaliste; ein Zustand, der ganz offenbar mit einem sehr frühen Entwickelungsstadium zusammenfällt. Die Verljindung des ersten Metacarpus mit der Handwurzel ist hei Siren ganz dieselbe wie bei Menobranchus. - Der rollständige Mangel der Beine kam selbstrerständlich un aus einer Rüickbildung erklärt werden.

Die Extremitäten ron Amphiuma (tridactyla) und Protens (Fig. 40-43) lassen sich allerdings, sobald man mit der Hand von Siren im Reinen ist, olne Schwierigkeit auf den gleichen bisher nachgewiesenen Typus zurïckführen. Immerlin gewinnt die beziigliche Deutung dadurch sehr wesentlich, dass ich an einem in der Regeneration begriffenen Bein ron Proteus* unmittelbar erkannte, wie dort Unterschenkel mol Fufs gleichfalls aus zwei Aesten herrorgingen, ron denen innerhalb des Tarsalabschnittes der tibiale Ast ungetheilt bleibt und in die erste Zehe ansläuft, deren anderer einer Zweitheilung unterliegt und in die zweite Zehe sich fortsetzt (Taf. IV Fig. 27). Wir werden nicht umhin können, darin jenes Entwickelungsstadium des Tarsus der höheren Urodelen wiederzuerkennen, no ein dritter Tarsalast und die zugehörigen Zehen noch nicht zur Sonderung gelangt sind (Fig. 15); da dieser dritte Tarsalast aber aus dem ursprünglichen fibularen durch eine Art Längstheilung hervorgeht, so dïrfen wir auch jene zwei fibularen Tarsalstiicke von Proteus in einem gerrissen Sime als Vertreter aller Tars. mI-III und f I-III ansehen (Fig. $43 \mathrm{mf}$ IIl, mf I. II), wie dies schon Gegenbaur vermuthete. Diese Auffassung wird noch dadurch bestätigt. dass wir im

* Diese Regeneration war crst $1^{1 / 2}$. Jahre nach erfolgter Amputation eingetreten!

* Gegenbaur, Untersuchnngen zur vergleichenden Anatomie der Wirbelthiere. Heft I. S. 55. 
Carpus ron Proteus, damn dem Tarsus und Carpus ron Amphiuma diejenigen weiteren Entrickelungsstufen wiedererkennen, welche die allmähliche Absonderung des dritten Tarsal- oder Karpalastes in der Ontogenie der Tritonen bezeiclmen. Der Carpus ron Protens und derjenige ron Amphiuma stimmen nämlich vollkommen mit der ontogenetischen Anlage von Tritun ïberein, wo der dritte Finger (dritte Zehe) mit dem u (f) III in der Sondernng begriffen oder bereits gesondert ist, ehe noch $и$ (f) II und III exschienen sind (Fig. 16, 41, 42); und der Tarsus ron Amphiuma zeigt bereits die drei deutlich gesonderten Tarsalïste, ron denen der mediane und fibulare in je zwei Stiicke zerfallen sind (Fig. 18, 40). Noch bliebe zu bemerken, dass die Verbindung der beiden IIauptskeletïste am distalen Ende der Hand- und Fufsmuzel, welche sich noch bei Siren im Carp. rm III zeigt. bei Amphiuma und Proteus in älnhlicher Weise gelockert ist wie bei Batrachoseps, indem der erste Finger und die erste Zehe mmittelbar den radialen und tibialen Hand- und Fufswuzelstücken anfsitzen.

Fassen wir das Ergebniss der angestellten Vergleiche kurz zusammen, so lönnen wir behumten: erstens, dass das Gliedmafsenskelet aller Urodelen im allgemeinen nach demselben Typus gebaut ist, der sich ans der Entwickelung derselwen Theile bei Triton ergibt: zweitens, diss die besonderen Unterschiede sich theils auf unwesentliche, den Typus nicht beriihrende Modifikitionen (Vertoppelung des mII und fII, sekundäre Verschmelzung ron mI und f I bei Menobranehus, Verkiummernug des r.II u. s. w.), theils auf die Fixirung verschiedener Entwickelungsstufen jenes Bildungsganges beziehen. In letzterer Hinsicht ist rornehmlich an das Zurückbleiben unter der bei den Tritonen erreichten Entwickelungshöhu zu erimern: theilweiser oder gänzlicher Ausfall der Verknöcherung des Carpus mnd Tirsus (Salamandra, Batrachoseps, Ichthyodea), entschiedener Ausfall der Velbindung ron r (t) III und mIII (Batrachoseps, Amplimma, Protens) und ron mI-uI (Batrachoseps, Menopoma, Siren, Amphiuma, Protens), Iusfall der füuften Zehe (Silamanhrina, Salamantrella, Batrachoseps, Menobranchus, Amphiuma, Proteus), theilneiser Ausfall der Gliederung der Karpal- und Tarsaläste (Menobranchus, Siren, Amphiuma, Proteus), eudlich allmälllicher Ausfall des dritten liarpal- und Tarsalastes (Amphiuma, Protens). Eine typische Verrollstïndigung des gewöhnlichen Banes des Tar'sus zeigen Riuodon und Cryptobrinchus in den auf rudimentäre äberzählige Zehen zu beziehenden fibuliren Kinorpelstïckchen.

Es ist ganz natiurlich, dass wir uns nun anch die weitere Frage rorlegen, ob und welche Schlüsse wir aus diesem Ergebnisse der Tergleichung hinsichtlich des phyletischen Zusammenhanges der verschiedenen Extremititenformen der Urodelen unter sieh und mit denen der anderen Vertebraten ziehen liönnen.

Die weitere Bedentung der individuellen Entwickelungsgeschichte beruht anerkauntermafsen darin, dass die in ihr sich darstellenden Reihen rerschiedener Bildnngsznstände auf ähnliche Bildungsreihen in der phyletischen Entwickelung dieser Thiere hindeuten. Es wird aber nicht selten zwischen dieser allgemeinen Bedentung der Ontogenie und den besonderen Deutungen, welche sich darauf stützen, nicht genïgend unterschiedes, und erstere daher leiclıt unterschätzt, sobald man öfter Gelegenheit hatte, die besonderen Schlussfolgerungen als irrige zn erkennen, in welche jene allgemeine Lelne der individnellen Entwickelungsgeschichte umgesetzt wurde. Und doch ist der Werth der letzteren nicht hoch genug anzuschlagen, wenn man ihr nur nicht das als mfehlbare lionsequenz entnimmt, was sic lolofs bedingterweise lehrt. - Ich habe lieine Veranlassung, solche Ueberlegungen 
ïher die Grenzen des vorliegenden Falles hinaus zu verfolgen, halte aber denselben für lehrreich genu'g, um an ihm das Gesagte etwas ausführlicher darzulegen.

Ans der Thatsache der snccessiren Zunahme der Skeletïste, ihrer Gliederung und Verknöcherung in der mitgetheilten Ontogenie des Gliedmafsenskelets wird man zuerst schliefsen können, dass die in dieser Beziehung einfacher gebauten Extremitäten auch phyletisch den reicher gegliederten vorausgingen: und da wir die meisten jener bei den Molchen angetroftenen Entwickelungsstufen im Skeletbau der fertigen Gliedmafsen der Ichthyodea wiederfinden, so scheint nichts näher zn liegen als der weitere Schluss, dass unter den Urodelen eine mit Protens begimnende phyletische Entwickelungsreihe der Gliedmafsen anfzustellen und für dic Stammform derselben etwa ein gabelig anslanfender Kinorpelstab als Gliedmalsenskelet zu postuliren sei.* Und doch erweist sich eine solche Schlussfolgerung unter allen Unständen als voreilige. Demn die Ontogenie kann naturgemäfs nur den in der Genese begründeten kausalen Zusammenhang der verschiedenen Formen lehren, aber nicht das Bild ibrer Vertheilnng auf eine bestimmte phyletische Reihe geben. Sie kann es nicht, weil alle Abänderungen dex fertigen anatomischen Formen anch in ihrer Ontogenie, wenngleich in schwächerem Grade, vorgebildet sind, und daher oft selbst diejenigen Entwiekelungsstufen merklich betreffen, welche die der Abänderung phyletisch vorausgegangenen Zustände wiederspiegeh sollen. Ich denke dabei nicht an Vorgänge, welche den ererbten, genetisch-kausalen Formznsammenhang und damit die angegebene Bedentung der Ontogenie ganz aufheben, sondern an solche, welche obne jenen Zusammenlang zu berülıren, etwa die zeitliche Reihenfolge, die Zahl, das Gröfsenverhältniss der Einzeltheile n. Ä. abändem und dadurch ein äufserlich ganz anderes Bild zeigen, als worauf sie zuriickweisen. Ich erimere hier z. B. daran, dass, während die Regeneration der Gliedmafsen bei jungen Larven genau so verläult wie die primäre Entwickelung, hei dem gleichen Vorgange an älteren Thieren die dritte, gelegentlich anch die vierte und fünfte Zehe nicht mehr als distale und seitliche Fortsätze eines vorher gesonderten dritten Tarsalastes, sondem gewissermafsen als direkte Seitenzweige des fibularen Hanptastes entstehen, deren Basen erst sich zu der definitiven fibularen Tarsalreihe rerbinden (rgl. S. 21). Gegeniiber solchen bis zu einem gewissen Grade (nämlich hinsichtlich der dritten Zehe) und unter gewissen Umständen konstanten Abändermugen des Bildungsganges während der Regeneration. melche doch sonst nit der primären Entwickelung identisch erscheint, lässt sich die Möghichkeit nicht ron der Hand weisen, dass dieselben ebenfills, etwa im Simne eines Rïckschlages auf phyletisch vorausgegangene Zustände hinweisen; und diese Möglichkeit würde schon mit den rorhin aufgestellten Schlnssfolgerungen ron der innerhalls der Urodelen fortschreitenden Dichotomie der Skeletïste nicht übereinstimmen.

Eine weitere Einschrïnkung erfährt die Deutungsfähigkeit der Ontogenie dadurch, dass eine vorliegende anatomische Reihe, wie diejenige der verschiedenen Extremitäten der Urodelen, der ontogenetischen Bildungseihe ganz wohl entsprechen kann, ohne dass damit schon eine Entscheidung

* Eine solche Anffassung vertritt thatsächlich BRÜHL, indem er in iler Reihe der Gliedmafsen der Urodelen eine fortschreitende dichotomische Theilung (freilich in anderen als den von mir festgestellten Linien des genetischen Zusammenhanges) einer anfaugs einfingerigen Extremität zn erkennen glaubt; lionsequenterweise würde also las Bein ron Proteus die ilteste der uns bekannten derartigen Formen darstellen und als unmittelbar rorausgehende Grundform einen einfachen gegliederten oder ungegliederten Stab roraussetzen (Zootomie aller Thierklassen, Atlas, Erklärung zu Taf XXill und XXvi. 
dariiber gegeben wäre, ob die erstere eine aufsteigende oder eine absteigende Reibe ist, ob also in unserem Falle der gröfste Theil der Ichthyodea himsichtlich des Extremuitätenskelets nicht durch successive Rïckbildung ron höher organisirten Formen abzuleiten wäre. Diese Möglichlieit wäre um so mehr in Betracht zu ziehen, als das Gliedmafsenskelet ron den höheren Urodelen aufwärts in der gesammten Gliederung vielmehr Rüick- als Fortschritte zeigt.

Dis schwerwiegendeste Bedenken gegen die Stichhaltigkeit unserer crsten supponirten Schlussfolgermg aus der Ontogenie des Extremitätenskelets läge aber offenbar darin, dass die ontogenetische Reihe an sich - namentlich bei Körpertheilen wie die Gliedmafsen, deren Entwickelung mit derjenigen des ïbrigen Organismus so wenig parallel läuft - kein Merkmal darbietet, auf welche näheren und eageren oder entfernteren, weiteren Kreise die Vergleichung ausgedehnt werden soll. Dass man dabei zuerst an die nächstrerwandten líreise denkt, ist natïlich aber durchaus nicht immer begründet, wie das folgende Beispiel lehrt. Eine entfernt ähnliche Erseheinung wie die successive Gliederung des sich entwickelnden Extremitïtenskelets der Urodelen findet sich bekanntlich anch in den Embryonen der höheren Wirbelthiere: die allmähliche Zunahme der Körpersegmente vun einigen wenigen an. Wollte man darans schliefsen, dass in den uns noch unbekannten Anfängen der Wirbelthierreihe nur eine ganz beschränkte Segmentzahl bestanden labe, so widerspräche dem die Thatsache. dass die uns bekamnten niederen Vertebraten im allgemeinen gerade durch eine gröfsere Segmentzahl ror len höheren ausgezeichnet sind. Der Umstand aher, dass jene ontogenetische Succession der Segmente noch bei Amphioxus dieselbe ist wie hei den höheren Vertebraten. ja bei den. Gliederthieren sich ähnlich wiederholt, kam allerdings rielleicht oder wahrscheinlich anzeigen, dass die Quergliederung des Körpers ïherhaupt wit einer geringen Zahl ron Segmenten begann. So braucht die amaloge successive Zunahme der Gesammtgliedermg in der Outogenic der von mir untersuchten Extremitäten der Annahme nicht zn widersprechen, dass die näheren Stammformen derselben eine vielleicht noch reichere Gliederung besafsen, wogegen es gewiss nicht unmahrscheinlich zu nemnen ist, dass das erste Extremitätenskelet. der ganzen Wirbelthierreihe einfacher gebaut war als die darauf folgenden.

Diese Erwägmngen erweisen nun ganz unzweideutig die Nothwendigkeit, bei allen Verallgemeinernngen ron ontogenetischen Bildungsreihen sich zuerst die Grenzen zn rergegenwärtigen, in welchen sich die gesuchte phylogenetische Reihe ausdehnen kam und der Vergleichung nicht ein näheres Ziel zu stecken, bevor man sich rergewissert hat, dass dadurch ein Anschluss über das letztere hinaus nicht numöglich gemacht ist. Die Annahme, welche uns von der Ontogenie des Gliedmafsenskelets der höheren Urodelen aus zumächst gerechtfertigt erscheinen mag, dass deren jenseits Proteus zu suchende Stammformen ein stabförmiges, gabelig oder einfach auslaufendes Extremitätenskelet besessen hätten, erweist sich als mindestens bedenklich, wenn wir ïberlegen, dass wir dabei eigentlich ganz anf die Möglichkeit rerzichten, die oligalitinoten Formen jener Organe, welche ron den Urodelen aus ganz sicher in engen Zusammenhang gehracht werden können, mit den polyaktinoten Formen zn verbinden, welche von den Enaliosauriern her doch so wahe an die ersteren, sowie sie sich gerade bei den höheren Urodelen fiuden, herantreten. In diesem Sime ist die Forderung begründet, dass wir den phyletischen Zusammenhang unserer Organe bei den Urodelen und danit zugleich ihre nächsten Stamnformen nicht eher festzustellen suchen, als bis wir uns iiber ihre Anschlüsse nach abwärts wenigstens orientirt haben. Diese Aufgalbe hat aber Gegexbaur 
in seinen bezüglichen fundamentalen Arbeiten gelöst, sodass mir nur dio Untersuchung übrig bleibt, wie sich meine entwickelungsgeschichtlichen Beobachtungen zu den allgemeinen und besonderen Aufstellungen Gegenbaur's verhalten.

Ich darf hier den ganzen Verlauf jener Lntersnchungen iiber die verwandtschaftlichen Beziehungen der oligalitinoten und polyaktinoten Extremitäten* als genügend bekannt roraussetzen und mich blofs an den gegenwärtigen Stand der Frage halten. Gegexabur geht jetzt von einer Crundform (Archipterygium) ans, welche im wesentlichen aus einem gegliederten Stamme nnd ilnm zweizeilig ansitzenden Strahlen besteht. Dazu kommen noch Strahlen, welche ummittelbar an dem die freie Gliedmafse tragenden Bogen über und nuter dem Ansatze des Stammes befestigt sind (Morphologisches Jahrbuch Bd. II S. 417). Bei den Selachiern ist der Stamm mit einer vollständigen und einer nur anf distale Rudimente reducirten Strahlenreihe (Stammradien) im Metapterygium enthalten; Meso- und Propterygium stellen die nur einseitig erhaltenen (oberen) Bogenradien dar. Ceratodus besitzt blofs das gleichmäfsig biseriale Archipterygium, welches bei Protopterus die eine, bei Lepidosiren sogar beide Strahlenreihen verloren hat.** Bei den Enaliosauriern nnd Amphibien wird blofs eine Stammreihe mit vorherrschend einer Strahlemreihe und ganz spärlichen Resten der zweiten unterschieden; auf Grund der Vergleichung mit Selachiern wird die Stammreihe am ulnaren Rande des Armes uud fibularen Rande des Beines angenommen.

Gegenüber diesel Archipterygium-Theorie haben wir zuerst zu fragen. ob die Entwickelung des Gliedmafsenskelets der Urodelen ülrerhaupt anf einen Zusammenhang seiner Theile in gewissen Linien hindentet, und meine Beobachtungen gestatten, wie ich glaube, eine nubedingte Bejihung dieser Frage. Die ron mir so genannten Sekletäste kömmen, vorbehaltlich ihrer besonderen Dentung als Stamm- und Strahlenreihen, auf solche im allgemeinen ganz wohl bezogen werden. Allerdings liönnte hierzu hemerkt werden, dass jene Theorie einer solchen Bestätigung durch die Ontogenie gar nicht bedürfe, indem die anatomische Vergleichung bereits sattsam die Nothwendigkeit erwiesen habe, die einzehnen Stiicke des Extremitätenskelets auf genetisch znsammenhängende Reihen zurüickzufiihren. Dagegen nuss ich aher die Bedeutung des Umstandes hervorheben, dass uns in jener Ontogenie nicht lediglich eine solche bereits anerkannte Nothwendigkeit im allgemeinen bestätigt, sondern jener Znsammenhang im einzehnen, wie er bisher durch umfassende Vergleiche zwischen Amphibien, Enaliosauriern und Fischen zu erschliefsen versucht wurde, unmittelbar dargelegt wird. Auch kann ich nicht zugeben, dass diese unmittelbaren Befunde der Ontogenie an Werth olne weiteres zurückzustehen hätten gegeniiber den amatomischen Vergleichen, falls beide nicht übereinstimmten. Ein solches Zugeständniss wïrde voraussetzen, dass der in der individuellen Entwickelnngsgeschichte der Urodelen gegenwärtig vorliegende Zusanmenhang nicht mehr der ursprüngliche sei, wie er dem Archipterygium in seinen frülseren Formen zu Grunde lag, dass dieser sich vielmehr

* Gegenbadr, Untersuchungen zur vergleichenden Anatomie der Wirbelthiere. Ileft I, Il. - Ueber das Gliedmafsenskelet der Enaliosaurier, in: Jenaische Zeitschrift für Mlediein und Naturwissenschaft Bd. V. - Ueber das Skelet der Gliedmafsen der Wirbelthiere im Allgemeinen und der Hintergliedmafsen der Selachier insbesondere, ebendaselbst. - Teber das Archipterygium, ebendaselhst 13d. VIl. - Zur IIorphologie der Gliedmafsen der Wirbelthiere, in: Morphologisches Jahrbnch Bd. II.

* Die Ganoiden und Teleostier interessiren uns hier nicht nmmittelbar, da ihre Flossen, obgleich direkt von denen der Selachier ableitbar. in ganz einseitiger Umbildung sich ron den oligaktinoten Formen weit entfernen. 
phyletisch in die einzelnen Theile völlig aufgelöst habe. welche dann bei den Urodelen doch wieder, aber nur in den jingsten Anlagen, zu einer nenen Kombination sich rerbanden. Und eine solche wunderbare Doppelhypothese, welche natiirlich die ganze Bedlentung der Ontogenie in Frage stellte, stände überdies ir einem argen Missrerhältnisse zu dem dadurch zu erreichenden Zweelie. welcher darin bestände, nicht etwa Zweifel gegen die Arehipterygium-Theorie ïberhaupt zu beseitigen dieselbe wird rielmehr, wie ich zu erweisen hoffe, dureh meine Erfahtrungen bestätigt —, sondern lediglich die bisherige Deutung jedes einzelnen Strahles in Gliedmafsenskelet der Amplhibien aufrechtzuerhalten. Gegexbaur sellst hat aber sehr klar und bestimmt zwischen dem wesentlichen Inhalte und den ,in zweiter Linie stehenden" Momenten seiner Theorie untersehieden (a. a. 0 . S. 406-408); zum ersteren rechnet er die Zurüekfühung des Gliedmafsenskelets auf eine Stanmreihe und deren Radien iberhaupt, zu den anderen ansdrücklich „die spezielle Vergleichung der. einzelnen Stüeke“, welche hinsichtlich des Terlanfes der Stammreihe und der Zahl der Radien bei oligaktinoten Formen durch ihn selbst bereits Morlifikationen erlitten hat. Wenn daher gegeniiber dem anatomisch nicht röllig gesicherten Nachweis des Details die Ontogenie eine bestimmte Ausliunft zu geben im Stande ist, so kann ich zur Zeit einen begründeten Einwurf gegen ihre Kompetenz nicht erkennen. Und allerdings lehrt sie uns in den erwähnten Skeletïsten einen genetisehen Zusammenhang der Einzeltheile im Extremitätenskelet der Urodelen kennen (rgl. S. 29), welcher mit dem ron Gegexbaur angenommenen Verlaufe der Stamm- und Strahlenreihen nicht gauz üboreinstimmt.

Zur leichteren Vergleichung habe ich in die Umrisszeichnung eines Beinskelets ron Salamandra neben meineu eigenen Linien diejenigen ron Gegknbaur (a. a. O. S. 405), welche ron den ersteren abweichen, eingetragen (Fig. 47); die Reihe: Femur, Fibula, Tars. fI, fa, d(igit.) $Y$ hält Gegexbaur für die Stammreihe, von welcher folgende Strahlen anslanfen: Tibia, tI, tII, d.I mI I-III, d.II - mII, fIII, d. III - fII, d. IT. Wie man sieht, fallen ein Theil der Stammreihe und die zwei gröfsten Strahlen Gegerbadr's mit meinen Linien zusammen.* Die weitere Fortsetzung seiner Stammreile (fI, fa, d. V) lässt sich aber so nicht mehr aufrechterhalten, da fa nicht unmittelbar mit $\mathrm{fI}$, sondern mit $\mathrm{fII}$ zusanmenhängt; wïre an einer ulnaren Zusammenlangsreile durchaus festzuhalten, so müsste sie entweder merkwürdig geknickt (fI, fII, fa, d. V) oder dureh ein ungetheiltes fII verlaufen ( $\mathrm{I}$, fII, d.V). Die vierte Zehe wïrde dann in jedem Falle unmittelbar, ohne zwischengefiigtes Tarsale jener Stammreihe aufsitzen. Der in die dritte Zehe anslaufende Strahl ist aber in dem ron Gegexbaur vorgezeichneten Verlauf mit den ontogenetischen Linien nicht in Uebereinstimmung zu bringen. GEgExBdur hat hekanntlich, um nur die Möglichkeit dieses Verlanfes neben demjenigen des zweiten Strahles (mI-III und fI, mII, fIII) zu begründen, angenommen, dass das beiden Strahlen gemeinsame $\mathrm{mII}$ oder Centrale, welches sich in einzelnen Fällen wirklich verdoppelt zeigt (vgl. S. 31), ursprünglich durchweg durch zwei Stïcke vertreten

* In dem ron Gegenbatr selbst mitgetheilten Schema tritt die tibiale Linie aus $t$ II unmittelbar in den ersten Metatarsns ein, weil beide Stücke in vollkommener Berührung gezeichnet sind. Dies entspricht aber nur in den selteneren Fälen dem genetischen Verhalten beider Stücke (vgl. Batrachoseps, Amphinma, Proteus Fig. 31, 4(-43); gewöhnlich wird jene Linie zwischen $t$ II usd IIetat. I eine durch den Ausfall eines Stückes $(t$ III entstandene. also nicht bedeutungslose Lücke, wie im vorliegeuden Falle, oder ein tm III durchsetzen wie z. B. hei Triton (vgl. Fig. 47. 48 . 
war (Cntersuchungen zu veryleichenten Anatomie Heft II, S. 165), welche sieh auch bei den Enaliosauriern finden sollten (Jenrischc Zeitschift Bd. T); das tibiale Stiick sollte dem zweiten, das andere dem dritten Strahle angehören, ilue Verschmelzung zu einem m II eine sekundäre Erscheinung sein. Aber abgesehen daron, dass rlie hänfigere Lage dieser Stiicke bei den Urodelen — hintereinander statt nebeneinander (Fig. 37) - jener Vertheilung widerspricht, indem dann beide Centralia im Verlaufe des zweiten Struhles liegen*, erreichte jene Anmahme ihren Zweek erst dann, wenn die Zugehörigkeit beider. Stïcke zu zwei genetisch getrennten Strahlen bewiesen wäre. Nach allen ihren Lagebeziehungen zu urtheilen, gehören sie aber beide dom medianen Tarsalaste an, und wären alsdamn der zweite und dritte Gegexbaursehe Strahl das dichotomisch getheilte Ende der Reilıe f, m 1, m II; und wollte man das eine Centrale zum fibularen Tarsalast rechnen, so fiele iiberall, wo es ungesondert in fI oder fII enthalten wäre, also in der ganz überwiegenden Mehrzahl aller Fälle, die betreffende GEGEnButr'sche Linie mit rer meinigen zusammen. Ist nun also die erstere jedenfalls aufzugeben, so füllt damit natürlich auch die bezügliche Bedeutung der zwei Centralia, deren Torkommen folglich aus einer gelegentlichen Theilung eines gewöhulich einfachen Stiickes zu erklären wäre, wie denn auch GErExbıtn selbst nenerdings die Möglichkeit einer derartigen Abändelung seines Schemas angedeutet hat (1Lorphologisches Jahrunch Bd. II, S. 408).

Tie aus dem Vorstehenden ersichtlich. Jraucht der ron GEgExbaur konstruirte Linienverlauf eigentlich nur umbedentend alygeämiert zu werden, um mit dem in der Ontogenie vorgezeichneten zusammenzufallen. Aler damit ist noch nicht alles entschieden; denn es ist klar, dass in der festgestellten Linienzeichnung die Stammeile in jeden der fünf Finger auslanfend und demgemäfs eine sehr verschiedene Anordnung der Strahlen angenommen werden kann. - GEgenbaur hat sieh zuletzt für die fibulare (ulnare) Stammreihe: f, fI, fa, d. I - ausgesprochen, weil diese nach HuxuEY's Darstelhung der Basalreihe des Metapterygium oder der Stammreihe der Fische, inshesondere der Selachier, entspräche. Beror ich jedoch diesen Vergleich prüfe, sei noch herrorgehoben, dass die Ontogenie jede andere Reihe eher als jene fibulare als Stammreihe deuten lassen würde. Denn es kann doch nicht für unwesentlich angesehen werden, dass erstens jene angelıliche Stammreilıe zu allerletzt distal auswächst und zwar in Form eines abgebogenen Seitenzweiges (fa, d. V) des letzten dichotomischen Strahles (fI-III, d.III, IV), der selbst wieder sich als einem anderen. dem zweiten Gegexbatrischen Strahl oder meinem filularen Hauptaste (f, mI-III, d. II) untergeordnet darstellt; dass zweitens alle Fedulitionen an der uämlichen Stammreihe anfangen und nicht nur iiberhiupt hänfig, sondern an der Hanl aller Urodelen ganz ständig sind, indem dort ein fünfter Finger fehlt. Freilich sind diese der Ontogenie entnommenen Bedenken gegen die Aufstellung einer fibularen Stammreilue nicht röllig und klar entscheidend. Man kann sie aber nicht unbeachtet lassen, wenn man iiberlegt, dass der Tergleich mit den Selachiern an sich noch nicht die Gewähr einer gröfseren Sicherheit des Resultates trägt, da jede der beiden Strahlenserien des Arehipterygiums schwiuden und daher hei den Amphibien eventuell ebenso wie bei Protopterus* eine andere Serie fehlen liann als bei den Selachiern. Immerhin verschliefse ich mich der Berleutung eines solchen Vergleiches

* Wiedersheim erklärt dies für eine seliundäe .Verwerfung* (NIorphologisches Jahrbuch Bd. II, S. 429).

* Tgl. Buxge, Teber die Nachweisbarkeit eines biserialen Archipterygium bei Selachiern und Dipnoërn, in: Jenaische Zeitschrift für Medicin und Naturwissenschaft Bd. YIll. 
durehans nicht und will jetzt priffen, wie weit die bezeichnete Auffassung Hexler's begründet ist, dass das Metapterygium der Selachier jener fibularen Randreihe bei den Urodelen entspreche.

Die primäre Lage der Extremitäten überhaupt ist nach Hoxuer* die horizontale mit einem vorderen oder präaxialen und einem hinteren oder pastaxialen Rande, suwie sie noch bei den Selachiern beständig ist, deren Flossen an ihrem Hinterrande das Metapterygim enthalten. Die Flossen ron Ceratodus sowie der iihrigen Fisehe seien (bei gewöhnlicher Stellung) derart nach oben umgeschlageu, dass die ursprïngliche Bauchseite nach aufsen, der präaxiale Raud nach oben gerichtet seien. Die Amphibien besälsen dagegen in der Regel „noch jene ursprüngliehen Lagebeziehungen der Extremitäten, sodass deren Radial- oder Tibialrand sich als vorderer oder präaxialer, der Uhar- oder Fibularrand als hinterer oder postaxialed darstelle. Folglich sei der nluare (fibulare) Rand des Gliedmafseuskelets der Amphibien dem postaxialen Metapterygium (genauer der Basalreihe lesselben) homolog, - Dieser Vergleich beruht aber auf irrigen Voraussetzungen.

Erstens: Wenu ron allen bekannten Gliedmafsen der Vertebraten dicjenigen des Ceratodus nach ihrem Bau anerkanntermafsen die urspriinglichsten sind, warum sollen ihre gewöhnlichen Lagebeziehungen nicht zum Ansgangspunkte für die Bestimmung aller ïbrigen genommen werden? Gesehicht dies aber, so haben wir von einer sagittalen Stellung der nach hinten gerichteten Extremität auszugehen. In der entsprechend nach oben umgeschlagenen Brustflosse der Haie lïge also der metapterygiale Rand unten, und da wir eine solche sagittale Stellung der Extremitäten bei den Urodelen bereits als urspriungliche kennen gelernt hahen (rgl. S. 24), so folgt daraus, dass die beiderlei unteren Ränder einander entsprechen, dass also der metapterygiale Rand der Haiflosse nicht dem (oberen) ulnaren, sondern dem unteren (radialen) Rande des Urodelenarmes homolog ist.

Zweitens: Wenn die Brustflossen ron Ceratodus und den Haien aus der sagittalen (senkrechten) Stellung durch einen solchen einfachen Umseblag (Pronationsbewegung) in die horizontale ïbergefïhrt werden, dass die anfïngliche Aufsenseite zur Unterseite wird, so hat man bei den Amphibien, um die gleichen Verhältnisse herzustellen, cbenso zu verfahren, wobei der obere ulnare Rand zum äufseren rorderen (präaxialen) wïrde, wogegen wieder der nach hinten und innen gerichtete radiale Rand dem metapterygialen entspräche. Die ron HuxLer berücksichtigte gewöhnliche quere Stellung der Extremitäten der Urodelen, robei die ursprüngliche Aufsenseite zur dorsalen geworden ist, wird ron der ursprünglichen sagittalen Lage aus, wie wir salen (S. 26) durch cine komplizirte horizontale und Supinationsbewegung erreicht, kam also mit jener in Folge einer Pronation eingenommenen horizontalen Lage der. Brustflosse ron Ceratodus und der Haie nieht rerglichen merden.

Drittens: Allerdings fehlt aber diesen Vergleichen zur rollen Eridenz eine ihrem Wesen nach unveränderliche, dureh physiologiseh herbeigefïhrte Lageveründerungen der Extremitäten nicht berührte morphologische Beziehung derselhen zu anderen relatir fixen Körpertheilen. Eine solche findet sich aber in der Verbindung der Gliedmafsen mit dem betreffenden Schulter- oder Beckengürtel. Diese Verbindung bei Ceratodus zu beurtheilen fehlen mir leider genauere Anhaltspunkte; dagegen ergeben sich solche bei den Selachiern und Amphibien. - Wem die ursprïngliche Lage

* Hexlex, Contributions to Morplology. Ichthyopsida. No. 1. On Ceratodus Forsteri, with Observations on the Classification of Fishes, in: Proceedings of the scientific meetings of the Zoological Society. 1876. - Derselbe, Handbuch der Anatomie del Wirbelthiere, dentsch ron Patzel. S. 2i, 34. 
2. B. an der Brustflosse der ersteren eine horizontale wäre. so nüisste auch die Befestigung derselben am Schultergürtel dem entsprechen, d. h. es müssten dort die proximalen Enden des Pro-, Mesound Metapterygiums horizontal hintereinander liegen. Dies ist aber nicht der Fall; rielmeln liegen jene Enden, wo sie gemeinsam bis zun Schultergürtel reichen, mehr oder weniger schrïg ühereinander, wie ich es am denthichsten bei Chimaera selie, sodass Gegexbaur desshall dis Pro- und Nesopter'ygium als obere, iiber' dem Metapterygium dem Schultergürtel angefügte „Bogenradien“ bezeichuete (Morplologisches Jatubuch Bd. II, S. 41S). An sehr jumgen Embryonen von Scyllium canicula habe ich num allerdings gefunden, dass die Radien, ans denen Pro- und Iesopteryginm herrorgehen, ebenfalls rem Stamme des Metapterygiums ansitzen, also keine Bogeuradien im Sinne GEgExB.tTr's sind (Fig. 44); democh erkanute ich, dass der freie Rand jenes mit dem Scluultergïrtel noch kontimirlich zusammenhängenden Stammes in die untere Hälfte, der strahlenbesetzte Riand aber in die obere Hälfte des Schultergiirtels auslief. Es erwies sich sonach die horizontale Lage anch der embryonalen Flosse als durch eine Pronation der peripheren Theile herbeigeführt, woran die Wurzel der Flosse nicht theilnimmt. Wir müssen daher jene Lage für cine sekundäre, die sagittal-senkrechte für die primäre ansehen und demgemaifs den propterggialen Flosseurand als einen eigentlich oberen, den metapterygialen als unteren bezeichnen. Gerale so haben wir aber schon bei den Urodelen den ladialen Rand als unteren, den nluaren dagegen als oberen kennen gelernt (vgl. Fig. 44, 45).

Der Vergleich des Urodelenarmes mit ler Brustflosse der Haie führt uns also gerade zu einem der Insicht Ildaser's entgegengesetzten Ergebnisse: nicht der ulnare, sondern der radiale Rand jenes Armes entspricht dem metapterygialen Rande rler Flosse. - Sollten wir num desshalls die Stammreihe, das Homologon der Basalreihe des Metapterygium, am radialen (tibialen) Rande der Urodelenextremitait suchen? - Eine solche (ron GEgExBarr bekannthich friiher angenommene) Stammreihe würde nach den ontogenetischen Befunden un einen einzigen, baumförmig verzweigten Strahl (Ulna mI-III, uI-III. d. II-IV) tragen: ein dem Archipterygium wenig entsprechendes, wenn auch nicht gerade widersprechendes Bild (rgl. Fig. 44, 45); und iiberdies verlangt ja der Vergleich mit den Selachiem gar nicht ein einzeiliges Archipterygium, alsu eine durchweg am Rande verlaufende Stammreihe bei den Amphibien. da das Mefapterygium distalwärts auch am hinteren Rande (postaxial) Strahlen trägt (rgl. Gegexbaur, Ueber das Arehipterygium a. a. 0. und Bunge a. a. O.). Huxber hat bereits den Versuch gemacht, das Extremitätenskelet ganz allgemein als ziemlich vollkommen biseriales machzuweisen (a. a. 0.). Bei den Selachiern sollte das Mesopteryginm den Rest des Stammes, das Propterygrium die präiaxialen, das NIetapterygium die zum Theil verschmolzenen postaxialeu Strahlen darstellen; bei den Amphibien u. s. w. sollten Humerus, m I, m II, uIII d. III den Stamm, Radius, r I, rII, rm III, d.I unı II die präaxiale, Uha, u I, u II, d. IV (und V) die postaxialen Strahlenserien bilden. Hinsichtlich der Selachier genügt aber ein Blick auf die embryonale Flosse (Fig. 4t), um die Auffassung Gegexbatr's bestätigt zu, finden, dass die Stammreihe durch das Mletapterygium rerläuft, Pro- und Mesopterygium aber lediglich Lnbildungen ron einzelnen Strahlen sind; und was die Amphibien betrifft, so liat bereits GEGENB.1ur in seiner letzten Arbeit uiber diesen Gegenstanıl (a. a. O. S. 403) die Ansicht Hoxuer's widerlegt: die direkte Verbindung ron Humerus und Intermelium (1nI) ist ehen in keiner Weise wahrscheinlich zu machen. - Versuchen win dalıer die Lösung der Frage hlots an der Hand der Ontogenie und sehen zu, oh sich dabei Widerspriebe orler Uebereinstimmung mit allen anatomischen Befunden ergeben. 
Ich habe zwei primäre vom Humerus oder Femur ausgehende Skeletiste gefunden, denen die anderen Slieletanlagen der lliund und des Fufses sich unterordnen, von ihneu sekundir ausgehen; wir baben also allen Grund, die mit dem Humerus oder Femur beginnende Stammreihe in einen jener beiden primitisen Aeste zu verfolgen (vgl. Fig. 47, 48). Ihre seheinbare Koordination kinn natürlich nicht dagegen sprechen; denn das Ende der Stammreihe und der letzte ihm anliegende Strahl erscheinen nicht selten anch bei Haien koordinirt, wie eine dichotomische Theilnug derselben. Die Bedenken gegen die Auffassung des tibialen (raclialen) Astes als der Fortsetzung des eigentlichen Stammes habe ieb bereits genamnt; dasselbe trifft aber für den anderen, fibularen (uhnaren) Hauptast, der im Tarsus (Carpus) später zum medianen wird und in die zweite Zehe (zweiten Finger) auslänft. überhaupt nicht oder mur scheinbar zu. Der ans dem Femur und diesem fibularen Iranptaste bestehende Stamm trüge auf seiner tibialen Seite freilieh mu einen Strahl, den tibialen Ast; dies wiurde aber der Reduktion der Strahleu am homologen hinteren liande der Selachierflosse entsprechen, wo oft ebenfalls nur ein stïrkerer Strahl übrig bleibt (rgl. Fig. 4.1 und 45 , to und 48 ). An anderen Rande wïrde mnser Stamm scheinbar ebenfalls nur einen, freilich dreitheilig anslanfenlen Strahl, den dritten Tarsalast mit der dritten bis fünften Zehe, tragen (man rergleiche Fig. 45 und die punktirte Linie in Fig. 48). Hier möchte ich aber nun das rerwerthen, was die primäre Entwiekelung nur unvollkommen, desto klarer die spätere Regeneration erkennen lässt, dass nämlich die dritte Zehe und bisweilen sellsst die vierte nnd fünfte nieht als Fortsïtze jenes vorher gesonderten dritten Tarsalastes, sondern nebst den zugehörigen Tarsalia als direkte Seitenzweige des fibularen Hauptastes oder eben unserer Stammreihe entstehen (S. 21, 33, 34); eine Erseheinung, welehe dadurch an Bedentung gewimnt, dass sie sieh an den fertigen Extremitäten von Protens und Amphiuma wiederholt, und welche, wie ich schon erlikïrte, unter Umständen ganz wohl als eine Art Riickschlag aufgefasst werden kam. Liegt es aber alsdann nieht nahe, anzmehmen, dass jener dritte Tarsalast lediglich aus einer Yersehmelzung der Basen (Tirs. fI-III) von drei oder rier Strahlen (von denen der letztere nur noch bei Ranodon und Cryptobranchus Spuren zuriiekliefs) herrorgeht, welche eigentlich koordinint nebeneinander dem Stamme ansitzend zu denken sind (Fig. 48)? Diese Auffassung wird noch dadurch unterstiitzt, dass die entsprechenden Strahlen der Haie ebenfalls häufigg wit den Basen rersehmolzen sind (Gegexbaur). Kurz, ich glaube so ein mit den ontogenetischen Befunden in vollem Einklange stehendes Bild ron der Anordung des Arehipterygium bei den Lrodelen gewomnen zu haben, welches, obwohl ron den bisher anerkannten abweichend, zu einem Vergleiche mit dem Archipterygium der Flossenformen mindestens ebenso geeignet ist. Wenn ioh die Enaliosaurier bisher nicht in den Vergleieh hereinzog, so bramehe ich es jetzt nieht weiter auszuführen, dass ihre Flossen sich dem nenen Sehema gerade so gut fügen, wie dem friiheren; ja vielleicht noch besser, indem die geringe Zahl der Tarsalia und Carpalia bei Plesiosaurus nach dem, was ich über die Verminderung dieser Theile bei den Urodelen sagte, gegenwärtig leine Schwierigkeiten ihrer Dentung bieten kann. Und an diescr Stelle will ich noch daranf hinweisen, dass die Outogenie aufser ihren allgemeinen Aufschlüssen über den Znsanmenhang der oligaktinoten und polyaktinoten Extremitätenformen auch noch speziellere Fingerzeige iiber die Stammformen der Urodelenextremität gibt. Eimmal ist es nicht zu verkemnen, dass die Aulagen der Arm- und Schenkelkuochen in Verhältniss zu denen der Curpalia und Tarsalia un so kürzer erscheinen, je juinger sie sind, ja bisweilcn liaum länger als ein Carpale oder Tarsale (Fig. 5, 15-18, 27). Zweitens er- 
immere ich daran. dass dic Fingeranlagen im Gegentbeil gerade anfungs excessir lang sind und dass ilne Gliedernng rom Carpus oder Tursus distal fortschreitend in einer bedeutenden Entfermung ron (ler Spitze aufhört (Fig. 4. 5). Dass der dabei unbemutzt bleibende distale Kunorpelfaden endlich atrophirt und schwindet, kiann daher nur so gedentet werden, dass die Fingeranlagen urspriinglich zur Bildung einer grösferen als der gegenwärtig rorkommenden Anzahl ron Gliedern bestimmt waren. Verbinden wir beide Erscheinungen als Ilinweise auf die Stammformen der Gliedmafsen der Urodelen, so hätten wir für diese Formen kurze Arm- und Schenkelknochen und rielgliederige Finger und Zchen anzunehmen, - Merkmale, wie sie ms insbesomlere bei den Enaliosauriern entgegentreten, aber auch ganz allgemein auî Flossenformen hindenten.

Dieser Hinweis anf die nähren wahrscheinlichen Stanmformen der Gliedmal'sen der Urodelen führt mich zum Anfang meiner vergleichenten Betrachtnugen zurtiek, zu der Frage nach der bezüglichen phyletischen Reihe unter diesen Thioren selbst. Wenn die Zalıl der Carpalia und Tarsalia bei den Urodelen im ganzen eine untergurdnete Rolle spielt. die stammreilne und der radiale (tiliale) Strahl iiberall nachweisbar sind, und un die Zahl der ulnaren (fibularen) Strahlen schwankt, so könnte alleufalls die lutztere eine auf- oder absteigende Reihe in morphologischer Hinsicht hegriunlen, so zwar, dass die zalhlreicheren Strahlen auf einen engeren Iuschlus an die wahrseheinliche Stammform hinwiesen, als die an Zahl reduzirten Strahlen. Diese Zahl schwankt aber von den Salamandrinen lis zu Menuluanchus und Siren nur zwischen zwei und drei (vgl. Taf. V); diese heiden letzteren Thiere besitzen iiberdies gerade noch so viele uluare Strahlen wie alle löheren Urodelen und Meuobrandhus, uoch so viele fibulare als manche Salumandrinen (Batrachoseps, Salamandrina, Salamamdrellil), welde darin wieder son einigen lchtlyodea (Menopoma. Cryptrbranchns) ibertroffen werden. Noch weniger fibulare (uluare) Stralsen kommen nur bei I'rotens und Amlhiuma ror. Bei dieser lnkongruenz zwischen der Entwiekelung der Gliednafsen und der iibrigen Organisation und der in allgeneinen kann nemenswerthen Differenz in der entscheidenden Hinsicht urscheint es unthunlicls, cine bestimnte phyletische Reihe aufzustellen. Nehmen wir Amphiuma und Protens ans dem angefïhrten Grunde als zurückgebildete formen ans (Siren schliefst sich ihnes Inreh den Ausfall der hinteren Extremität an), so kömen wir sagen, dass die ïbrigen Crodelen hinsichtlich des morphologischen banes ihrer Extremitäten umregehmäfsig schwankente Verhültnisse zeigen und dass ihrer hordnung in einer anfsteigenden Entwickelungsreihe nach anderen Mlerkmalen ron dieser Seite kein Hinderniss in Wege stelit.

Ils Hauptergelniss meiner Untersichnngen darf ich aber hezeichen, dass es mir. wie ich hoffe, gelungen ist. auch in der imlividnelleu Entrickelnugsgeschiehte eine Bestaitigung und im Einzelnen sugar eine uïhere Beegrüudung einer der bedentsausten Theorien in der Moryhologie der Wirbelthiere, der Archipterygium-Theorie Gegexparr's zu finden. 


\section{Nachtrag.}

Durch die Giite des HIn. In. Strısser habe ich einen Separataludruck seiner demuächst im

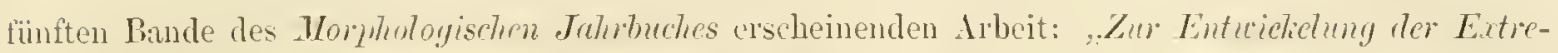
mitütenlinorncl bei Saltumantern und Tritonen" erhalten, jedoch zu spät, um dieselbe noch in meiner Darstellung anzufuihren, wo nur eine liurze Besprechung der vorläufigen Mlitheilung STr.ssser s Platz gefunden hat (S. 22).* Unsere beiderseitigen Angaben stimmen in wesentlichen erst ron der Entwickelungsstufe an iiberein, wamn der Carpus (Tarsus) bereits aus den mn mir heschriebenen drei Lesten hesteht. Hinsichtlich der rurangehenden und frühesten Zustände des Extremitätenskelets läugnet Strasser auslrücklich die Anwesenheit der zwei ursprünglich getremnten Skcletäste und hehauptet, dass die Enden der heiden gutrennten Stïcke des Vorderarmes (Untersclienkels) in den Raund einer kontinuirlichen Platte (Carıs, Tarsus) eingefügt seien, welche distal zwei Fortsätzc (die zwei ersten Finger oder Zehen), am ulnaren (fibularen) Rande aluer die anfangs nur undeutlich gesonderten Anlagen der übrigen Finger (Zehen) trägt (S. 39. 40. 73 des Sepratabdruckes). Mlle Carpalia (Tarsalia) entständen durch Differenzirung aus dieser einheitlichen, kontimuirlichen Platte. und das den zwei ersten Fingern (Zchen) gemeinsame Stïck sei auch genetisch ein einfaches. Alle knorjeligen Einzelanlagen hingen anfangs dureh eine knorpelige Verlindungsmasse zusammen. sodass jedoch die ersteren schon im prochondralen Gewebe gesondert (..centrirt" STR.) seiu können (S. 71).

Dem gegenüber hebe ich zunïchst lervor, dass jene rergïngliche knorpelige Verljindungsmasse die Sonderung der heiden ursprünglichen Skeletäste, auf die es im Grunde allein ankommt, gar nicht aufhelot, da ich dieselben schon in nichtkuorpeligen Znstande unterschieden habe, und beim Vergleiche der mimären Lntrickelung mit der Regeneration, welche letztere Strasser nicht kennt, die gleichen Anlagen unabhüngig von der sehr verschierenen Zeit ihrer Verknorpelung in gleicher Gestalt und Lagebeziehung auftreten sah. Wenn Strusser auf Durchschnitten gehärteter Ohjekte die beiden Skeletiiste nicht fand, so sind sie doch nach meiner Methode sowohl an primär

* Strasser hat dic missverstänlliche Ansicht. dass ich das ganze Extremitatenskelet aus einem vom Humerus (Femur) auswachsenden und sich rerastelnden ..Knorpelbaum liervorgehen lasse, anch in seine letzte Arbeit aufgenommen (S. T3), deren Nanuskript er an 1. December abschloss, withend meine Zurechtstellung jener Ansicht bereits in To. 14 des zoologischen Anzcigers rom 2. Dec. 18 s veröftentlicht wurle. 
entwickelten, wie insbesondere charakteristisch an regenerirten Gliedmalsen nicht zu rerkennen. sodass entweder STRasser`s Untersuchungsmethode. welehe ihm für das histiologische Detail so viel geleistet hat, in jener Beziehnng unzureichend ist, - was sich beim Nangel beziiglicher Abbildungen in seiner Arbeit nicht entscheiden lässt - oder seine histiologischen Befunde (rergängliche kuorpelige Verhindungsmasse) sowie die Unkenntniss der dafü sehr wichtigen Regenerationsrorgänge ihn den Verlauf der beiden Skeletïste ïbersehen liefsen. Dass Strasser den dritten und vierten Finger gleichzeitig angelegt sein lässt, wälurenr ich die zeitliche Tremung ilher Bildung in der primären Entwickehng als Regel ansehe, ist bei dem ron mir konstatirten Wechsel dieser Eutwickelungstorginge (S. 21) nicht ron Belang. Die genctische Beileutung des Carp. r'm JIl oder Tars. tm III stiitzt sich aber ebenso wie die meisten meiner allgemeinen Schlussfolgerungen über ¿en Aufban des Extremitätenskelets auf die thatsächliche Anwesenheit jener zwei primären Skelet¿iste, für deren Nichtrorhandensein ich bei STrusser, gegentiber meinen Angaben nnd Abbildungen, keine Spur von Beweis finde. Um so eigenthiimlicher hat es mich beriihrt, die Aufzählung meiner Beobachtungen über jene Skeletäste und ihre weitere Umbillung in meiner ersten bezüglichen Nittheilung (Amtlicher Bericht der Naturforscherversammlung zu München 187t. S. 172), welche anch sehon alles das enthält, was Strasser iiber die spätere Glierlerung des Carpus und Tarsus angibt, in seiner letzten Arbeit als Theorie bezeichnet zu sehen. Er sagt wörtlich (S. 73): „Der Versuch ron A. Goette. eine besondere Strahlentheorie an Stelle der Archipterygiumtheorie entwickelnngsgeschichtlich zu begrïnden, muss, soweit wenigstens Goette sich dabei auf Tritonen stïtzt, von vornherein als misslungen betrachtet werden." Wohin eine solche Beurtheilung fremder Beohachtungen, namentlich gegenïber einer kurzgefassten rorläufigen Anzeige, führt, ergibt sich in unserem Falle daraus, dass meine erst in dieser Abhandlung bekanntgegrebene ..Theorie“ nichts weiter ist, als die nur in untergeordneten Punkten modifizirte Archipterysinmtheorie selbst. 


\section{Erklärung der Abbildungen.}

Die Figuren der vier ersten Tafeln sind I'hotographien meiner Handzeichnungen, mit Ausnahme der Figuren 3, 8, 11, welche direkte photographische Aufnahnen der bezinglichen I'rïnarite sind. Die Zeichnungen wuden mit wenigen Ansnahmen (Fig. 21-24 mit einem X.chet'schen Zeichenapparat, aber zur Vermeidung von störenden Gröfsenunterschieden nach rerschiedenen Wafsstabe angelegt. Die Zahlen und Buchstaben beziehen sich auf die in gleicher Höhe befindlichen Theile; bisweilen sind zwei nebeneinanderliegende Theile von einer und derselben Seite her so bezeichnet, dass die Zeichen in derselben Peihenfolge ebenfalls nebeneinandergestellt, aber durch eiuen Strich getrenut wurden, z. B. I'- m fü zwei nebeneinanderliegende Karpaläste, den radialen und medialen.

\section{Algemeine Bezeichmungen.}

(Vgl. die Tabelle S. 10.)

ob Oberhaut.

h llunerus.

e Femur.

u Irsprïnglicher ulnarer Skeletast, spüter IIna.

u' Tilnarer liarpalast.

4 1-1II Die aus dem letzteren hervorgehenden ulnaren Carpalia.

r Ursprùglicher radialer Skeletast, später Radius.

$r$ Radialer Karpalast.

r 1, r II Die proximalwäts aus demselben hervorgehenden radialen Carpalia.

m Medianer Karpal- oder Tarsalast.

mI-III Die ans demselben herrorgehenden medianen Carpalia oder Tarsalia.

rm 111 Das aus der Verschmelzung der beiden urspriinglichen Skcletäste am distalen Ende des Carpus, bez. aus der Terschmelzung von r 111 und m III herrorgehenle Carpale.

f Fibula.

f' Fibularer Tarsalast.

fl-III Die ans demselben hervorgehenden tibularen Tarsalia.

t Tibia.

$t^{\prime}$ Tibialer Tarsalast.

t I, t Il Die proximalwärts ans demselben hervorgehenden tibialen Tarsalia.

tm IlI Das aus der Verschmelzung der beilen ursprünglichen Skeletäste am distalen Ende des Tarsus lıervorgehende Tarsale.

I-V Die Skeletaxen der Finger und Zehen, von der radialen oder fibularen Seite aus gerechnet. 


\section{Tafel I.}

Fig. 1. Tolarseite des linken Armes einer ganz jungen Larve von Triton cristatus.

Fig. $\therefore$. Dursalseite des rechten Armes ciner wenig alteren Larve ron Tritun cristatus.

Fig. 3. Ein Theil der Dorsalseite des linken Armes riner ebensoldhen Lare: in der unteren Häfte der Figur sind die karpalen, in der uheren die Fingerabschnite der heiden urspüunglichen Skeletäste, rechts des molialen. links des uharen, enthalten. Die karpalen Absclnitte sind proximalwirts dicht zusammengertickt, aber dentlich gesondert, distalwärts zu cinem runden rmllI verschmolzen. rom dem die beideu Skeletaxen ansgehen. Am ['lnarrande dieses primären Carpus ist die erste knorpelige Anlage des dritten Karpalastes zu sehen rol. u' in Fig. 2 \%

Fig. f. Dorsalseite des rechten Armes einer etwas ilteren larve von Triton cristatus.

Fiy. j. Dasselbe in einem weiteren Stadium.

Fiy. G. Tolarseite eines regenerirten linken Armes von einer noch alteren larve: die Amputationsstelle liegt dort, wo der Humerus sich gegen sein distales Ende jlotzlich rerschmilert.

Fig. \% Dorsalseite des regenerirten rechten Armes einer weit jungeren Larve ron Triton cristatus; die Amputationsstelle in der distalen Halfte des llumerus ist völlig rerwischt.

\section{$r_{\text {Tafel II. }}$}

Fig. \&. Der Mitteltheil der Dorsalansicht eines dinken Armes ron eimer selu jungen Larve ron Triton cristatus (rg]. Fig. 2 und 3; die Jiczeichnumg des radialen liaryalastes recluts ist unterblieben.

Fiy. \%. Dorsalansicht des rechten Armes einer Larve ron Tritun taeniatus, dhe auf Fig. 5 folgende Stufe; die Znsammensetzung ron $\mathrm{rm}$ III aus zwei stïcken ist gut zu erkenuen, hinter mu 1 hat eine kleine Verletzung des Prïprarats stattgefunden.

Fig. ll. Dorsalansicht des rechten Armes einer älteren Larve rou Triton taeniatus.

Fig. 11. Dorsalansicht des linken dimes einer beinahe gleich alten Larre von Triton cristatus.

Fig. 12. Dorsalansicht des rechten leines ciner Larve von Triton taeniatts igl. S. 6 und 14 .

Fig 1:3. Dorsalansicht des rechten Brines einer äleren Lare von Triton cristatus.

\section{$\checkmark$ Tafel III.}

Fig. 14. Dorsalansicht des regenerirten rechten Armes einer in Metamorjhose befindlichen Larve ron Triton taeniatus.

Fig. 15. Dorsalansicht des regenerirten rechten Armes eines jungen Triton rristatus.

Fig. 16. Tolaransicht des regenerirten linken Armes einer gröfseren Larve ron Triton cristatus.

Fiy. 12. Volaransicht des regenerirten linken Armes einer in Metamorphose hefindlichen Lare ron Triton cristatus.

Figl 15. Volaransicht des regenerirten Jinlsen Beines einer in Metamorphose hefindlichen Larve von Triton cristatus.

Fig. 1!. Volatansicht des regenerirten linken Armes einer in Metamorphose hefindichen Lare ron Triton cristatus.

\section{Tafel IV.}

Fig) ¿avo. Dorsalansicht des regenerirten rechten Armes eines erwachsenen Triton cristatus: die Amputation traf beide Vorderarmknochen, deren Enden noch in der angesetzten, Callus-artigen Masse kenutlich sind.

Fig. :1 Zwei Endphalangen von zwei gleich grofsen Hänlen, a. vor der Metamoryhose und mit dem linorpeligen Endfacien, b. nach der Netamorphose und olme jenen Endfaden.

Fig. :2:-34. Die rechten Armslielete von drei verschieden alten Larven von Triton cristatus, in der Ruhelage von aufsen geselien; se Scapula, co Coracoideum, lı' Processus lateralis humeri. 
Fig. 2.5. Dorsalansicht des rechten Iseines eines aIteren Embryo von Salamandra maculata; m II Centrale) und fllI sind ohne Bezeichmug geblieben.

1.ig. 26. Dasselbe von einer neugeborenen salamanderlarve.

Fig. 2. Tolarseite des regenerirten linlsen beines von Protens anguinens; mf I. Il und mf III repräsentiren die Tarsalia m I-III mu f I-III der anteren L'rodelen.

\section{Tafel Y.}

Die Bezeichmungen der in Fig. 27-43 durchweg ron der Iorsalseite dargestellten rechten Extremititen verschiedener TrodeIen simI licselben wie rorhin; die Zusammenzichungen, z. B. l. I. Il u. s. w. denten an. welehen gesonderten Stürlien das so bezeichnete dinfache entsprieht. $x$ in Fig. 35 und das zweite m II in Fig. 37 bezeiehnen vlas accessorisehe Centrale.

Fiy. ㄱ. Hand ron Triton taeniatus.

Fug. 23. Fufs ron Triton eristatus.

Fiy. 2. Iland einer Larse ron Triton iristatns.

Fig. 30. Fufs ron Triton alpestris.

Fiy. 31. Hand von Batrachoseps attenuatus.

Fig. 32. Haud von Salamantlra maculata.

Fig. 3.3. Ful's rou Salamandra maculata nach BeёHL, Zootomischer Athes Tat. XXVI Fig. 3.

Fiy. 3t. Hand ron Menopoma alleghaniense.

Fin. 3.5. Fuls ron demselben.

Fig. 36. Hand von Siren lacertina.

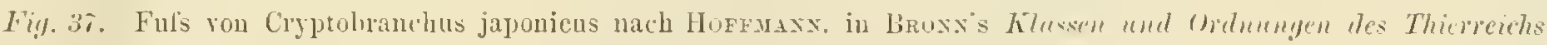
Bd. V1. 2. Tat. XIV.

Fig. 38. Hand von Meuoluranthus latrralis

Fig. 3\%. Fuls ron demsellsen.

Fig. 40 . Fufs ron Amphiuma tridactyla.

Fig. 41. Hand von demselben, beides nach Hrrt, cryptobunchre juynicus.

Fig. 4:. Hand von Protens anguineus.

Fig. 4.3. Fuls von demselben.

Fig. Af. Techte Brusttlosse eines Embryo von Scyllium canicula, hinaufgeschlagen und von anfsen gesehen; s Sehultergurtel. mt Metapterygium, mp Meso-, Propterygium, x postaxialer Strahi, wie ar bei anderen Haien rorkommt Fig. 46 .

Fig. 4.5. Rechter Arm einer Tritonlare in ursprünglicher Lage von anlisen gesehen rgl. Fig. 2.2: , schnltergürtel, h Humerns, u Clnarrand. r RadiaIrand, $\mathbf{V}$ Addeutung eines fïnften Fingers.

Fig. 46. Rechte Brustllosse eines Embryo ron Heptanchus cinerens ron anlsen gesehen, nach GeGexbitr (Leber dus. Archinterygum, in Jenaische Zeitschrift lür Naturwissenscluat, Lid. VII; mt Metajterygium, x postaxialer strahI, die breite rothe Linie bezcichnet die Stammeihe. die anderen Linien die Radien des Arehipterygiums.

Fig. 4i. Skeletschema des Beines von Salamanlra maculata mit $m$ III nnd vollstänlig̣em Auslall ron t III; die gauzen Linien bezcichnen den ontugenetisehen Znsammenhang der stücke. die punktirten Linien die Abweichungen des Getiexbatr'schen Schemas.

Fig. f8. Dasselbe Schema mit tm III unil linzurefugtem Rudiment einer sechsten Zche; die rothe Ilauptlinic bedentet die stammreihe, die anderen die tibialen nnd fibnlaren Larlien des Arrhijteryginms, die punktirten Linien bezeichnen die Tereinignng der Basen der drei fibularen strahlen zu dem ontogenetisch meist einheitlich erscheinenden dritten Tarsalaste. 



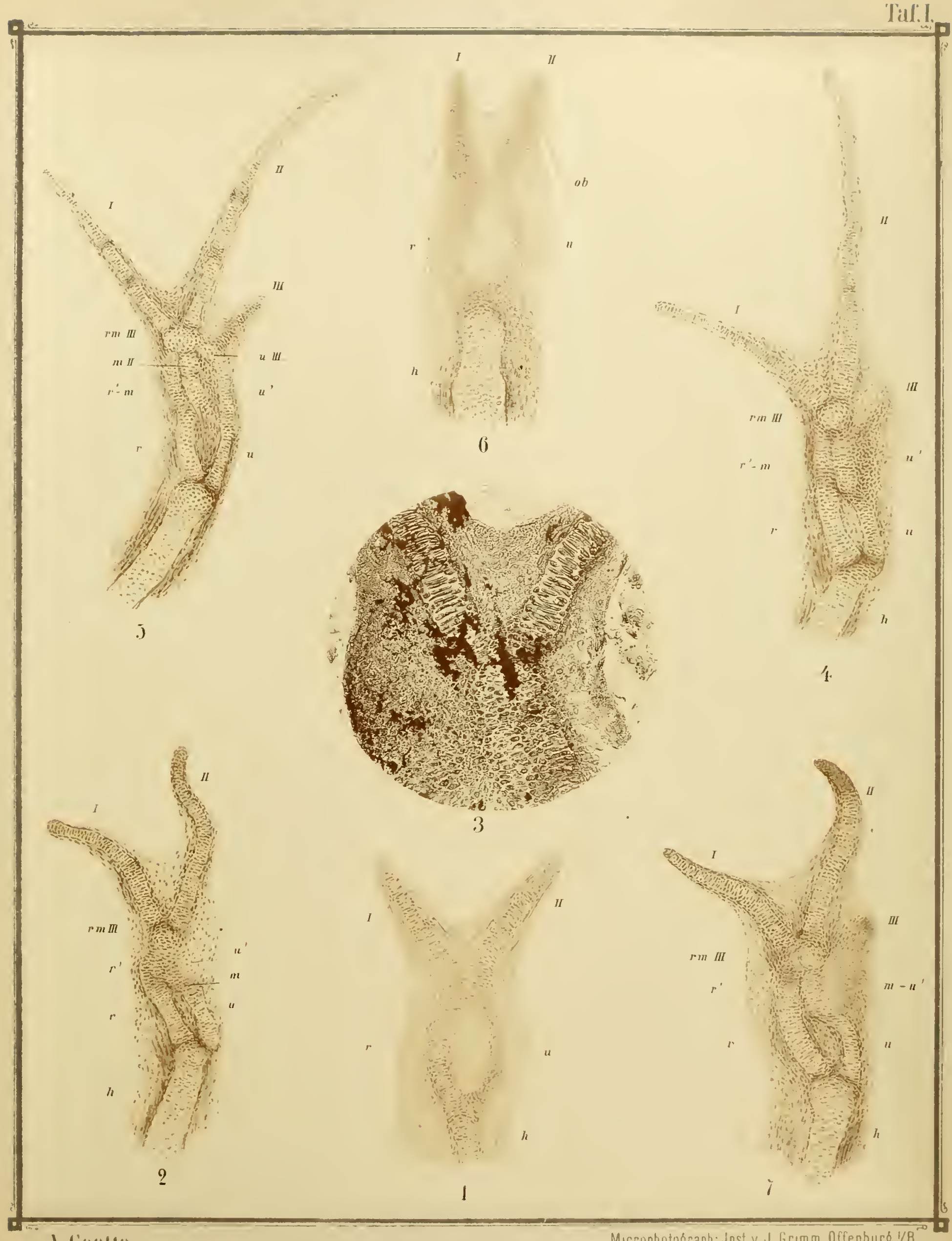

1. linulli.

Micruphotograph: Inst v J.Grımm, Offenburǵ 1/B 



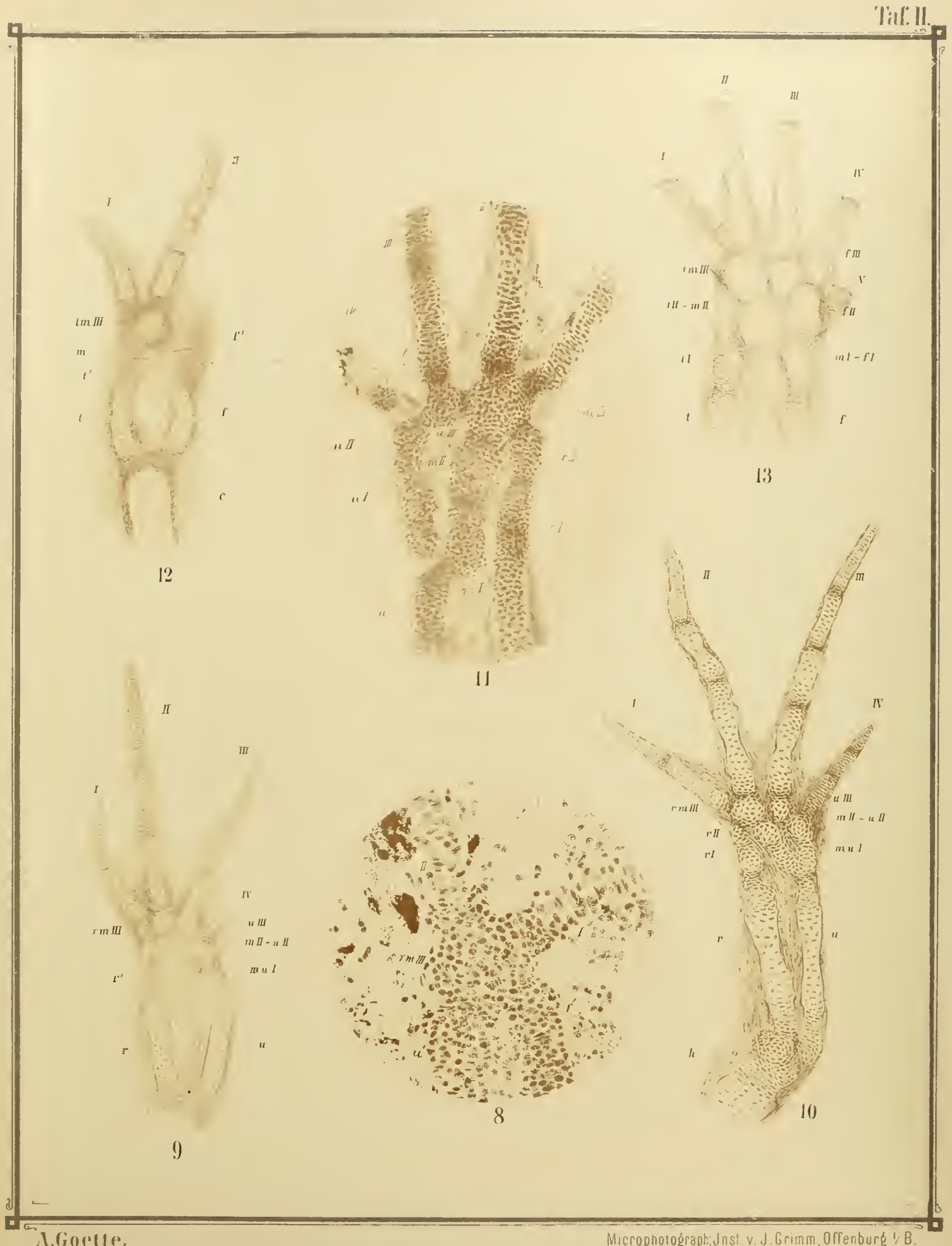





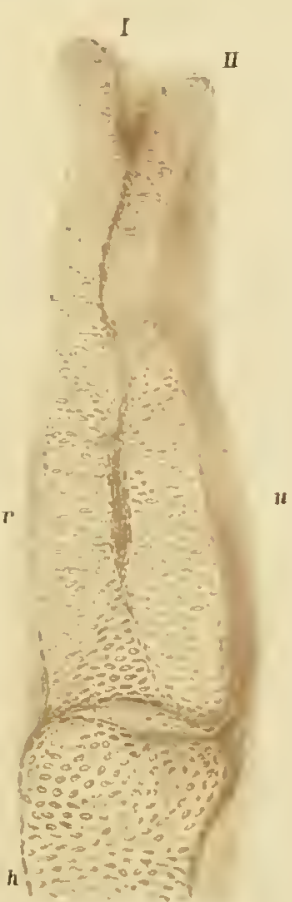

14

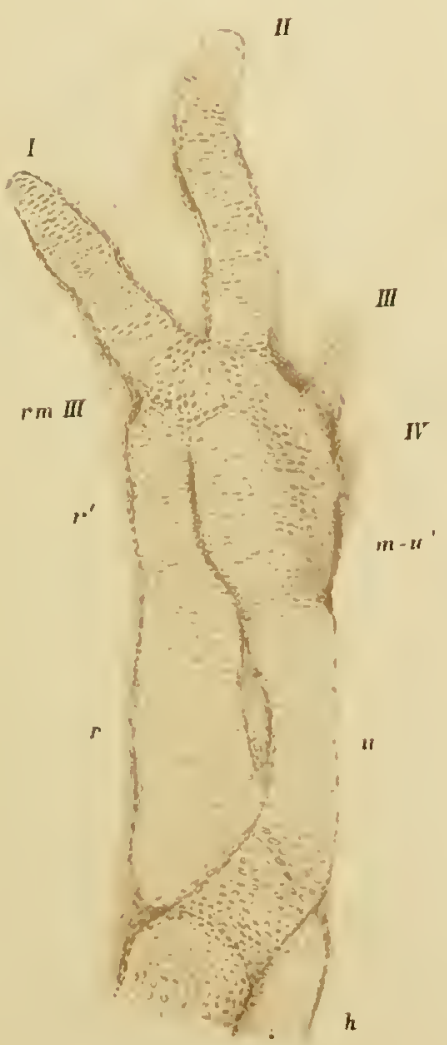

17

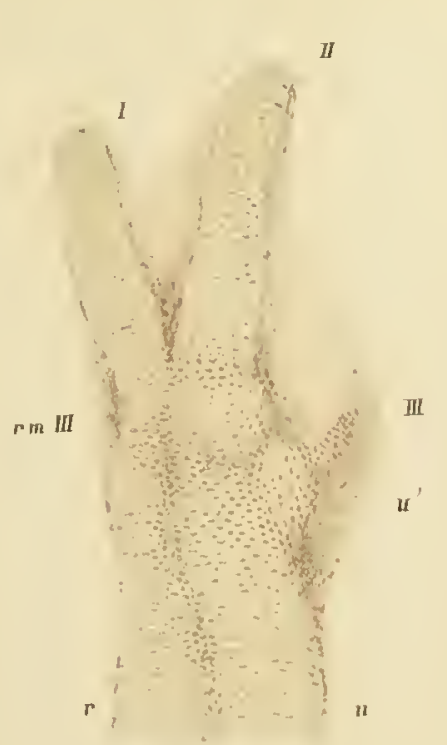

16

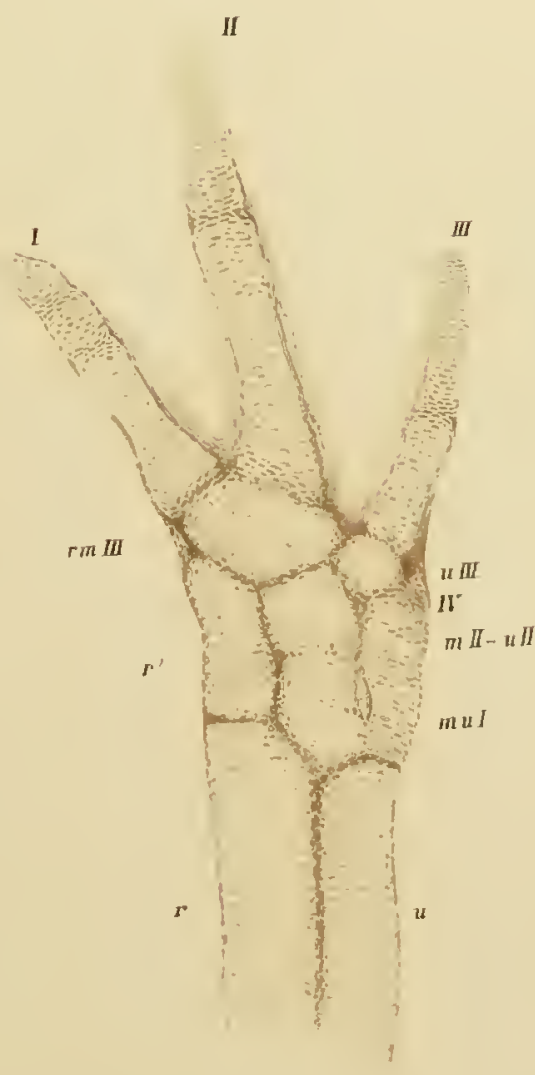

19

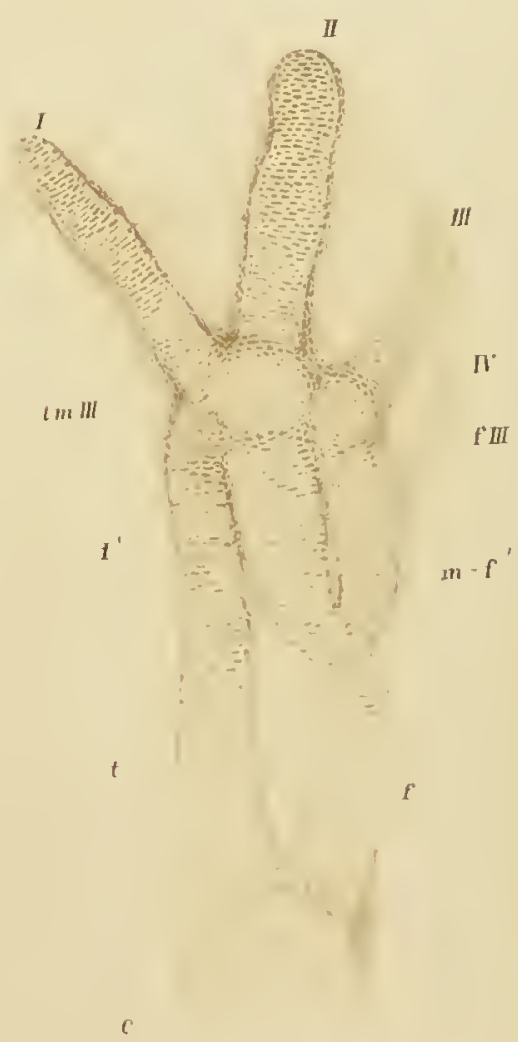

18 

Taf I

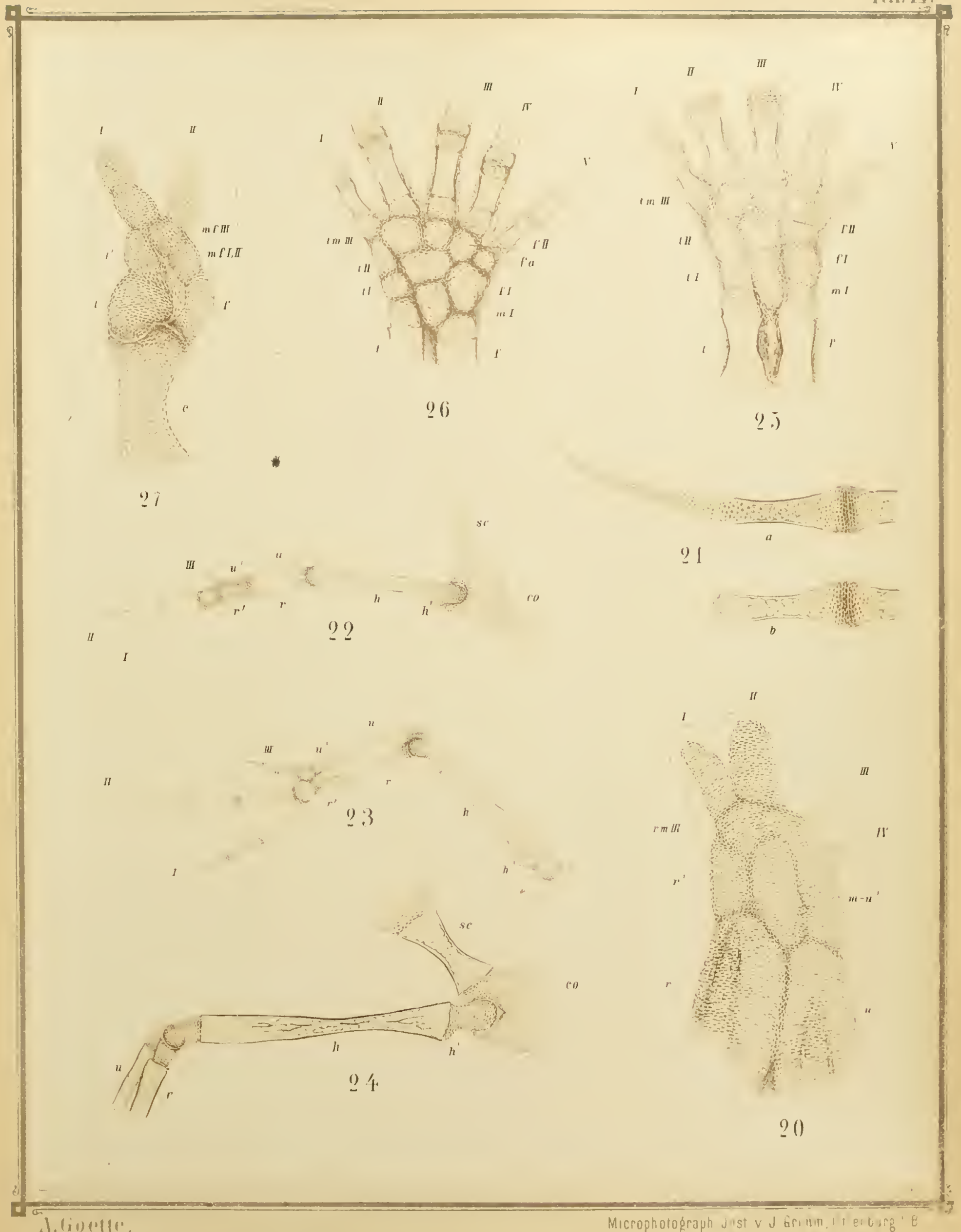





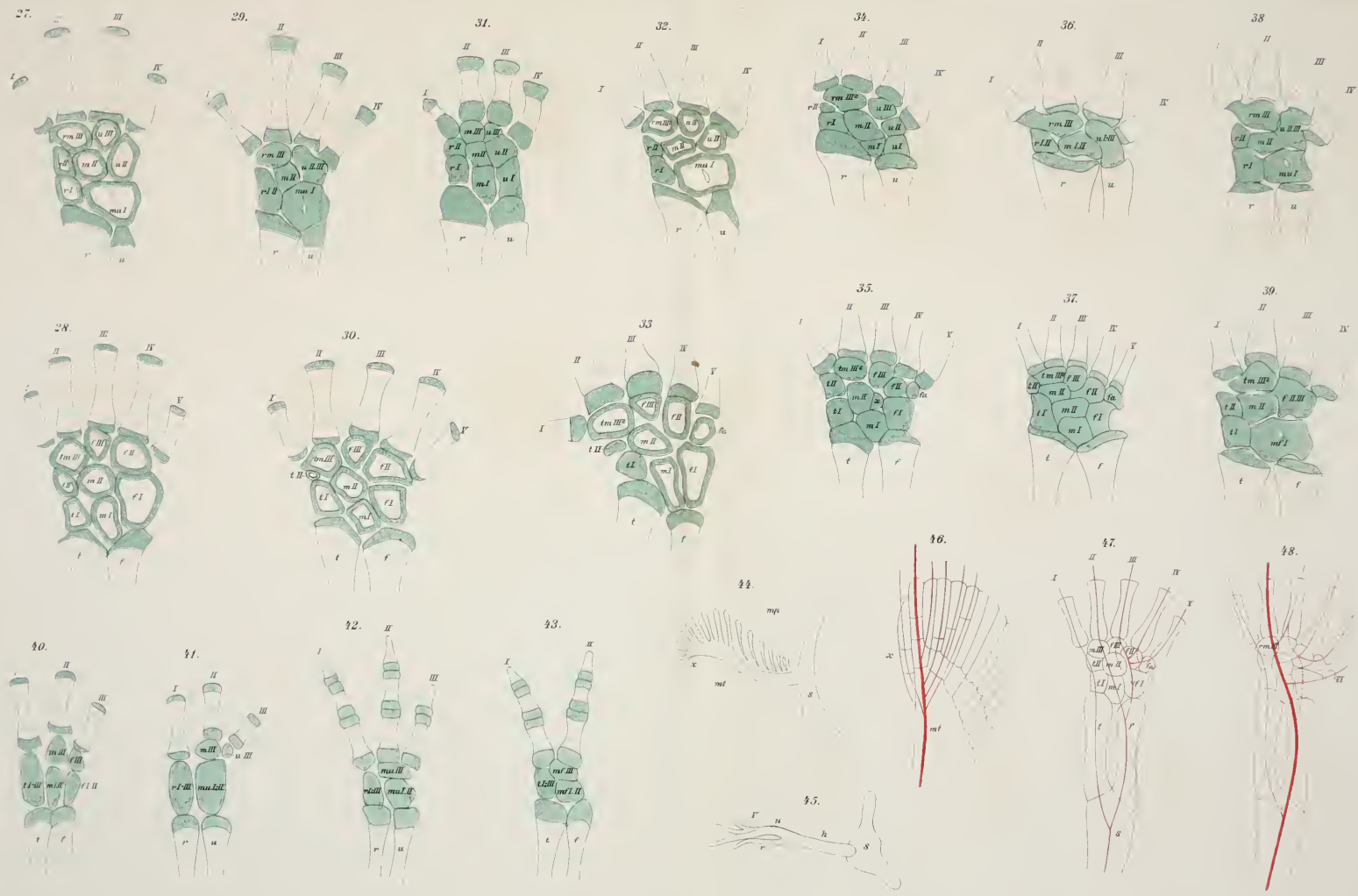







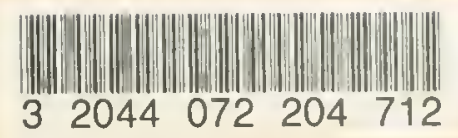


